\title{
Low voltage ride-through strategies for a 3-phase grid-connected PV system
} by

Hao Wen

\author{
A thesis submitted to \\ SWANSEA UNIVERSITY \\ in fulfilment of the requirements for the Degree of \\ DOCTOR OF PHILOSOPHY
}

College of Engineering SWANSEA UNIVERSITY 2021

Prifysgol Abertawe
Swansea University 


\section{Declarations}

This work has not previously been accepted in substance for any degree and is not being concurrently submitted in candidature for any degree.

Signed.......

Date $.05 / 01 / 2021$

This thesis is the result of my own investigations, except where otherwise stated. Other sources are acknowledged by footnotes giving explicit references. A bibliography is appended.

Signed

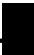

Date $.05 / 01 / 2021$

I hereby give consent for my thesis, if accepted, to be available for photocopying and for inter-library loan, and for the title and summary to be made available to outside organisations.

Signed......

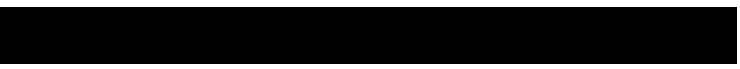

Date $.05 / 01 / 2021$ 


\section{ABSTRACT}

Grid codes is a technical specification which defines the parameters a power system that are connected to the national power systems has to ensure safe, secure and economic proper functioning of the electric system. One of these requirements is to stay connected to the grid during faults. In such scenarios, the generating unit should remain connected to the grid for a certain period and provide reactive power to support the grid. This is called low voltage ride-through capability. At the early stage, low voltage ridethrough requirements were imposed for large scale generators connected to the transmission network. However, with the increased penetration of distributed generation, such as PV panels implemented in the distribution network, the low voltage ridethrough requirements are also required for distributed generation.

With the maturity of PV technology, the cost of PV generation has decreased. Therefore, the total installed capacity of grid-connected PV generation has increased; this has created new challenges to the low voltage ride-through. Power quality and transient performance are the most critical aspects of the grid-connected PV systems under grid faults. PV generation is permitted to switch off from the grid during a fault; however, with the high penetration of the installed PV system, it will degrade the power quality if the same method applied. It is necessary to make sure that the inverter currents remain sinusoidal and within the acceptable limits at the instant of the fault, during and after the fault clearance for different types of faults. Accordingly, this thesis proposes two low voltage ride-through strategies for a 3-phase grid-connected PV system in different reference frames. 
The presented low voltage ride-through control algorithm in the synchronous reference frame, which fulfils a voltage compensation unit and the reactive power injection block is designed to protect the inverter from overcurrent failure under both symmetrical and asymmetrical faults, reduce the double grid frequency oscillations and provides reactive power support by applying a voltage compensation unit. The inverter can also inject sinusoidal current during asymmetrical faults. The method does not require a hard switch from the Maximum Power Point Tracking to a non-Maximum Power Point Tracking algorithm, which ensures a smooth transition.

The proposed method in the stationary reference frame provides a fast post-fault recovery, which is essential to minimize the fault impacts on the loads and the converter. The method, which consists of a new reference currents calculation block and the voltage compensation unit, maintains the converter current within acceptable limits, produces sinusoidal current even during asymmetrical faults, improves the post-fault recovery performance, and provides independent control for active and reactive powers. 


\section{ACKNOWLEDGEMENTS}

I would like to vivaciously appreciate my supervisor Dr. M. Fazeli for his incredible support, guidance and constructive feedback towards the completion of this project. Without his excellent advice and encouragement this work would not have been completed. My profound also goes to Dr. A. Egwebe, Dr. J. Macaulay and Mr. M. Baruwa for their kindly assistance and advice towards my research and this thesis as their contribution was vital to the successful completion of this Ph.D. project.

My heartful gratitude goes to my parents, for their encouragement, advice and support during my studies. I cannot thank you enough, your immense support love and care pulled me through challenging times.

To my wife Mrs. Xinyi Li, your wisdom and wonderful words of encouragement are priceless. Thank you for your meticulous care.

Lastly, my thanks and appreciation go to all my colleagues and the staff in the College of Engineering and Swansea University, for providing an enabling environment for this work. 


\section{CONTENTS}

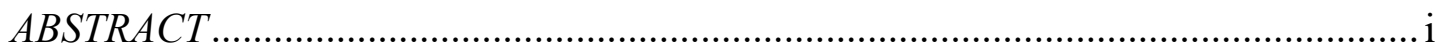

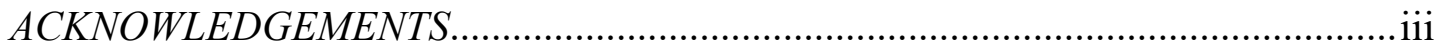

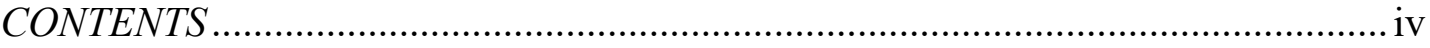

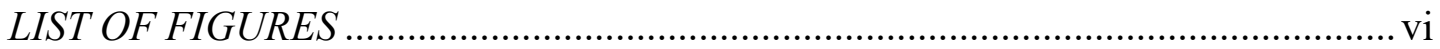

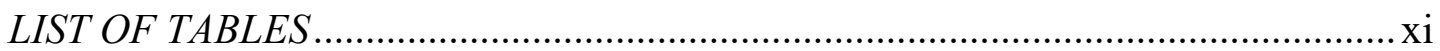

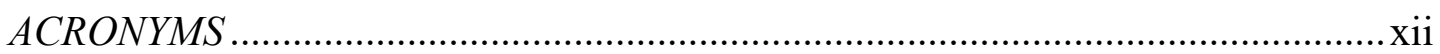

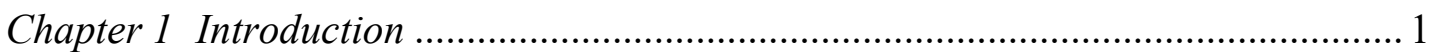

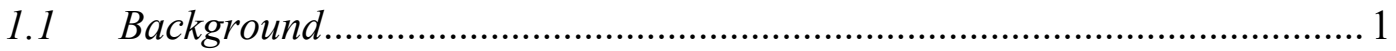

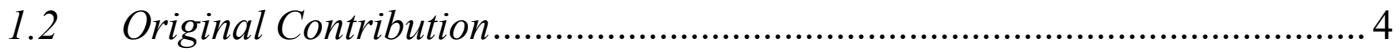

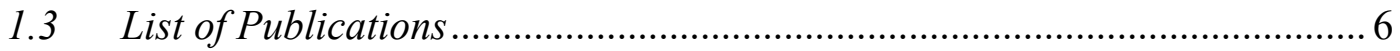

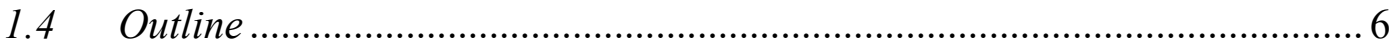

Chapter 2 Grid-connected PV system and Literature Review for LVRT strategies ... 8

$2.1 \quad$ Photovoltaic Technology ............................................................................ 8

2.1.1 Electrical and Mathematical Modelling of a PV cell............................ 9

2.1.2 Maximum Power Point Tracking ...................................................... 15

2.2 Control of grid-connected PV system ..................................................... 17

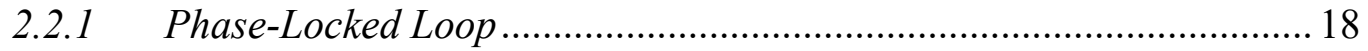

2.2.2 Conventional Current Loop ............................................................. 21

2.3 Grid Code and Low-voltage ride-through................................................. 23

2.3.1 Low voltage ride-through requirements........................................... 23

2.3.2 Reactive power injection .................................................................... 26

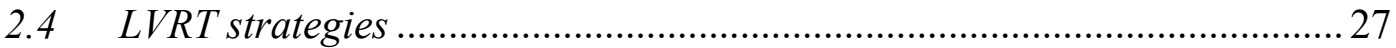

2.4.1 Conventional LVRT strategy for grid-connected PV system ............... 27

2.4.2 Asymmetrical fault and Symmetrical components separation ............. 29

$2.5 \quad$ States-of-the-art on LVRT in SYRF ....................................................... 31

2.6 Dynamic performance for LVRT strategy in STRF .................................. 33

2.7 State-of-the-art on LVRT in STRF considering post-fault recovery............ 34

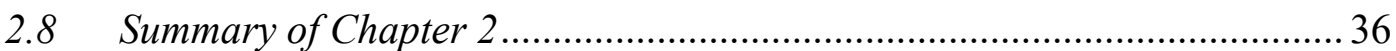

Chapter 3 AN LVRT Strategy for 3-phase grid-connected PV Systems in the SYRF 38

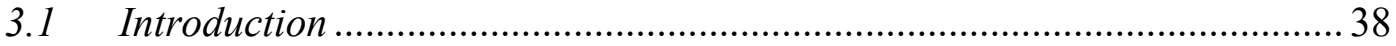

3.2 Proposed LVRT for grid-connected PV system in SYRF ........................... 39

3.2.1 Symmetrical components generation ................................................ 40

3.2.2 Current controller design ............................................................... 41 


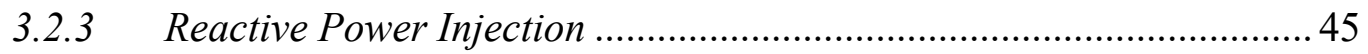

3.2.4 Design of the proposed VCU ............................................................. 46

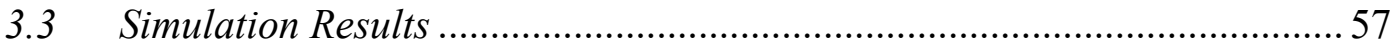

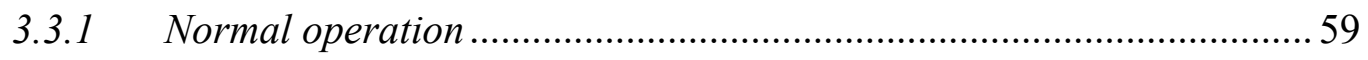

3.3.2 Simulation results for the simplified $V C U$........................................ 60

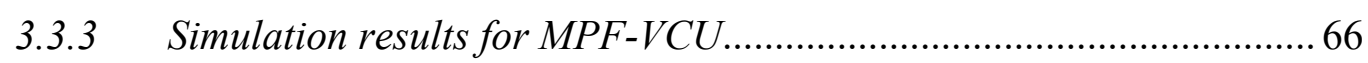

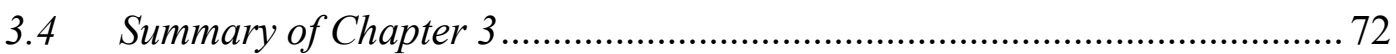

Chapter 4 AN LVRT Strategy for 3-phase grid-connected PV Systems in the STRF 75

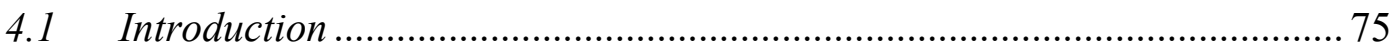

4.2 Proposed LVRT for grid-connected PV system in the STRF ..................... 76

4.2.1 Reference Current Calculation ........................................................... 77

4.2.2 Reactive Power Calculation Block.................................................... 81

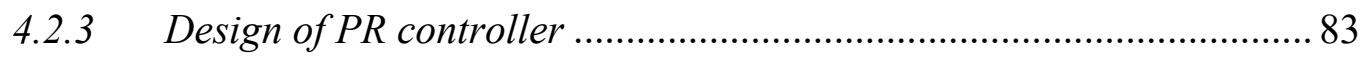

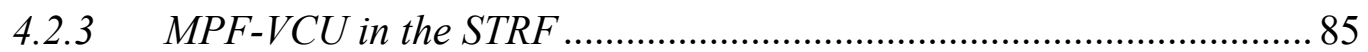

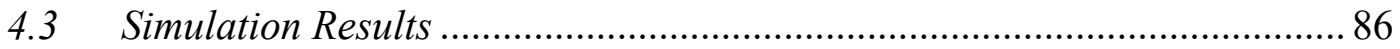

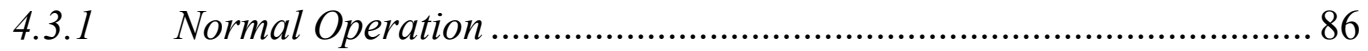

4.3.2 Simulation results under different faults .......................................... 88

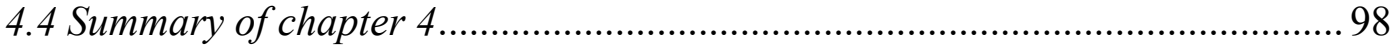

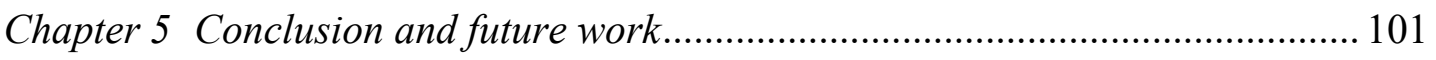

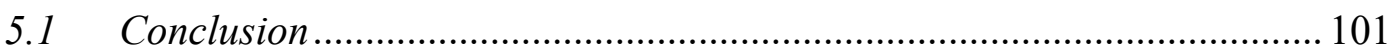

5.2 Potential Future Work ......................................................................... 102

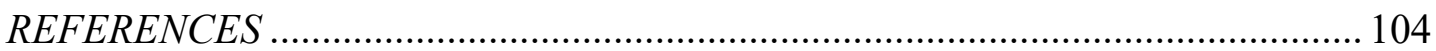

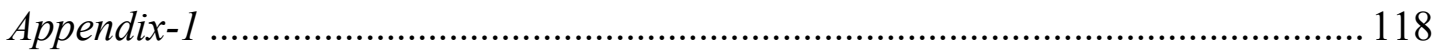

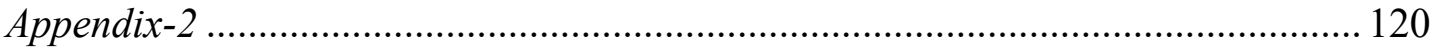




\section{LIST OF FIGURES}

FIGURE 1.1: CHINA AVERAGE ANNUAL NET CAPACITY ADDITIONS BY TYPE FROM 2017 TO 2040 [2] 1

FIGURE 1.2: UK ENERGY PRODUCTION FOR THE FIRST QUARTER OF 2019 [3] ............... 2

FigURE 1.3: INSTALLED AND TOTAL PV CAPACITY FROM 2014 TO 2018 [8] .................. 3

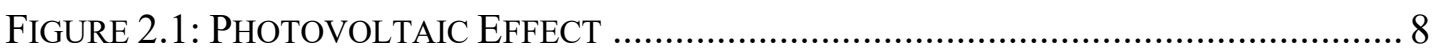

FIGURE 2.2: PV MATHEMATICAL MODELLING [12] ................................................ 9

FigURE 2.3: $I$ - $V$ OUTPUT CHARACTERISTIC CURVE OF A PV CELL ................................ 11

FIGURE 2.4: $P$ - $V$ OUTPUT CHARACTERISTIC CURVE OF A PV MODULE FOR VARYING SOLAR IRRADIANCE.

FIGURE 2.5: $I$ - $V$ OUTPUT CHARACTERISTIC CURVE OF A PV MODULE FOR VARYING SOLAR IRRADIANCE.

FIGURE 2.6: $P$ - $V$ OUTPUT CHARACTERISTIC CURVE OF A PV MODULE FOR VARYING TEMPERATURE

FIGURE 2.7: $I$ - $V$ OUTPUT CHARACTERISTIC CURVE OF A PV MODULE FOR VARYING TEMPERATURE 14

FIGURE 2.8: THE FLOWCHART OF A P\&O MPPT ALGORITHM 17

FIGURE 2.9: BASIC CONTROL SCHEME FOR A GRID-CONNECTED PV SYSTEM................ 18

FIGURE 2.10: PLL CONTROL SCHEME................................................................... 19

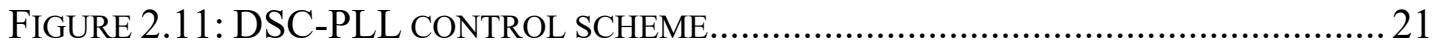

FIGURE 2.12: EQUIVALENT CIRCUIT FOR MATHEMATICAL MODELLING ....................... 21

FIGURE 2.13: CURRENT CONTROLLER IN SYRF ...................................................... 22

FIGURE 2.14: VOLTAGE PROFILE REQUIREMENT [34] .............................................. 24

FIGURE 2.15: LVRT REQUIREMENTS IN CHINA [36] ............................................... 25

FIGURE 2.16: LVRT REQUIREMENTS IN THE UK [33] ............................................... 25

FIGURE 2.17: GRID CODES FOR REACTIVE POWER INJECTION OF EACH COUNTRY [48] 26

FIGURE 2.18: A SIMPLE SYSTEM WITH FAULT DETECTION BLOCK ................................ 28

FIGURE 3.1: THE GRID-CONNECTED PV SYSTEM UNDER STUDY ................................. 39

FIGURE 3.2: THE SYMMETRICAL SEQUENCES SEPARATION BLOCK.............................. 41

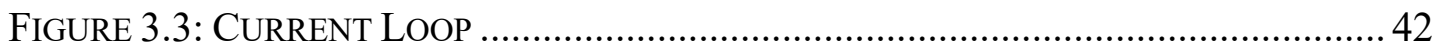

FIGURE 3.4: REACTIVE POWER INJECTION BLOCK.................................................... 45 
FIGURE 3.5: INVERTER POWER VS POWER ANGLE CHARACTERISTIC

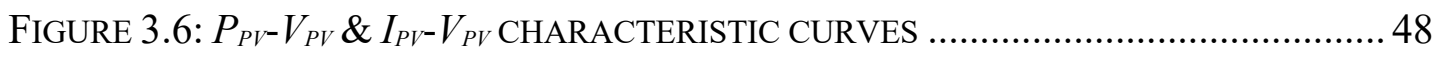

FIGURE 3.7: THE PROPOSED SIMPLIFIED VCU ........................................................ 49

FIGURE 3.8: THE SIMPLIFIED MODEL OF THE PROPOSED PV SYSTEM ........................... 52

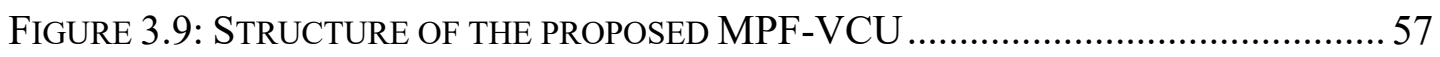

FIGURE 3.10: ROOT LOCUS DIAGRAM OF THE PROPOSED CURRENT LOOP ....................58

FIGURE 3.11: ACTIVE AND REACTIVE POWER WHEN IRRADIANCE CHANGES................ 59

FIGURE 3.12: ACTIVE AND REACTIVE POWER WHEN REACTIVE POWER CHANGES.........60

FigURE 3.13: SiMULATION RESULTS UNDER 3-PHASE FAULT WITHOUT VCU (ALL IN PU): (A) INVERTER VOLTAGE, (B) INVERTER CURRENT, (C) DC-LINK VOLTAGE, (D) INVERTER SIDE ACTIVE POWER, (E) PV POWER, (F) REACTIVE POWER 61

FIGURE 3.14: SIMULATION RESULTS UNDER 3-PHASE FAULT WITH SIMPLIFIED VCU (ALL IN PU): (A) INVERTER VOLTAGE, (B) INVERTER CURRENT, (C) DC-LINK VOLTAGE, (D) INVERTER SIDE ACTIVE POWER, (E) PV POWER, (F) REACTIVE POWER 61

FIGURE 3.15: SIMULATION RESULTS UNDER DLG FAULT WITH SIMPLIFIED VCU (ALL IN PU): (A) INVERTER VOLTAGE, (B) INVERTER CURRENT, (C) DC-LINK VOLTAGE, (D) INVERTER SIDE ACTIVE POWER, (E) PV POWER, (F) REACTIVE POWER 62

FiguRE 3.16: SimULATION RESULTS UNDER DLG FAULT WITHOUT VCU (ALL IN PU): (A) INVERTER VOLTAGE, (B) INVERTER CURRENT, (C) DC-LINK VOLTAGE, (D) INVERTER SIDE ACTIVE POWER, (E) PV POWER, (F) REACTIVE POWER 63

FIGURE 3.17: SIMULATION RESULTS UNDER DL FAULT WITH SIMPLIFIED VCU (ALL IN PU): (A) INVERTER VOLTAGE, (B) INVERTER CURRENT, (C) DC-LINK VOLTAGE, (D) INVERTER SIDE ACTIVE POWER, (E) PV POWER, (F) REACTIVE POWER 64

FiguRE 3.18: SiMULATION RESULTS UNDER DL FAULT WiTHOUT VCU (ALL IN PU): (A) INVERTER VOLTAGE, (B) INVERTER CURRENT, (C) DC-LINK VOLTAGE, (D) INVERTER SIDE ACTIVE POWER, (E) PV POWER, (F) REACTIVE POWER 64

FigURE 3.19: SiMULATION RESULTS UNDER SLG FAULT WITH SIMPLIFIED VCU (ALL IN PU): (A) INVERTER VOLTAGE, (B) INVERTER CURRENT, (C) DC-LINK VOLTAGE, (D) INVERTER SIDE ACTIVE POWER, (E) PV POWER, (F) REACTIVE POWER 65 
FiguRE 3.20: SimULATION RESULTS UNDER SLG FAULT WiTHOUT VCU (ALL IN PU):

(A) INVERTER VOLTAGE, (B) INVERTER CURRENT, (C) DC-LINK VOLTAGE, (D)

INVERTER SIDE ACTIVE POWER, (E) PV POWER, (F) REACTIVE POWER 66

FiguRE 3.21: SimULATION RESULTS UNDER 3-PHASE FAULT WITH MPF-VCU (ALL IN PU): (A) INVERTER VOLTAGE, (B) INVERTER CURRENT, (C) DC-LINK VOLTAGE, (D) INVERTER SIDE ACTIVE POWER, (E) PV POWER, (F) REACTIVE POWER . 67

FIGURE 3.22: SiMULATION RESULTS UNDER DLG FAULT WITH MPF-VCU (ALL IN PU):

(A) INVERTER VOLTAGE, (B) INVERTER CURRENT, (C) DC-LINK VOLTAGE, (D)

INVERTER SIDE ACTIVE POWER, (E) PV POWER, (F) REACTIVE POWER 68

FiguRE 3.23: SiMULATION RESULTS UNDER DL FAULT WITH MPF-VCU (ALL IN PU):

(A) INVERTER VOLTAGE, (B) INVERTER CURRENT, (C) DC-LINK VOLTAGE, (D)

INVERTER SIDE ACTIVE POWER, (E) PV POWER, (F) REACTIVE POWER 69

FIGURE 3.24: INVERTER POWER COMPARISON BETWEEN SIMPLIFIED VCU AND MPF-

VCU UNDER DL FAULT 69

FIGURE 3.25: FFT ANALYSIS FOR THE INVERTER POWER UNDER DL FAULT WITH MPFVCU 70

FIGURE 3.26: FFT ANALYSIS FOR THE INVERTER POWER UNDER DL FAULT WITH SIMPLIFIED VCU 70

FigURE 3.27: SiMULATION RESULTS UNDER SLG FAULT WITH MPF-VCU (ALL IN PU):

(A) INVERTER VOLTAGE, (B) INVERTER CURRENT, (C) DC-LINK VOLTAGE, (D) INVERTER SIDE ACTIVE POWER, (E) PV POWER, (F) REACTIVE POWER 71

FIGURE 3.28: FFT ANALYSIS FOR THE INVERTER POWER UNDER SLG FAULT WITH MPF-VCU .72

FIGURE 3.29: FFT ANALYSIS FOR THE INVERTER POWER UNDER SLG FAULT WITH

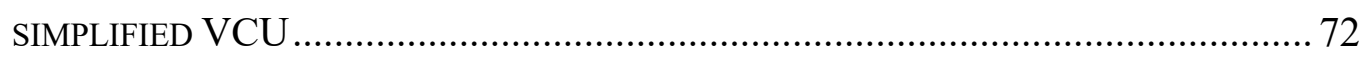

FIGURE 4.1: THE PROPOSED CONTROL SCHEME FOR THE SYSTEM UNDER STUDY .......... 76

FIGURE 4.2: THE CONTROL SCHEME FOR THE REACTIVE POWER CALCULATION BLOCK83 FigURE 4.3: THE BODE PLOT FOR THE UNDER STUDY CONTROL PLANT WHEN $\mathrm{K}_{\mathrm{R}}$ VARIES 84

FigURE 4.4: THE BODE PLOT FOR THE UNDER STUDY CONTROL PLANT WHEN K $\mathrm{K}_{\mathrm{P}}$ VARIES .85

FiguRE 4.5: STRUCTURE OF THE PROPOSED MPF-VCU.... .85 
FIGURE 4.6: ACTIVE AND REACTIVE POWER PERFORMANCES WITH IRRADIANCE VARY87

FIGURE 4.7: ACTIVE AND REACTIVE POWER PERFORMANCES WITH REACTIVE POWER VARY .87

Figure 4.8: 3-PHASE FAult (ALl RESUlts in PU) (A) THE 3-PHASE VOltage. (B) The AVERAGE OF THE RMS INVERTER PHASE CURRENTS.

Figure 4.9: 3-PHASE FAUlt (ALl RESUltS IN PU) (A) THE ACTIVE POWER. (B) THE REACTIVE POWER 89

FIGURE 4.10: THE 3-PHASE INVERTER CURRENTS UNDER 3-PHASE FAULT (RESULT IN $\mathrm{PU})$

FIGURE 4.11: THE PROPOSED CONTROL SCHEME FOR THE SYSTEM UNDER STUDY WHICH IS THE SAME AS [79] 90

FiguRE 4.12: 3-PHASE FAULT WITH LVRT APPLIED TO [79] (ALL RESUlTS IN PU) (A)

THE 3-PHASE VOltage. (B) THE AVERAGE OF THE RMS INVERTER PHASE CURRENTS

FigURE 4.13: 3-PHASE FAULT WITH LVRT APPLIED TO [79] (ALL RESULTS IN PU) (A) THE ACTIVE POWER. (B) THE REACTIVE POWER

FIGURE 4.14: THE 3-PHASE INVERTER CURRENTS UNDER 3-PHASE FAULT WITH LVRT APPLIED TO [79] (RESULT IN PU).

FiguRE 4.15: Light 3-PHASE FAUlt (ALL RESUltS IN PU) (A) THE 3-PHASE VOLTAGE.

(B) THE AVERAGE OF THE RMS INVERTER PHASE CURRENTS. .92

Figure 4.16: Light 3-PHASE FAUlt (ALl RESUltS IN PU) (A) THE ACTIVE POWER. (B) THE REACTIVE POWER 92

Figure 4.17: DLG fault (ALl Results in PU) (A) The 3-PHASE Voltage. (B) The AVERAGE OF THE RMS INVERTER PHASE CURRENTS. 93

Figure 4.18: DLG fault (ALl Results in PU) (A) THE ACTIVE POWER (B) THE REACTIVE POWER 94

FIGURE 4.19: THE 3-PHASE INVERTER CURRENTS UNDER DLG FAULT (RESULT IN PU) 94 Figure 4.20: DL fault (All Results in Pu) (A) The 3-PHASE Voltage. (B) The AVERAGE OF THE RMS INVERTER PHASE CURRENTS. .95

Figure 4.21: DL fault (ALl RESUlts in PU) (A) THE ACTIVE POWER. (B) THE REACTIVE POWER .95

FIGURE 4.22: THE 3-PHASE INVERTER CURRENTS UNDER DL FAULT (RESULT IN PU) .. 95 
Figure 4.23: SLG Fault (ALl Results in Pu) (A) The 3-PHASE Voltage. (B) The AVERAGE OF THE RMS INVERTER PHASE CURRENTS.

Figure 4.24: SLG FAULT (ALl RESUltS IN PU) (A) THE ACTIVE POWER. (B) THE

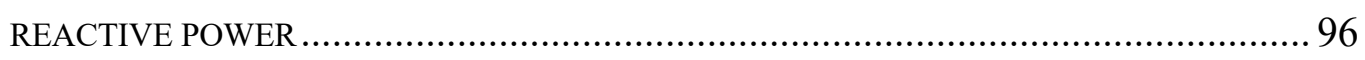

FIGURE 4.25: THE 3-PHASE INVERTER CURRENTS UNDER SLG FAULT (RESULT IN PU) 97

FIGURE 4.26: SLG FAULT WITH LVRT APPLIED TO THE REFERENCE MODEL (ALL RESUltS IN PU) (A) THE 3-PHASE VOLTAGE. (B) THE AVERAGE OF THE RMS INVERTER PHASE CURRENTS. 97

FIGURE 4.27: SLG FAULT WITH LVRT APPLIED TO THE REFERENCE MODEL (ALL RESULTS IN PU) (A) THE ACTIVE POWER. (B) THE REACTIVE POWER..................... 98 FIGURE 4.28: THE 3-PHASE INVERTER CURRENTS UNDER SLG FAULT WITH LVRT APPLIED TO THE REFERENCE MODEL (RESULT IN PU) ..... 98 


\section{LIST OF TABLES}

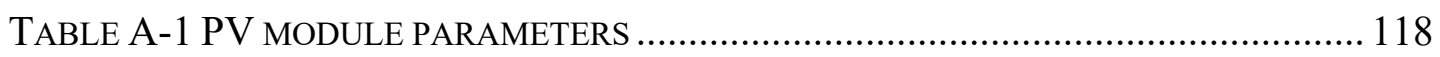

TABLE A-2 PARAMETERS FOR THE SYSTEM UNDER STUDY IN THE SYRF................. 118

TABLE A-3 PARAMETERS FOR THE SYSTEM UNDER STUDY IN THE STRF ................... 119 


\begin{tabular}{|c|c|}
\hline $\mathrm{CO}_{2}$ & Carbon Dioxide \\
\hline DC & Direct Current \\
\hline DG & Distributed Generation \\
\hline DSC & Delay Signal Cancellation \\
\hline FFT & Fast Fourier Transformation \\
\hline FOP & Fault Operation Point \\
\hline FRT & Fault Ride Through \\
\hline HVDC & High-Voltage Direct Current \\
\hline IC & Incremental Conductance \\
\hline IEA & International Energy Agency \\
\hline IGBT & Insulated Gate Bipolar Transistor \\
\hline LVRT & Low Voltage Ride-Through \\
\hline MPF & Mixed Potential Function \\
\hline MPP & Maximum Power Point \\
\hline MPPT & Maximum Power Point Tracking \\
\hline NRF & Natural Reference Frame \\
\hline PLL & Phase-Locked Loop \\
\hline PI & Proportional Integral \\
\hline PR & Proportional Resonant \\
\hline PV & Phototactic \\
\hline P\&O & Perturb \& Observe \\
\hline RES & Renewable Energy Sources \\
\hline RMS & Root Mean Square \\
\hline STRY & Stationary Reference Frame \\
\hline SYRF & Synchronous Reference Frame \\
\hline UK & United Kingdom \\
\hline
\end{tabular}


UVRT Under-Voltage Ride-Through

VCO Voltage-controlled Oscillator

VCU Voltage Compensation Unit

WPG Wind Power Generation 


\section{Chapter 1 Introduction}

\section{$1.1 \quad$ Background}

Carbon dioxide $\left(\mathrm{CO}_{2}\right)$ emissions have been remarkably worse in the last decades, but the problem goes far back. According to data provided by the International Energy Agency (IEA), the total $\mathrm{CO}_{2}$ fuel combustion in 2017 was 4618.2 million tonnes for electricity and heat generation in China. The total $\mathrm{CO}_{2}$ emissions in 2017 for electricity and heat generation in Europe was 2062 million tonnes [1]. The need for a clean and reliable energy generation has driven the renewable energy sources (RES) generation academic research and industry towards a new era. RES generation is one of the newest and environment-friendly approaches to meet the energy demand for humanity in the $21^{\text {st }}$ century. According to the newest released China's power mix [2], China plans to cut down coal generation from almost $59 \mathrm{GW}$ to nearly $6 \mathrm{GW}$ in the next two decades. Meanwhile, China will confirm its position as the global leader in the RES generation. Figure 1.1 shows the roadmap for the average annual net capacity additions by type from 2017 to 2040 .

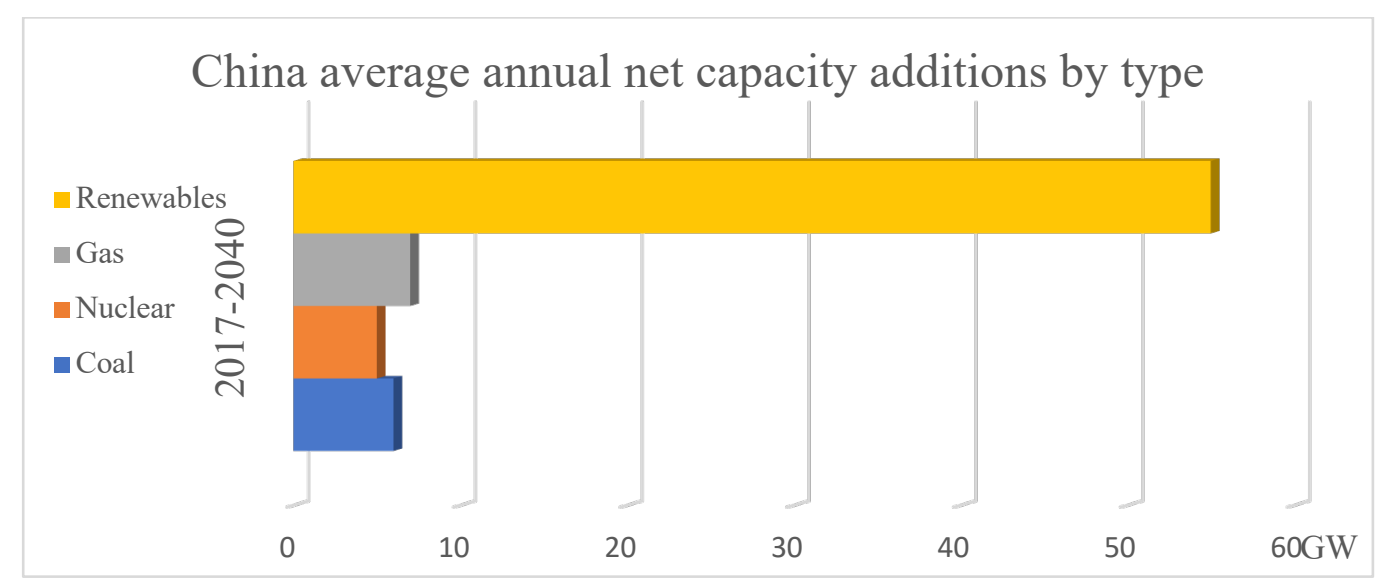

Figure 1.1: China average annual net capacity additions by type from 2017 to 2040 [2] 
In the United Kingdom (UK), 86.9 TWh electricity was generated in the first quarter of 2019. Figure 1.2 shows the percentage contribution to the UK's electricity generation from various energy sources for the first quarter of 2019 [3]. From their report, the RES generation was 31.1 TWh in the first quarter of 2019 , an increase of $9.2 \%$ a year earlier. Additional, solar PV generation was $2.12 \mathrm{TWh}$, an increase of $18.7 \% \mathrm{a}$ year earlier. Among all of the RES generation, wind and solar power are dominating the electric markets and research.

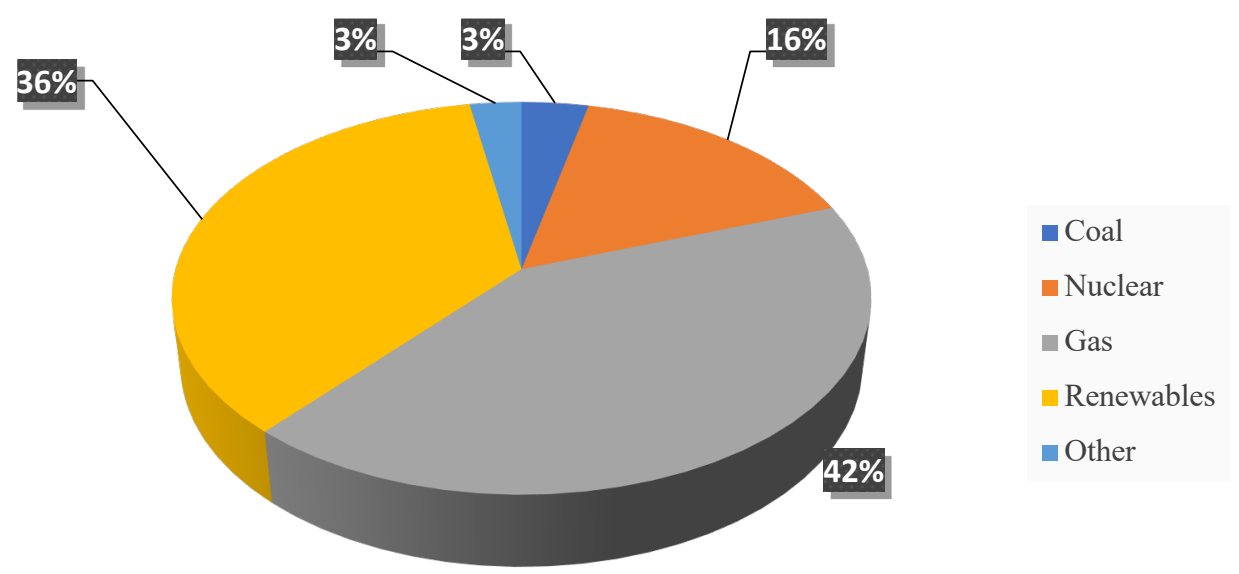

Figure 1.2: UK energy production for the first quarter of 2019 [3]

According to the IEA, the additional annual generation of wind and photovoltaic (PV) met almost all incremental demand for electricity in 2015 [4]. Compared with wind power generation (WPG), the modularity of the solar power generation is household or above, while WPG is community or above [4]. It means that solar power generation can be applied to either domestic level or distribution level. The power electronics technology and the development of PV, which is the most commonly used technology for the solar energy applicant, have made the solar power source available for domestic users. The PV system was initially motivated by the advancements of power electron- 
ics technology [5-7]. With the increasing research in PV based generation, the academic research interest in power electronic based control schemes has increased as well. Figure 1.3 is the IEA's on track data, which shows the installed and total solar power capacity around the world is increasing from 190TWh in 2014 to $585 \mathrm{TWh}$ in $2018[8]$.

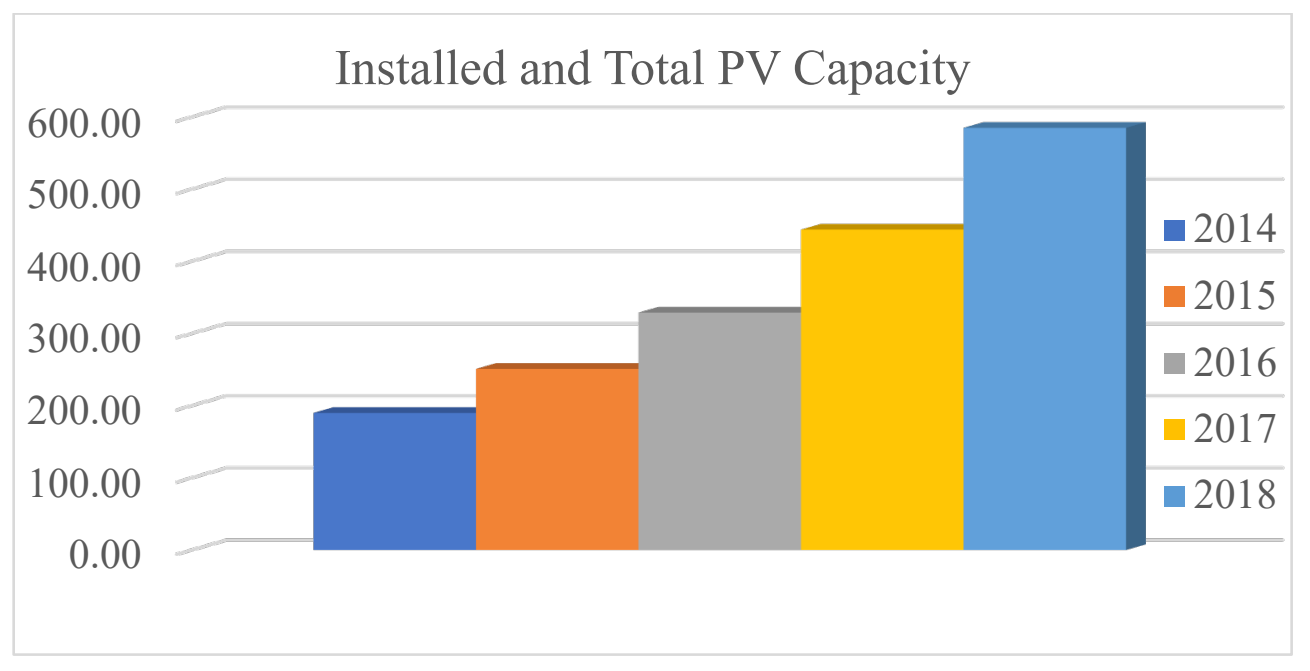

Figure 1.3: Installed and total PV capacity from 2014 to 2018 [8]

It is essential to introduce regulations for the grid-connected generators, which is known as Grid Codes to explain the requirements for the national power system that are connected to the grid. One of the requirements is to stay connected to the grid when voltage sag appears posed by the fault. During the fault, the generator should remain connected to the grid for a certain period and provide reactive power to support the grid. This is called low voltage ride-through (LVRT) capability. At the early stage, the LVRT requirements were imposed for large scale generators connected to the transmission network. However, with the increased penetration of distributed generation (DG), such as PV systems implemented in the distribution network, the LVRT requirements are also required for DGs. 
The cost of PV generation has decreased because of the maturity of the PV technology. Therefore, the total installed capacity of the PV generation has significantly increased. PV systems can be implemented both islanded and grid-connected. However, when the PV system connects to the grid, it will create some new challenges that need to be solved. The PV generation is permitted to switch off from the grid during a fault initially, however, with the high penetration of the installed PV system, it will degrade the power quality if the same method applied. Thus, Grid Codes including the LVRT requirements are introduced to the academic researches and industries in different places around the world to address the PV systems within certain power capacity or PV systems connected to a particular voltage level at the point of common coupling [9]. Moreover, power quality and transient performance are also the most critical aspects of the grid-connected PV system under grid faults. Consequently, it is necessary to make sure that the proposed LVRT method not only includes inverter current curtailment but also provides high quality fault current.

\subsection{Original Contribution}

LVRT requirements are required for grid-connected DG systems. Some conventional approaches for LVRT methods are proposed in the literature for PV systems, including chopper circuits or a non-MPPT mode when a fault is detected. However, both two methods require additional electronic elements, which increases the costs and losses of the system, and even lead to a non-smooth transition between the two modes. Moreover, some other methods considering LVRT have other disadvantages, e.g. the dynamic performance (at the instant of the fault, exactly after fault is cleared or post-fault recovery) during fault is poor. 
This thesis proposes two LVRT methods, which are investigated and developed in the synchronous reference frame (SYRF) and the stationary reference frame (STRF). The main contributions of the two methods are as follows:

1) Two voltage compensation units are proposed to achieve prevention of the activation of overcurrent protection through limiting the inverter current for both symmetrical and asymmetrical faults;

2) providing high-quality sinusoidal inverter voltage and current during faults;

3) reducing the double grid frequency oscillation;

4) eliminating the need to switch from the MPPT mode to non-MPPT mode;

5) supporting voltage through reactive power injection.

In addition to the above, the proposed STRF LVRT method has the following characteristics:

1) A simple and effective approach for the calculation of inverter reference currents that works for both normal operation and all types of faults in the STRF, which can provide independent active and reactive power control.

2) The reactive power calculation block, which contains a transient reactive power suppression unit is proposed. It can significantly reduce the inverter currents after the fault clearance.

3) The method provides fast post-fault recovery, maintains the currents within acceptable limitation, and produces sinusoidal currents even during asymmetrical faults.

4) The method eliminates the needs for a symmetrical components' separation strategy and the STRF to SYRF transformation. 


\subsection{List of Publications}

\section{List of published papers}

1. H. Wen and M. Fazeli, "A low-voltage ride-through strategy using mixed potential function for three-phase grid-connected PV systems", Electric Power Systems Research, vol. 173, pp. 271-280, 2019. Available: 10.1016/j.epsr.2019.04.039.

2. H. Wen and M. Fazeli, "A new control strategy for low-voltage ride-through of three-phase grid-connected PV systems", The Journal of Engineering, vol. 2019, no. 18, pp. 4900-4905, 2019. Available: 10.1049/joe.2018.9254

\section{Paper under peer-review}

1. H. Wen and M. Fazeli, " Enhancement of LVRT and Post-fault Performance for a 3-Phase Grid-Connected PV Systems in the Stationary Frame" (Electric Power System Research)

\subsection{Outline}

A detailed literature review is presented in Chapter 2, which discusses and reviews the state-of-the-art on the technical description of the results and contribution of various LVRT strategies for the grid-connected PV system. The drawbacks of these research works will also be discussed. The mathematical model of the PV cell is also explained in Chapter 2. Furthermore, the control scheme for a 3-phase inverter-based based gridconnected PV system is introduced. The main challenges facing the LVRT strategies for grid-connected PV system will be highlighted to emphasize the need for the work reported in this thesis. 
Chapter 3 presents an LVRT strategy for a 3-phase grid-connected PV system in the SYRF. The proposed method consists of a voltage compensation unit and a reactive power injection block. The equal-area criterion is used to investigate the stability of the new operation point during the faults. The mixed potential function is introduced to analysis the model under study and establish the equation used in the voltage compensation unit. The reactive power calculation block is introduced to support the grid during the faults.

The LVRT strategy for a 3-phase grid-connected PV system in the STRF is extended in Chapter 4. The proposed method uses a novel approach for the calculation of inverter reference current. In addition, the reactive power injection block includes a transient reactive power suppression unit, which can reduce the inverter current after the fault clearance for a severe fault. The strategy can improve post-fault recovery performance.

Chapter 5 presents a general conclusion of the overall work and provides some recommendations for future study. 


\section{Chapter 2 Grid-connected PV system and Literature Review for LVRT strategies}

\subsection{Photovoltaic Technology}

Solar energy is a sufficient resource on earth. By using renewable energy technologies, such as solar thermal power plant, solar concentrators and PV systems, solar energy is converted to electrical energy. The basic operation principle of a PV cell is called the photovoltaic effect.

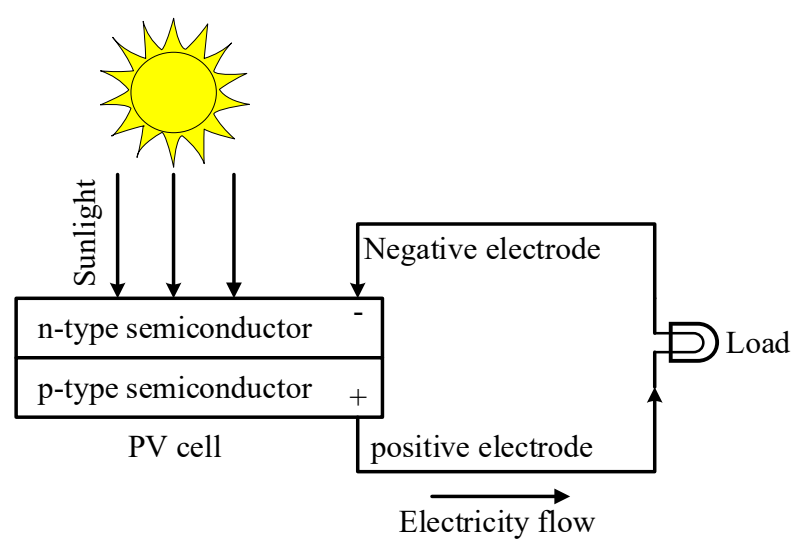

Figure 2.1: Photovoltaic Effect

As shown in Figure 2.1, when a semiconductor is exposed to sunlight, electrons, which are known as photoelectrons, will eject from the semiconductor [10]. The photoelectrons will only be ejected from the semiconductor when the wavelength of the light is smaller than the intrinsic wavelength of the material [11]. A PV cell behaves like a diode in nature, which allows a unidirectional flow of electrical current.

In the last decade, PV generation has seen massive growth leading to the widespread utilisation of PV systems in both domestic and industrial applications [8]. It offers low maintenance cost, flexible installation, and environmentally friendly energy. The electricity generated by the PV cells is determined by the amount of light incidence on the 
cells as well as the angle of incidence. The temperature of the cell also plays an important role in electricity generation. Other factors such as partial shading, cell mismatch, the area of the cell, ageing, and material type can also affect the output of the cell.

\subsubsection{Electrical and Mathematical Modelling of a PV cell}

The electrical model of a PV cell is shown in Figure 2.2. It consists of a single diode connected in parallel with an ideal current source. The PV cell operates like a controlled current source, which delivers current based on the solar irradiance [12, 13].

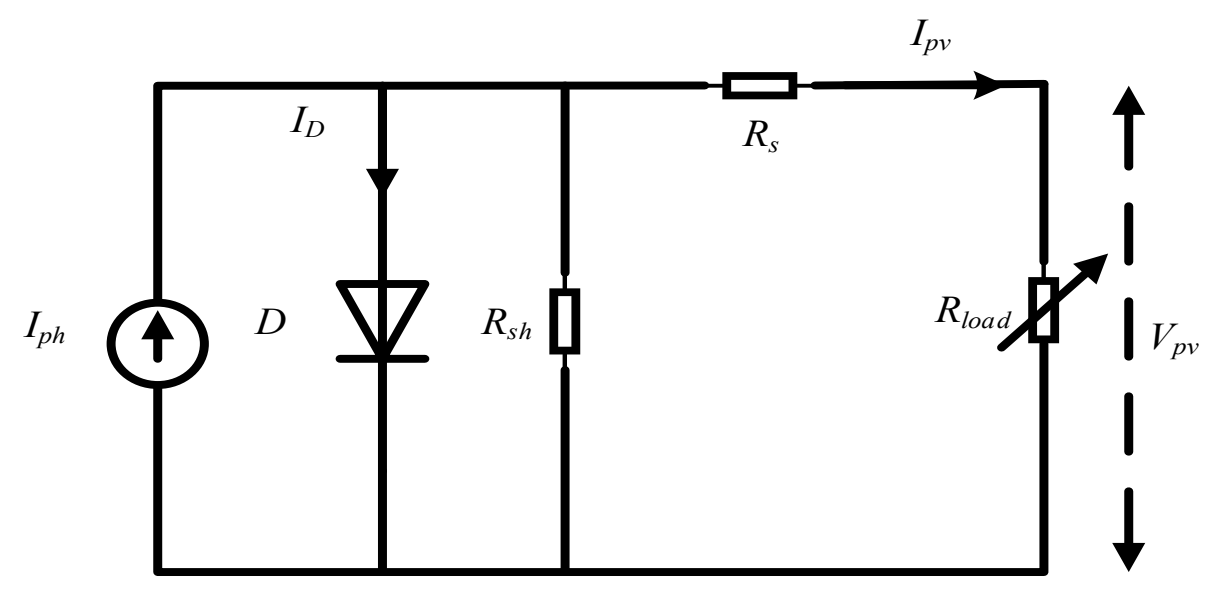

Figure 2.2: PV mathematical modelling [12]

In figure $2.2, I_{p h}$ is the photocurrent, $I_{D}$ is the diode current, $I_{p v}$ is the output current of the PV cell, $V_{p v}$ is the output voltage of the PV cell, $R_{\text {load }}$ represents the load connected to the PV cell. $R_{s}$ and $R_{s h}$ are the parasitic elements. A parasitic element is a circuit element that is possessed by an electrical component, but which is not desirable for it to have for its intended purpose. For an ideal PV model, $R_{s}$ and $R_{s h}$ are negligible; thus, $I_{p v}$ is given in equation (2.1):

$$
I_{p v}=I_{p h}-I_{D}
$$

The diode equation (2.2) is given by: 


$$
I_{D}=I_{0}\left(\exp \left(\frac{V_{D}}{\eta V_{T}}\right)-1\right)
$$

Thus, $I_{p v}$ is derived in equation (2.3):

$$
I_{p v}=I_{p h}-I_{0}\left(\exp \left(\frac{V_{D}}{\eta V_{T}}\right)-1\right)
$$

$I_{p h}$, which mainly depends on the solar irradiance and the working temperature of the cell, is described in equation (2.4).

$$
I_{p h}=\left(I_{s c}+C_{T}\left(T_{c}-T_{0}\right)\right) \frac{G}{G_{0}}
$$

The cell's saturation current $\left(I_{0}\right)$ varies with the cell temperature, which is given in equation (2.5).

$$
I_{0}=I_{r s}\left(\frac{T_{c}}{T_{0}}\right)^{3} \times \exp \left(\frac{q E_{g}}{\eta k}\left(\frac{1}{T_{0}}-\frac{1}{T_{c}}\right)\right)
$$

The reverse saturation current $\left(I_{r s}\right)$ at reference the temperature can be approximately derived in equation (2.6):

$$
I_{r s}=\frac{I_{s c}}{\exp \left(\frac{q V_{o c}}{\eta k T_{c}}\right)-1}
$$

Where,

$V_{D}$ is the voltage drop across the diode (in Volts);

$V_{T}$ is the thermal voltage $=26 \mathrm{mV}$;

$\eta$ is the ideality factor, which describes how closely the diode follows the ideal diode equation;

$I_{s c}$ is the short circuit current at reference temperature (in Ampere);

$C_{T}$ is the photocurrent temperature coefficient; 
$T_{c}$ is the cell surface temperature (in Kelvin);

$T_{0}$ is the reference temperature (in Kelvin);

$G$ is the solar irradiance (in $\mathrm{kW} / \mathrm{m}^{2}$ );

$G_{0}$ is the reference solar irradiance in $\left(\mathrm{kW} / \mathrm{m}^{2}\right)$;

$q$ is the electron charge $=1.6 \times 10^{-19} \mathrm{C}$;

$k$ is the Boltzmann's constant $=1.38 \times 10^{-23}($ Joules/Kelvin $)$;

$E_{g}$ is the band-gap energy of the semiconductor.

This thesis uses equations (2.1) - (2.6) to establish the PV cell model, where the scale of the PV array is computed based on the number of modules. Meanwhile, the scale of the PV module is computed based on the connected cells in series and parallel.

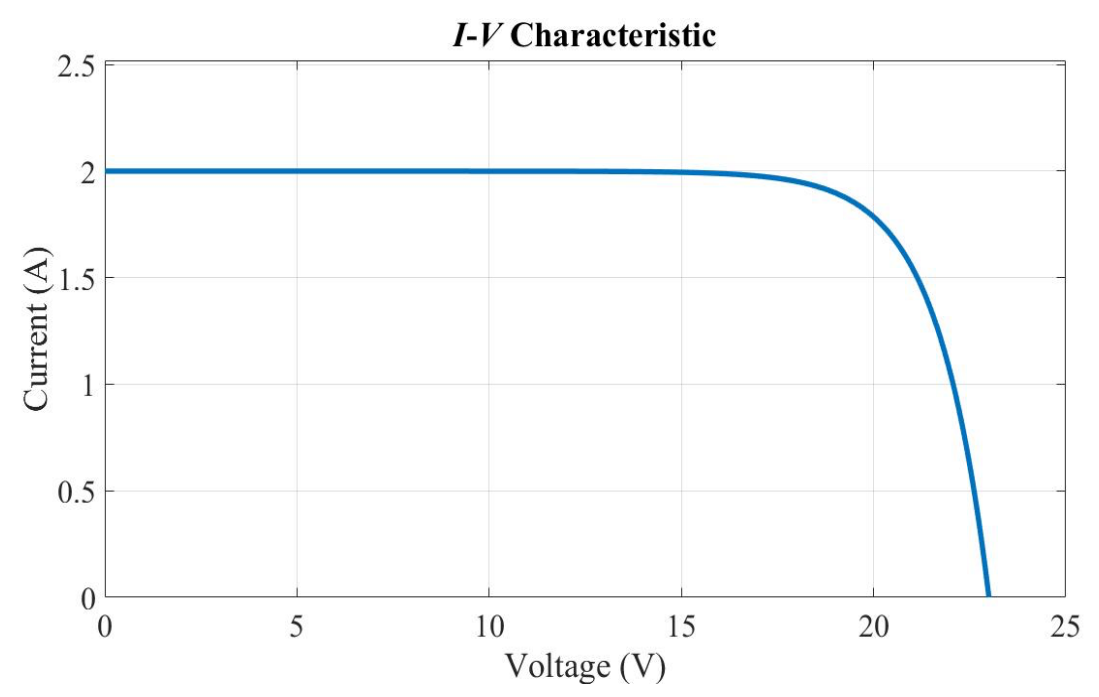

Figure 2.3: $I-V$ output characteristic curve of a PV cell

Figure 2.3 shows the $I-V$ output characteristic curve of a PV cell. The most substantial voltage across the PV cell is called the open-circuit voltage $\left(V_{o c}\right)$. The technology used to make the PV cell (e.g. polycrystalline silicon, which is the most common type used in PV) and the cells operating temperature determine $V_{o c}$. It increases with the cell 
temperature reducing or the irradiance increasing. Similarly, the highest current a PV cell can supply is called short-circuit current $\left(I_{s c}\right)$. $I_{s c}$ reduces as irradiance decreases.

The size of the module determines the amount of the electricity generated from the PV module. The larger the size of the module, the higher will be the amount of electricity generated [14]. A PV module typically consists of 28 to 36 cells in series or parallel. The parameters of the PV module used in this work are shown in Table A-1 in the appendix.

MATLAB Simulink toolbox is used to prove the effect of varying temperature and irradiance on a PV module's performance. Figure 2.4 and Figure 2.5 show the $P-V$ and $I-V$ output characteristic curves of the proposed PV module for different values of solar irradiance while the temperature is kept at a temperature of $25^{\circ} \mathrm{C}$. It can be found that the maximum output power increases significantly with the irradiance increases. However, changing the level of irradiance from $1000 \mathrm{~W} / \mathrm{m}^{2}$ to $200 \mathrm{~W} / \mathrm{m}^{2}$ has a slight effect on $V_{o c}\left(V_{o c}\right.$ varies in $\left.2 \mathrm{~V}\right)$. When irradiance is $1000 \mathrm{~W} / \mathrm{m}^{2}, V_{o c}$ is $23 \mathrm{~V}$; meanwhile $V_{o c}$ is $21 \mathrm{~V}$, when irradiance is $200 \mathrm{~W} / \mathrm{m}^{2}$. On the contrary, there is a dramatic effect on $I_{s c}$ with the irradiance changing. $I_{s c}$ is $2 \mathrm{~A}$, when irradiance is $1000 \mathrm{~W} / \mathrm{m}^{2}$; meanwhile, it is around $0.5 \mathrm{~A}$ when irradiance is $200 \mathrm{~W} / \mathrm{m}^{2}$. From equations (2.3) - (2.6), it can be easily found that $I_{p v}$ is mainly depended on the irradiance, i.e. $I_{p v}$ is proportional to the irradiance varying roughly. 


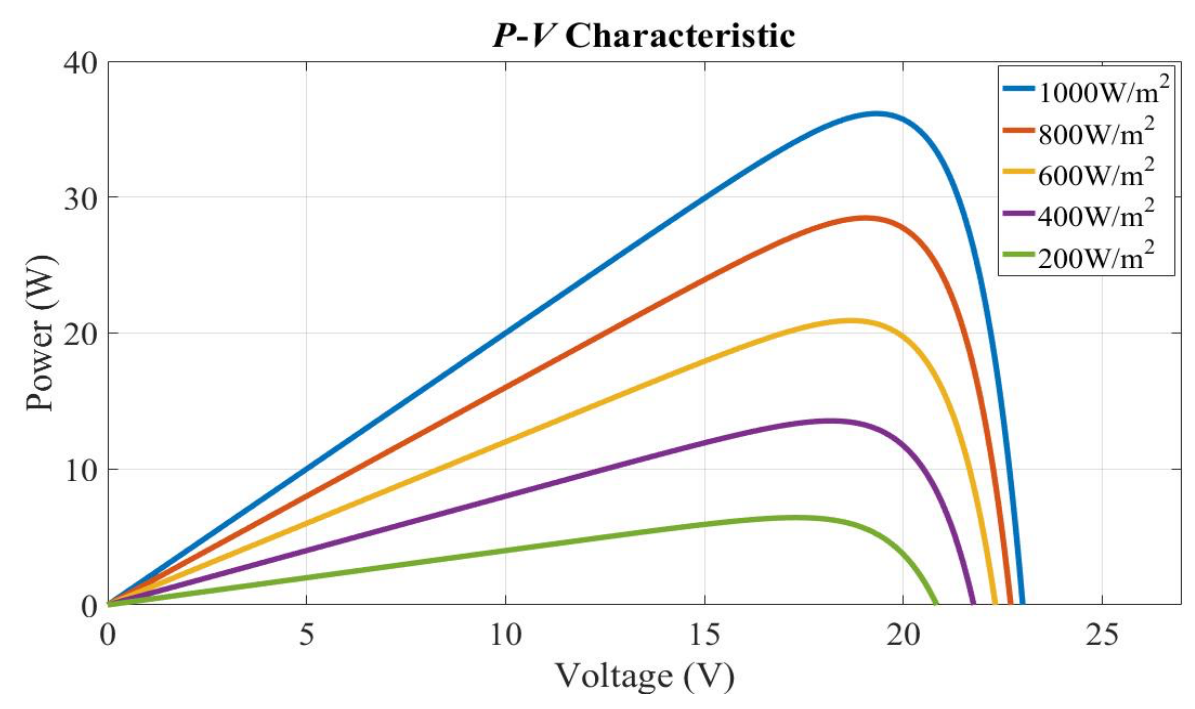

Figure 2.4: $P-V$ output characteristic curve of a PV module for varying solar irradiance

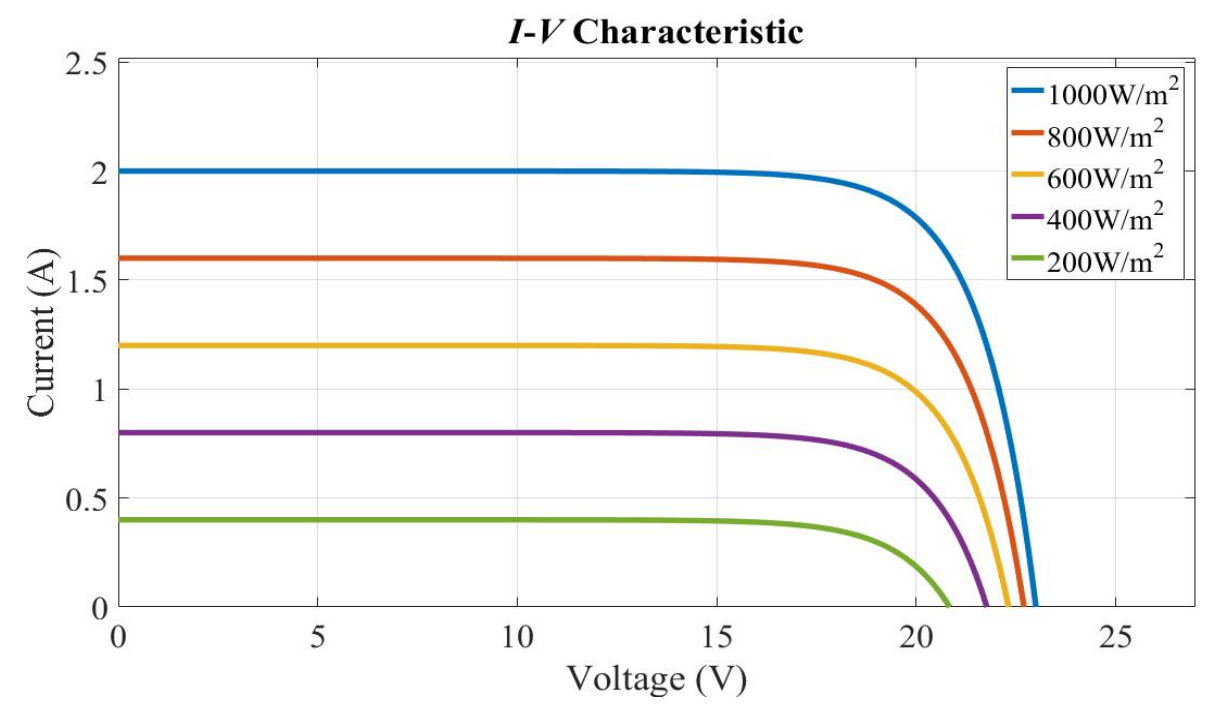

Figure 2.5: $I-V$ output characteristic curve of a PV module for varying solar irradiance

Figure 2.6 and Figure 2.7 show the $P-V$ and $I-V$ output characteristic curves of a PV module for varying temperature while the irradiance is kept at nominal conditions, (i.e., irradiance is $1000 \mathrm{~W} / \mathrm{m}^{2}$ ). A significant reduction of $V_{o c}$ is observed, while the temperature increases. However, the changing level of temperature has a slight effect on

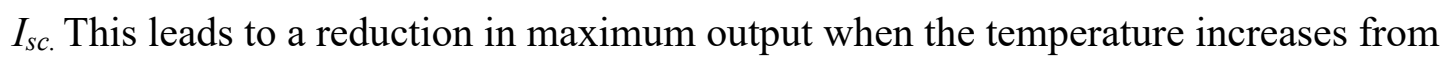
$25^{\circ} \mathrm{C}$ to $75{ }^{\circ} \mathrm{C}$. In practical, $60{ }^{\circ} \mathrm{C}$ or $75^{\circ} \mathrm{C}$ of the ambient temperature is not realistic; 
however, to compare the impact of the temperature, such conditions are simulated. The results show that the changing of the ambient conditions lead to varing in maximum power on the $P$ - $V$ curves. Hence, a maximum power point tracking (MPPT) technique is required to track the changes in the maximum power point (MPP).

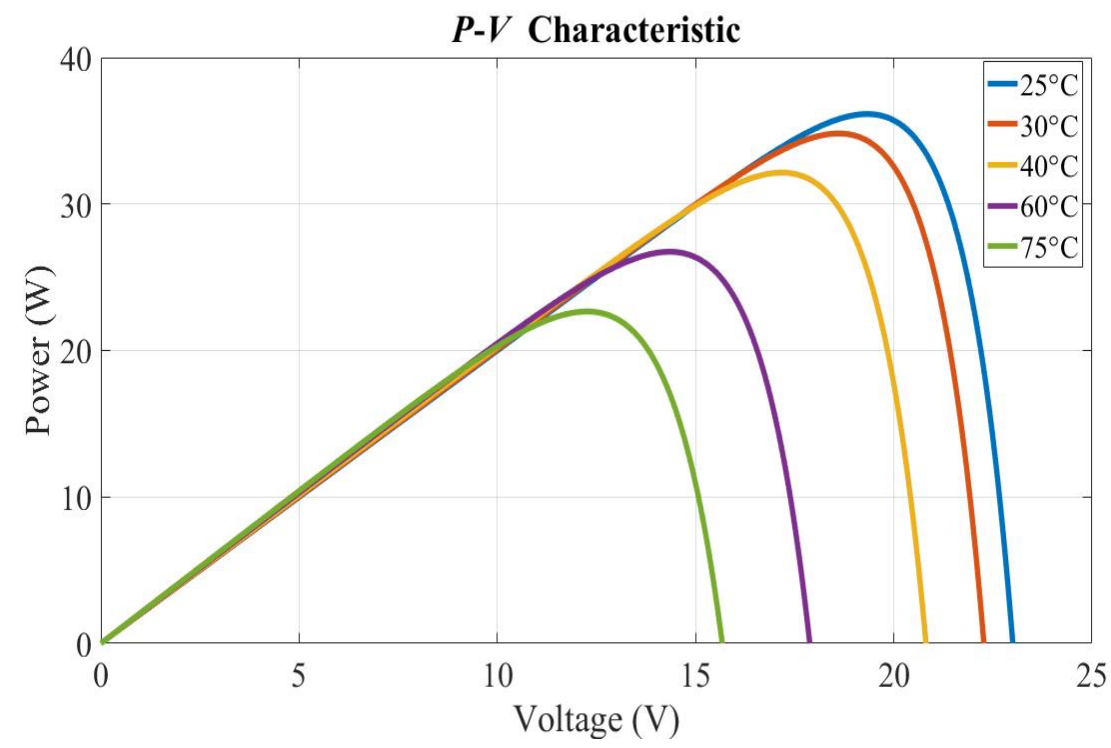

Figure 2.6: $P-V$ output characteristic curve of a PV module for varying temperature

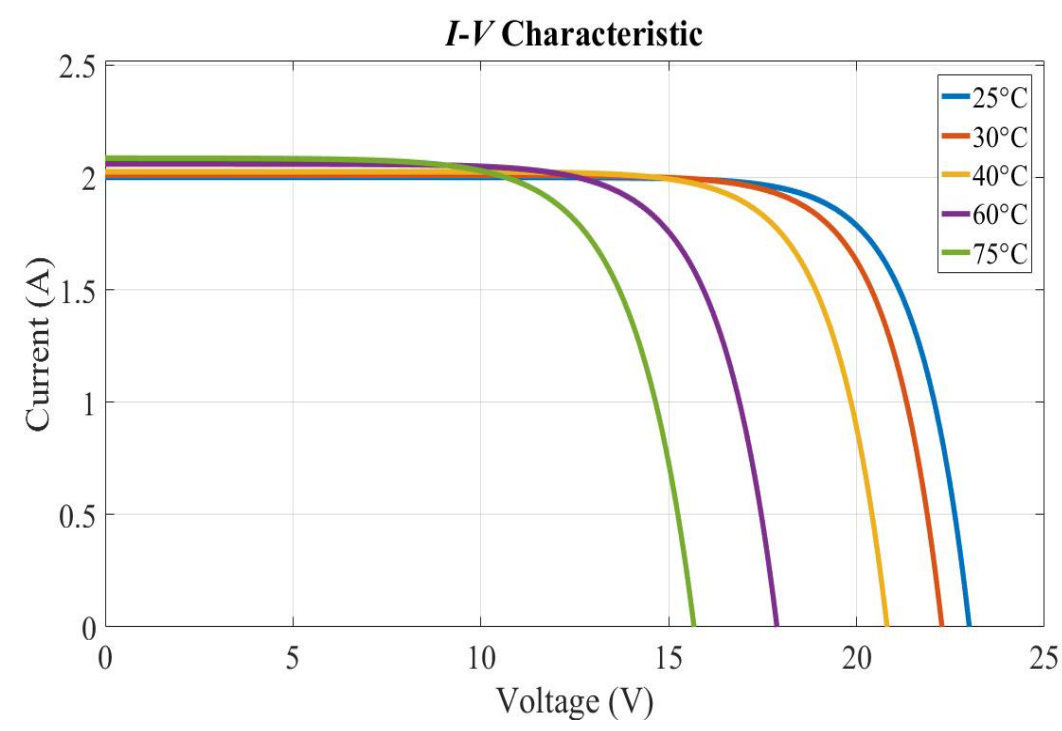

Figure 2.7: $I-V$ output characteristic curve of a PV module for varying temperature 


\subsubsection{Maximum Power Point Tracking}

As explained above, the variation of irradiance and temperature can be used to build the mathematical model of the PV module, which is nonlinear and will be affected by solar irradiance and operating temperature. Furthermore, the daily solar irradiance can be altered by the weather times during the day and year. Therefore, without a proper control scheme, the operating point of the PV module shifts continuously, which is not acceptable from a practical standpoint. In fact, the PV system's operating point must be adjusted to maximize the power produced. The MPPT algorithm is therefore used to ensure the PV system's operating point maintains at its MPP. Some different types of MPPT algorithm have been proposed in the literature [15-17], such as the constant voltage method, short current pulse method, open-voltage method, perturb and observe (P\&O) method and incremental conductance (IC) method. All of the above methods have their own drawbacks. For example, the constant voltage method, which provides constant voltages for a pre-measured temperature and irradiance, is simple but not accurate. Similar to the constant voltage method, both short current pulse and open-voltage methods require additional measurement of short-circuit current or open-circuit voltage, which cannot provide real-time MPPT (i.e. can add to the delay). IC method suffers from two main shortcomings. First, the mathematical process is complicated, which means an advanced control scheme is required. Furthermore, the performance of this method highly depends on the setting of the increment step.

Among all the MPPT techniques, the P\&O MPPT is one of the most commonly used MPPT approaches in the PV system. P\&O MPPT has some drawbacks. The main disadvantages for the P\&O MPPT are: The operating point is continuously oscillating around the MPP in steady-state when MPP is reached and poor tracking ability under 
sudden changes of irradiance [18-20]. However, P\&O MPPT has many advantages. Compared with the constant voltage method, short current pulse method and openvoltage method, it can provide true MPP tracking. Moreover, P\&O MPPT is not a PV array dependent algorithm, which means it can be applied to any PV system. Furthermore, it is a low-cost method, and the implementation is straightforward [18] (simple control scheme compared with the IC methods). Considering a P\&O MPPT has the above advantages, this work uses P\&O MPPT to control the PV system. The P\&O method algorithm operates by periodically perturbing the output voltage and current of the PV panel and comparing the PV output power to that of the previous cycle [18]. If the PV module output voltage changes and power increases, which means the

$$
\frac{d P_{p v}}{d V_{p v}}>0
$$

will drive the PV module operating point to that direction; otherwise, the operating point is moved in the opposite direction.

For easy understanding, the fundamental principles of the P\&O MPPT technique are shown in the flowchart in Figure 2.8. Initially, the control scheme defines the change of the PV output power $(\Delta P=P(n)-P(n-1))$ and voltage $(\Delta V=V(n)-V(n-1))$, where n-1 is the previous step of $\mathrm{n}$ and $\mathrm{n}$ is the number of the step. When $\Delta P=0$, it means that the output power reaches the MPP. The P\&O MPPT technique uses the algorithm shown in Figure 2.8 to detect the operation point of the PV array. When $\Delta P=0$, MPP is achieved. If $\Delta P \neq 0$, it is needed to identify whether the operating point is on the left or right-hand side of the MPP. If the operation point is detected at the left-hand side of the MPP, the controller will add $\Delta V$ to $V(n)$; thus, it drives the operation point towards the MPP. When the operation point is detected at the right-hand side of the MPP, $\Delta V$ 
will be subtracted from $V(n)$; thus, the operation point will be forced toward the MPP. In practice, this approach will make the operating point at the left-hand side of the MPP in one cycle, and at the right-hand side of the MPP in the next cycle. Thus, the operating point will oscillate around its MPP.

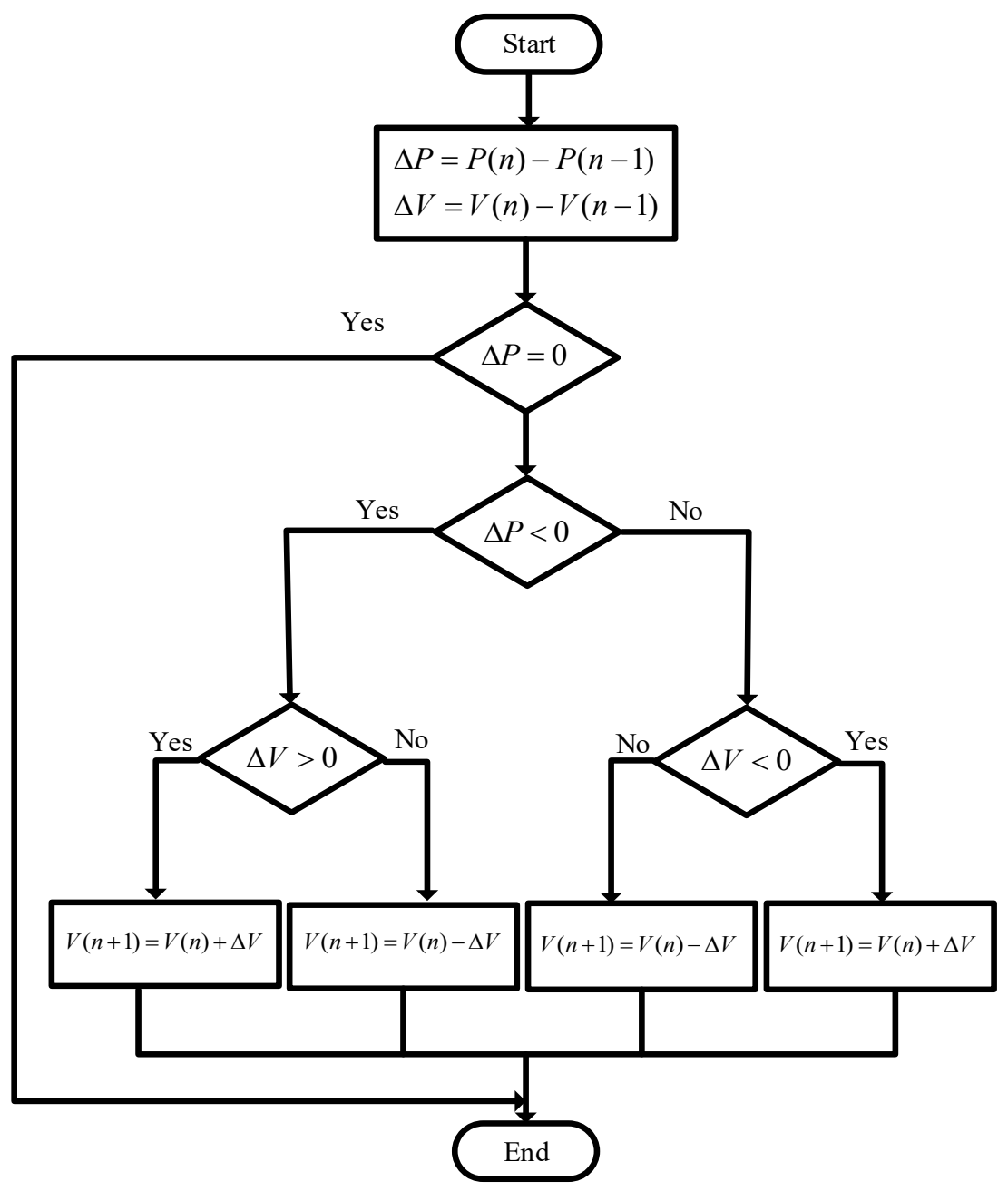

Figure 2.8: The flowchart of a P\&O MPPT algorithm

\subsection{Control of grid-connected PV system}

Since the output voltage of the PV generation is DC voltage, the inverter is required to transfer the DC voltage to AC for 3-phase grid-connected PV system. Thus, controlling the voltage and current is important for an inverter-based power system. Figure 2.9 
shows a basic control scheme for a grid-connected PV system. The PV system consists of a cascaded voltage and current loops in dq-frame (SYRF), and a Phase-Locked Loop (PLL). STRF is often used in electrical engineering with a 3-phase system. The transform can be used to rotate the reference frames of $\mathrm{AC}$ waveforms such that they become DC signals. Simplified calculations can then be carried out on these dc quantities before performing the inverse transform to recover the actual three-phase ac results. The PLL technique and current controller will be detailed in the next sections.

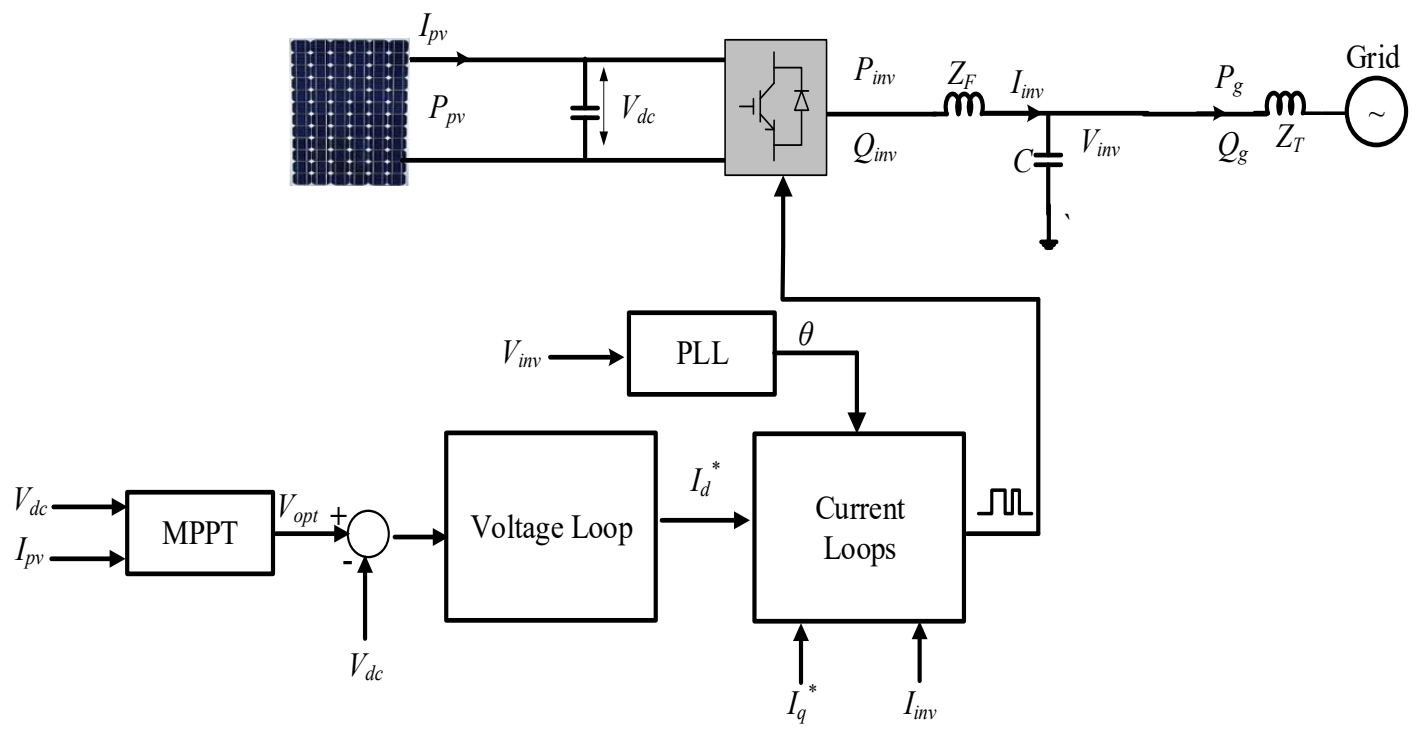

Figure 2.9: Basic control scheme for a grid-connected PV system

\subsubsection{Phase-Locked Loop}

A PLL is needed in a PV system to ensure that the PV system is synchronous with the grid [21]. The PLL is a control scheme that automatically tunes the phase of a locally estimated signal used as a reference to match the phase of the input signal. Normally, a PLL consists of three blocks: a phase detector block, loop filter and voltage-controlled oscillator (VCO) block. The advantage of VCO is that by changing its frequency relative to that of the other signal, billions of degrees of phase shift over time can be obtained [22]. There are many different types of PLL regarding the loop filter, 
such as first-order PLL, second-order PLL or even higher-order PLL. Since this thesis mainly focuses on the LVRT strategies for a grid-connected PV system, it considers a simple PLL to synchronise the grid frequency. Thus, the SYRF-PLL, which is a firstorder PLL and most commonly used technique, is used. The SYRF-PLL is easy to design. A basic structure of an SYRF-PLL is shown in Figure 2.10, which considers a PI controller for the loop filter. When considering an inverter-based PV system, the system is nonlinear; however, since the control plant of an SYRF-PLL is a feedforward control (to speed up the controller), where the reference frequency is $50 \mathrm{~Hz}$. When the frequency of the system closes to $50 \mathrm{~Hz}$, it can be assumed to be a linear system. This technique allows the voltage variables in the natural reference frame (NRF) transform to the SYRF, rotating at the angle $\theta^{*} . \omega_{0}$ is the nominal grid frequency in $\mathrm{rad} / \mathrm{s}$.

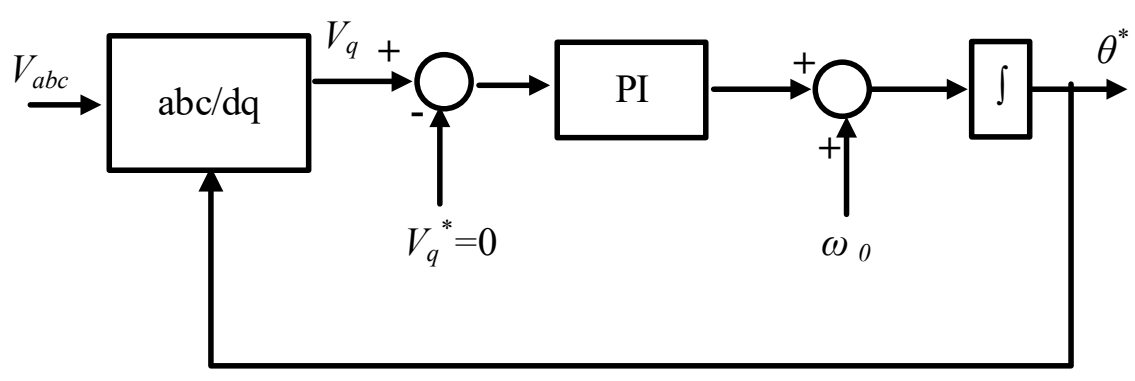

Figure 2.10: PLL control scheme

The Park Transformation for NRF to SYRF is given:

$$
V_{d q}=\left[\begin{array}{l}
V_{d} \\
V_{q}
\end{array}\right]=\frac{2}{3}\left[\begin{array}{ccc}
\cos \theta & \cos (\theta-2 \pi / 3) & \cos (\theta+2 \pi / 3) \\
\sin \theta & -\sin (\theta-2 \pi / 3) & -\sin (\theta+2 \pi / 3)
\end{array}\right]\left[\begin{array}{c}
V_{a} \\
V_{b} \\
V_{c}
\end{array}\right]
$$

The SYRF-PLL can lead to an error in the signals under unbalanced voltage conditions [23]. To achieve precious control of a PV system during abnormal operation, the delayed signal cancellation (DSC)-PLL $[24,25]$ is introduced. 
DSC, which a method used to cancel out the fundamental component of the negative sequences during an asymmetrical fault, is also used in this work for symmetrical components separation. DSC-PLL, which also uses PI controller as the loop filter can dramatically eliminate the oscillatory errors caused by the unbalanced voltages [26]. The principle of the DSC method can be described as below:

In general case of an asymmetrical voltage condition, the voltage in the $\operatorname{STRF}\left(v_{(\alpha, \beta)}(t)\right)$ can be written in equation (2.8):

$$
v_{(\alpha, \beta)}(t)=v_{(\alpha, \beta)}^{+}(t)+v_{(\alpha, \beta)}^{-}(t)
$$

Where $v^{+}(\alpha, \beta)(t)$ and $v_{(\alpha, \beta)}^{-}(t)$ is estimations of the positive and negative sequences voltage in the STRF. The DSC method is defined by equation (2.9):

$$
\begin{aligned}
& v_{(\alpha, \beta)}^{+}(t)=\frac{1}{2}\left[v_{\alpha, \beta}(t)+j v_{\alpha, \beta}\left(t-\frac{T}{4}\right)\right] \\
& v_{(\alpha, \beta)}^{-}(t)=\frac{1}{2}\left[v_{\alpha, \beta}(t)-j v_{\alpha, \beta}\left(t-\frac{T}{4}\right)\right]
\end{aligned}
$$

Where $T$ is the signal period, which is the same as the grid period. The method applies one quarter cycle delay to the input signal to obtain the output signal $[27,28]$. Then the output voltage signals are converted to the SYRF using standard STRF to SYRF Transformation. The structure of a DSC-PLL is given in Figure 2.11, where $V_{q p}$ is the positive sequence voltage in the SYRF and $V_{q p}{ }^{*}$ is the reference voltage. The DSCPLL is used to synchronise the frequency in Chapter 3. The DSC-PLL uses PI controller, which is used in a linear system to control the scheme. The current controller will be discussed in the next section. 


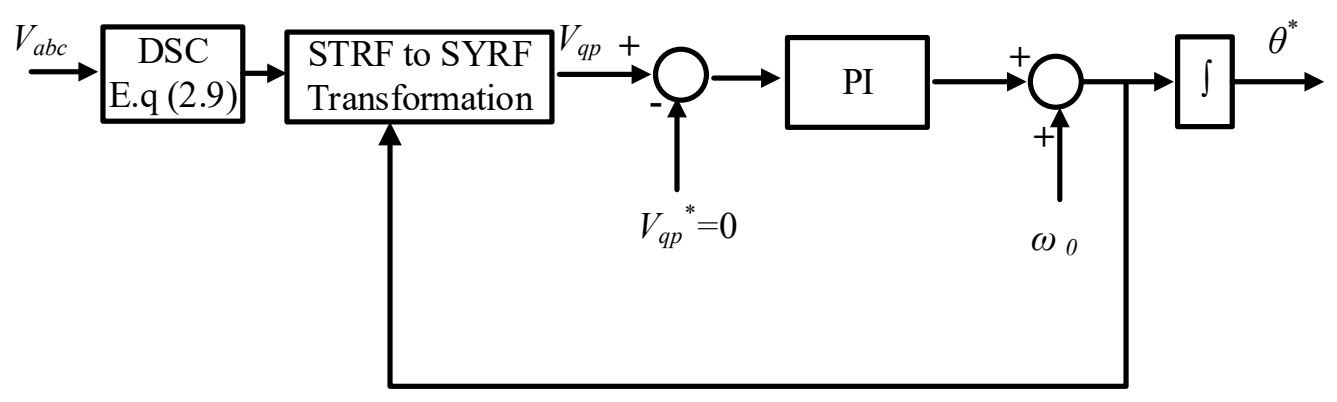

Figure 2.11: DSC-PLL control scheme

\subsubsection{Conventional Current Loop}

Figure 2.12 is the simplified equivalent circuit for a 3-phase PV system. $C_{d c}$ is the DClink capacitor. $I_{p v}$ is the PV output current at MPP, and $V_{p v}$ is the output voltage at MPP. $R_{f}, L_{f}, C_{f}$ are the LC filter elements. $V_{i a}, V_{i b}$ and $V_{i c}$ are the inverter 3-phase voltages before the filter and $V_{t a}, V_{t a}$ and $V_{t a}$ are the inverter 3-phase voltages after the filter.
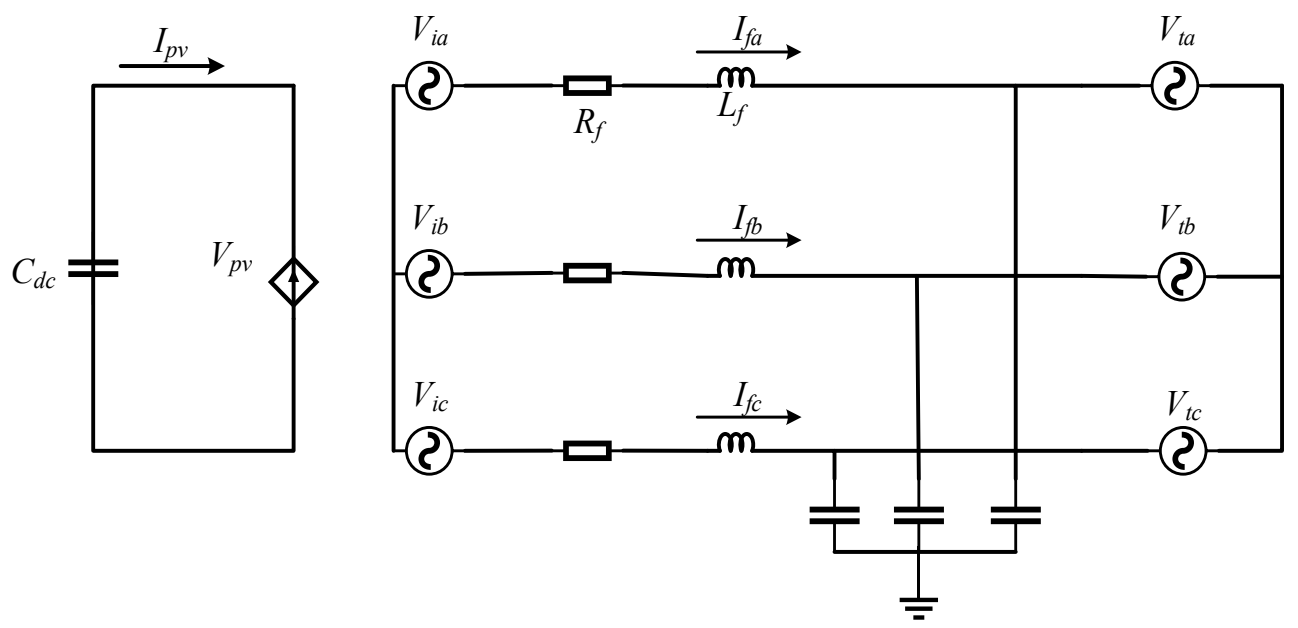

Figure 2.12: Equivalent circuit for mathematical modelling

By applying Kirchhoff's voltage law (KVL), and Kirchhoff's current law (KCL), equation (2.10) can be derived from the equivalent circuit:

$$
L_{f} \frac{d \boldsymbol{I}_{f}}{d t}=\boldsymbol{V}_{i}-R_{f} \boldsymbol{I}_{f}-\boldsymbol{V}_{t}
$$


Where $\boldsymbol{I}_{f}, \boldsymbol{V}_{i}$ and $\boldsymbol{V}_{t}$ are the 3-phase current and voltage vectors (e.g. $\boldsymbol{I}_{f}=\left[\begin{array}{lll}I_{f a} & I_{f b} & I_{f c}\end{array}\right]^{\mathrm{T}}$ ) (Note that a bold font is used here to consider vectors in 3-phase components). By using NRF to SYRF transformation for equation (2.10), equation (2.11) is given:

$$
\begin{aligned}
& L_{f} \frac{d I_{f d}}{d t}=V_{i d}-R_{f} I_{f d}-V_{t d}+\omega_{0} L_{f} I_{f q} \\
& L_{f} \frac{d I_{f q}}{d t}=V_{i q}-R_{f} I_{f q}-V_{t q}-\omega_{0} L_{f} I_{f d}
\end{aligned}
$$

Where $\omega_{0}$ is the grid frequency of the rotating SYRF. Assuming $R_{f}$ is very small, equation (2.11) can be written as:

$$
\begin{aligned}
& L_{f} \frac{d I_{f d}}{d t}=V_{i d}-V_{t d}+\omega_{0} L_{f} I_{f q} \\
& L_{f} \frac{d I_{f q}}{d t}=V_{i q}-V_{t q}-\omega_{0} L_{f} I_{f d}
\end{aligned}
$$

Thus, equation (2.12) can be used to control the inverter current. Figure 2.13 shows the conventional current controller in SYRF, which contains two compensation terms. One is $-I_{f d, q}\left(\omega L_{f}\right)$, another one is $V_{t d, q}$. Similar approaches can be derived to get the current controller in STRF. The control scheme shown in Figure 2.13 is used in chapter 3 for LVRT strategies design. Since this thesis proposes the LVRT methods based on the voltage loop, the detailed explanation of the voltage control will be introduced in Chapter 3 and 4.

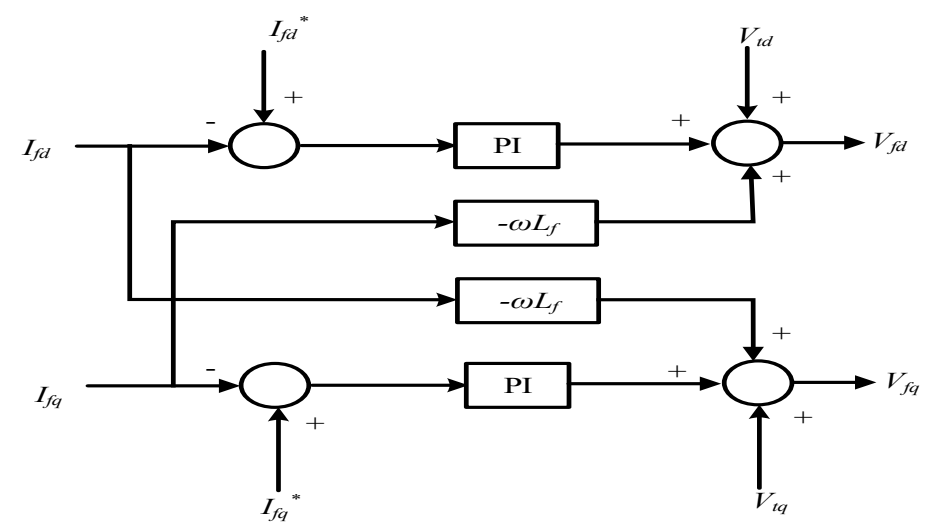

Figure 2.13: Current controller in SYRF 


\subsection{Grid Code and Low-voltage ride-through}

The National Grid is the system operator of Great Britain's electricity supply. It is the company that manages the network and distribution of electricity that powers all our homes and businesses. According to the National Grid, the definition of Grid Code is the technique code for connection and development of the national electricity transmission system [29]. A grid code, which introduces the parameters for an electricity generating plant, a consumer or a network connected to a public electric grid, must be met to ensure the safe, secure and economic proper functioning of the power system [30]. Since the grid codes are introduced by different countries or authorities around the world, it varies depending on the authority's requirements. Typically, a grid code will indicate the requirements of a grid-connected power system during the disturbances. For example, the voltage regulation, power factor, reactive power supply, response to a system failure, response to frequency changes on the grid and requirement to ride through short disturbances of connection, these are all included in a grid code [31]. With the rapid increase of installed DG units connected to the grid, the transmission level grid will be affected by these DG units. When disturbances or failure is detected near the DG side, the DG units should have the ability to ensure that the disturbances will not cause the public grid degrades. Thus, the LVRT techniques become more and more popular among the researchers and industries.

\subsubsection{Low voltage ride-through requirements}

LVRT, also known as fault ride-through (FRT) or under-voltage ride-through (UVRT) [32], is the ability of a generation unit to ride through faults and disturbances whilst connected to a healthy system circuit [33]. According to the National Grid, LVRT was 
first introduced to the GB Grid Code in June 2005 following grid code consultation H/04 [33]. To explain what exactly LVRT is, an overall profile for voltage requirements is illustrated in Figure 2.14.

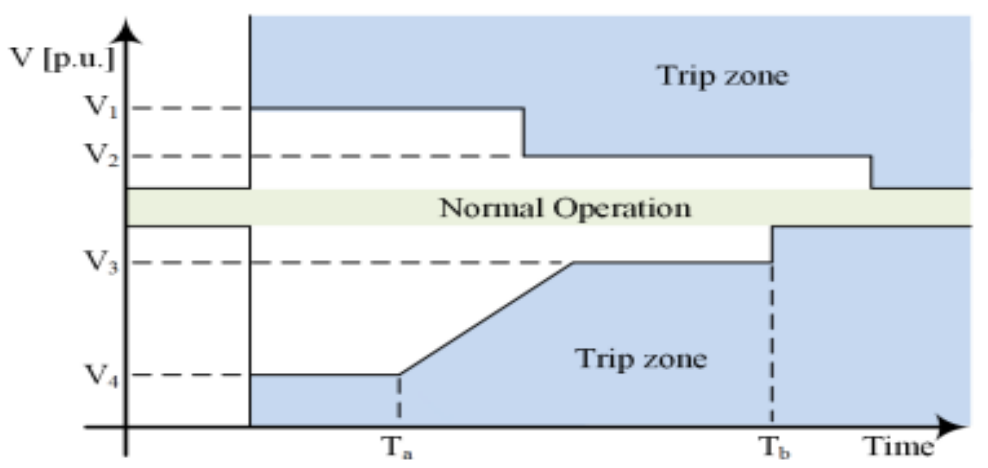

Figure 2.14: Voltage profile requirement [34]

The voltage range of a system, which is expected to withstand the voltage changes following a network disturbance or fault is known as normal operation zone, or steadystate voltage. The normal operation voltage is defined by different authorities, such as the National Grid in the U.K. or the State Grid Corporation of China. However, the operation zone is normally defined from 0.9 to $1.1 \mathrm{pu}$. In the UK, when the disturbance or fault is cleared within 15 minutes, the steady-state voltage requirement is 0.9 to 1.1 pu. However, when the disturbance or fault is continuous, the normal operation zone is from 1.05 to $0.9 \mathrm{pu}$ [35]. In Figure 2.14, $V_{4}$ is the lowest voltage that the desired system should tolerate for a certain period $\left(T_{a}\right)$. This ability is called LVRT ability. The slope between $V_{4}$ and $V_{3}$ is the voltage recovery after a fault is cleared. In China, the DG systems should stay connected to the electric grid for $150 \mathrm{~ms}$ when voltage drops to 0 pu. However, the LVRT requirements are different in different countries or regions. For example, the LVRT requirements in China and the UK is given in Figure 2.15 and Figure 2.16, respectively. In China, the system should be connected to the 
grid when the voltage drops to 0 pu for $150 \mathrm{~ms}$, meanwhile, the system is allowed to disconnect from the grid when the voltage drops to $0 \mathrm{pu}$. Considering that the LVRT requirements in China are stricter than the requirements in the U.K., this work uses Chinese Grid Code when designing the control scheme. Similarly, the ability for a system to stay connected to the grid when the voltage is higher than the normal operation zone is called high-voltage ride-through. $V_{1}$ and $V_{2}$ represent the higher voltage limits. However, only LVRT is studied in this work.

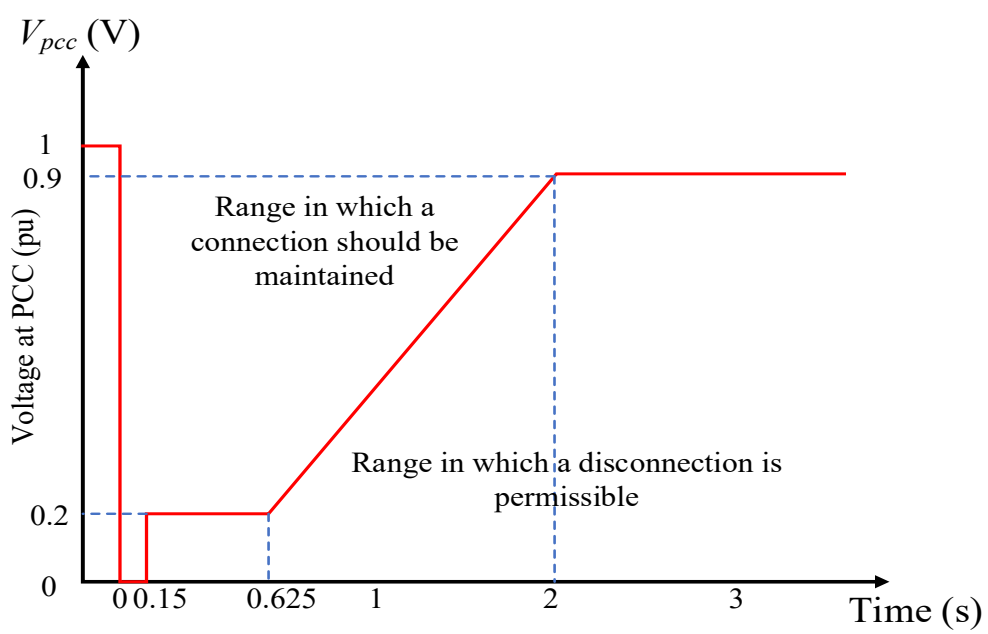

Figure 2.15: LVRT requirements in China [36]

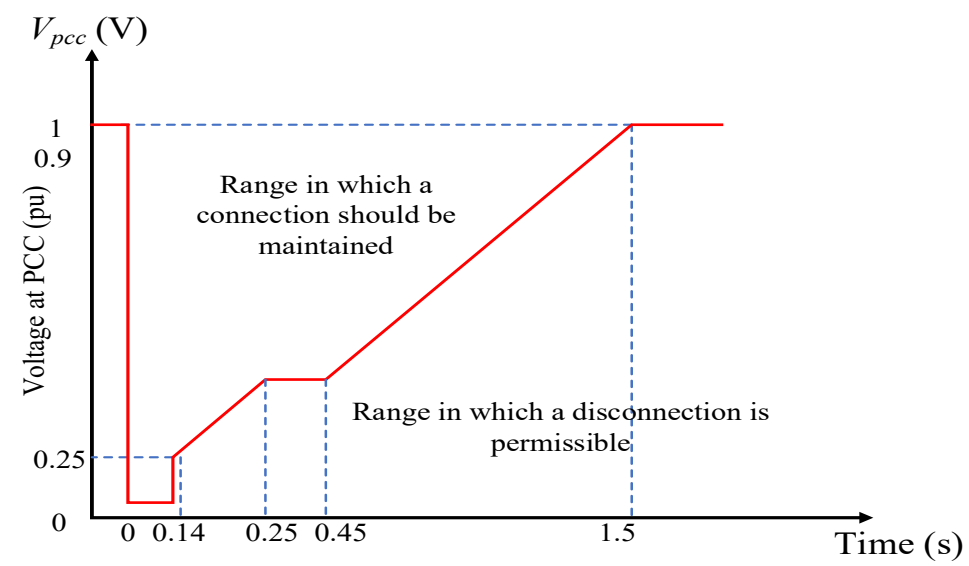

Figure 2.16: LVRT requirements in the UK [33] 


\subsubsection{Reactive power injection}

With the increasing adoption of the PV system, the performances of the grid will be affected. For instance, potential overloading or voltage rise may appear at distributed grid feeders especially when a high penetration level of the PV system is installed, due to the intermittent nature of the solar source and the unbalance between PV supply and load demands [37-40]. Thus, in some countries, the specific grid requirements for a PV system is introduced, which should be able to support the grid and voltage regulation through reactive power injection [41-44]. Moreover, the aggregated PV system may induce grid variations [45-47]. Hence, in response to grid fault and disturbances, it is recommended to apply reactive power injection when designing the LVRT techniques to provide dynamic grid support [37]. Figure 2.17 shows the reactive power injection requirements in different countries and regions. It can be found that Germany, Denmark and E. ON requires the system to inject 1 pu reactive power when the voltage sag $0.5 \mathrm{pu}$ ( $0.6 \mathrm{pu}$ in Germany), meanwhile only 0.8 pu reactive power is required in Spain. China has the strictest requirement, in which 1.05 pu reactive power is needed when the voltage sag is $0.8 \mathrm{pu}$. Considering the above, this work uses the Grid Code in China when considering the reactive power injection calculation.

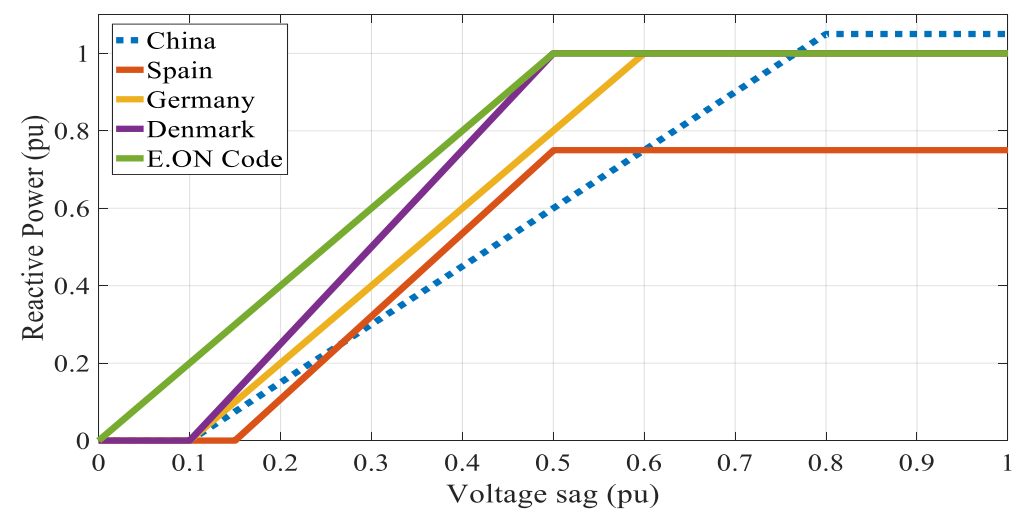

Figure 2.17: Grid Codes for reactive power injection of each country [48] 


\subsection{LVRT strategies}

The main challenges of an LVRT strategy for a grid-connected system are:

1) Preventing overcurrent failure (current curtailment) and restoring to normal operation.

2) Maintaining the DC-link voltage.

3) Providing sinusoidal inverter current for the healthy phases.

To achieve these goals, there are many LVRT techniques proposed in the literature. For example, a crowbar can be used in a doubly-fed induction generator (DFIG) system to prevent system failure [49]. Traditionally, a crowbar is a resistance, which is used to short circuit the rotor windings in the DFIG system [49]. However, there is a major shortcoming of the crowbar that when it is operating, the rotor-side converter is disabled, and the control of the DFIG is lost. An active crowbar is proposed in some studies to shorten the operation time of the crowbar, which can improve this type of method. Since this work only concentrates on the PV system, the crowbar will not be further discussed. The following part will introduce some LVRT strategies for a PV system.

\subsubsection{Conventional LVRT strategy for grid-connected PV system}

One of the most commonly used approaches for LVRT strategy for a PV system is switching the operation from MPPT control mode to a non-MPPT mode [50-52]. This is because it will be more complicated for LVRT designing if the MPPT is connected during the fault. Therefore, this technique requires a fault detection method [53-54]. A fault detection method requires the converter to detect the fault and react quickly to 
the disturbances to protect the converter and upstream system from the effects brought by the fault. Figure 2.18 shows a simple model of a PV system control scheme with an operation switching function and fault detection block for LVRT. When a fault is detected, the LVRT algorithm will choose whether to stay connected with the MPPT or switch off from the MPPT depending on the fault detection block. For example, if the voltage sag is smaller than $0.1 \mathrm{pu}$, the system will still be connected to MPPT; otherwise, it will be cut off from the MPPT.

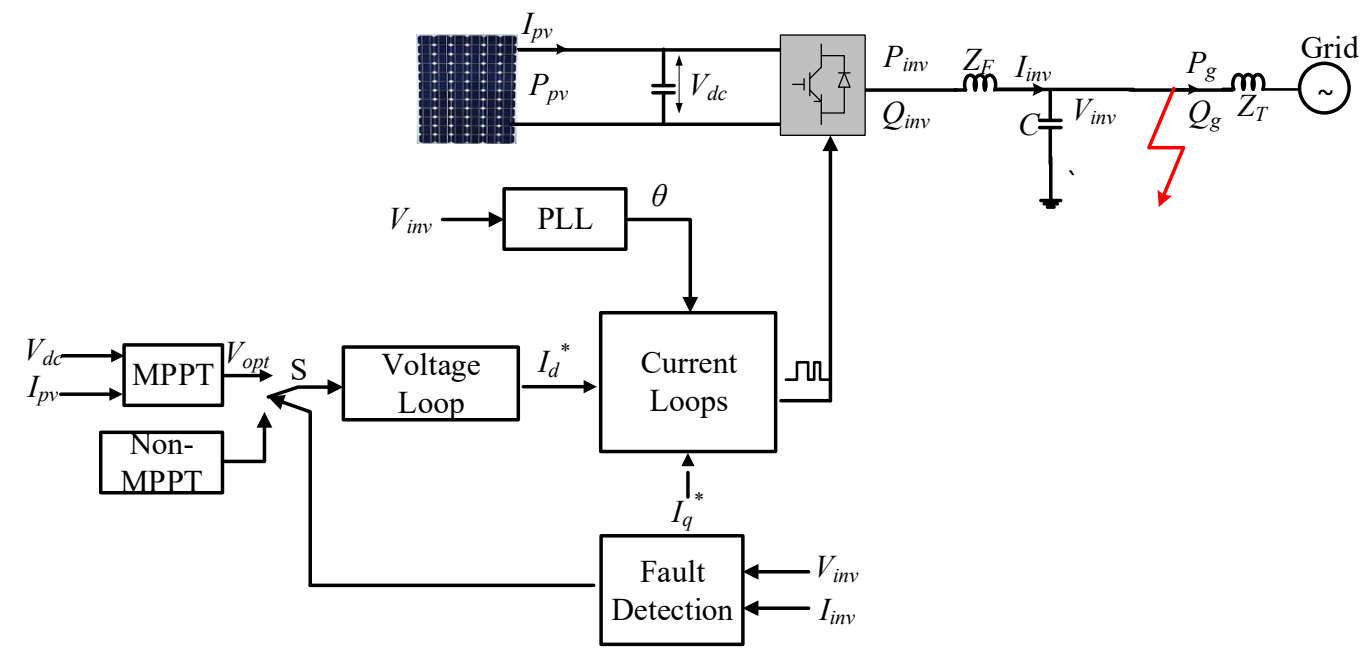

Figure 2.18: A simple system with fault detection block

Another widely used approach for current limitation is DC braking chopper or similar techniques [51, 55-57]. The chopper or the similar method is a power resistor, or a circuit contains power electronic devices, such as IGBTs or diodes $[51,56]$, which can prevent the DC-link capacitor from over-voltage damage. Since this work concentrates on the LVRT technique based on the control algorithm, details of this method are not explained. Another method is specific control algorithms based on symmetrical components $[50,58,59]$. This method is widely used under unbalanced faults, which will be explained in the next section. 


\subsubsection{Asymmetrical fault and Symmetrical components separation}

LVRT strategies, which take unbalanced voltage sags into account, are more complicated since the voltage and current contain oscillatory terms under asymmetrical conditions. Moreover, the voltage and current will be non-sinusoidal during the unbalanced condition. The following equations are derived to illustrate this phenomenon. Considering a 3-phase three-wire system, zero sequences will not be included in the phase currents. Thus, the voltages and currents are obtained as

$$
\begin{aligned}
& v_{a}=V^{+} \cos \left(\omega t+\varphi^{+}\right)+V^{-} \cos \left(\omega t+\varphi^{-}\right) \\
& v_{b}=V^{+} \cos \left(\omega t-\frac{2 \pi}{3}+\varphi^{+}\right)+V^{-} \cos \left(\omega t+\frac{2 \pi}{3}+\varphi^{-}\right) \\
& v_{c}=V^{+} \cos \left(\omega t+\frac{2 \pi}{3}+\varphi^{+}\right)+V^{-} \cos \left(\omega t-\frac{2 \pi}{3}+\varphi^{-}\right) \\
& i_{a}=I^{+} \sin \left(\omega t+\delta^{+}\right)+I^{-} \sin \left(\omega t+\delta^{-}\right) \\
& i_{b}=I^{+} \sin \left(\omega t-\frac{2 \pi}{3}+\delta^{+}\right)+I^{-} \sin \left(\omega t+\frac{2 \pi}{3}+\delta^{-}\right) \\
& i_{c}=I^{+} \sin \left(\omega t+\frac{2 \pi}{3}+\delta^{+}\right)+I^{-} \sin \left(\omega t-\frac{2 \pi}{3}+\delta^{-}\right)
\end{aligned}
$$

In equation (2.13) and (2.14), $v_{a}, v_{b}, v_{c}$ and $i_{a}, i_{b}, i_{c}$ are the 3 -phase voltages and currents in NRF. $V^{+}, V^{-}, I^{+}$and $I^{-}$are the positive and negative voltage and current sequences. $\varphi^{+}, \varphi^{+}, \delta^{+}$and $\delta$ are the phase angles of the voltage and current. The apparent power $S$ can be written in equation (2.15):

$$
S=\boldsymbol{v} \overline{\boldsymbol{i}}=P+j Q
$$

Where $\boldsymbol{v}$ is the voltage in phasor form and $\overline{\boldsymbol{i}}$ is the complex conjugate of current in the phasor form. $P$ and $Q$ are the active and reactive power, respectively. Then, equation (2.15) can be written as equation (2.16) by applying NRF to SYRF transformation: 


$$
S=v_{d q} \cdot i_{d q}=\left(v_{d q}^{+}+v_{d q}^{-}\right) \cdot\left(i_{d q}^{+}+i_{d q}^{-}\right)
$$

Equation (2.17) is written by extending equation (2.16)

$$
S=v_{d q}^{+} \cdot i_{d q}^{+}+v_{d q}^{+} \cdot i_{d q}^{-}+v_{d q}^{-} \cdot i_{d q}^{+}+v_{d q}^{-} \cdot i_{d q}^{-}
$$

Where $v_{d q^{+}}{ }^{+} v_{d q}{ }^{-}, i_{d q^{+}}{ }^{+}$and $i_{d q}{ }^{-}$are the positive and negative sequences voltage and current in SYRF. The symmetrical sequences can be derived by the DSC technique by using equation (2.9) as explained in the previous section. From equation (2.17), one can derive:

$$
\begin{aligned}
v_{d q}^{+} \cdot i_{d q}^{+} & =\left(v_{d}^{+}+j v_{q}^{+}\right) \cdot\left(i_{d}^{+}+j i_{q}^{+}\right)=v_{d}^{+} \cdot i_{d}^{+}+j v_{q}^{+} \cdot j i_{q}^{+}+j\left(v_{d}^{+} \cdot i_{q}^{+}+v_{q}^{+} i_{d}^{+}\right) \\
& =v_{d}^{+} \cdot i_{d}^{+}-v_{q}^{+} \cdot i_{q}^{+}+j\left(v_{d}^{+} \cdot i_{q}^{+}+v_{q}^{+} i_{d}^{+}\right) \\
& =P_{1}+Q_{1}
\end{aligned}
$$

Where

$$
\begin{gathered}
P_{1}=v_{d}^{+} \cdot i_{d}^{+}-v_{q}^{+} \cdot i_{q}^{+} \\
Q_{1}=j\left(v_{d}^{+} \cdot i_{q}^{+}+v_{q}^{+} i_{d}^{+}\right)
\end{gathered}
$$

Similarly, the following equations can be derived from equation (2.17), where $P_{2}$ and $Q_{2}$ is the constant the active and reactive power, $P_{3}, P_{4}, Q_{3}$ and $Q_{4}$ is the oscillatory active and reactive power.

$$
\begin{aligned}
& P_{2}=v_{d}^{-} \cdot i_{d}^{-}-v_{q}^{-} \cdot i_{q}^{-} \\
& Q_{2}=j\left(v_{d}^{-} \cdot i_{q}^{-}+v_{q}^{-} i_{d}^{-}\right) \\
& P_{3}=v_{d}^{+} \cdot i_{d}^{-}-v_{q}^{+} \cdot i_{q}^{-} \\
& Q_{3}=j\left(v_{d}^{+} \cdot i_{q}^{-}+v_{q}^{+} i_{d}^{-}\right)
\end{aligned}
$$




$$
\begin{gathered}
P_{4}=v_{d}^{-} \cdot i_{d}^{+}-v_{q}^{-} \cdot i_{q}^{+} \\
Q_{4}=j\left(v_{d}^{-} \cdot i_{q}^{+}+v_{q}^{-} i_{d}^{+}\right)
\end{gathered}
$$

From equation (2.19) to (2.22), it can be easily concluded that $P_{1}, Q_{1}, P_{2}, Q_{2}$ are constant terms in active and reactive power (multiplying the same sequences will get a constant term). On the contrary, $P_{3}, Q_{3}, P_{4}, Q_{4}$ contains oscillatory active and reactive power due to the multiplication of positive and negative sequences. Since the negative sequences components only exist under asymmetrical fault, it can be concluded that there are no oscillatory terms during normal operation or 3-phase faults. However, the voltage, current and power will contain oscillatory terms and will not be sinusoidal during unbalanced faults. These oscillations are widely existing in all the components in a power system, which influence the performance and quality of the delivered voltage, current and power. However, the oscillatory terms can be eliminated or removed by separating the negative sequences from the positive sequences. Hence, methods like the DSC technique to separate the positive and negative sequences is needed when studying the LVRT strategy under asymmetrical faults.

\subsection{States-of-the-art on LVRT in SYRF}

Different LVRT strategies for grid-connected PV system in SYRF have been proposed in the literature. For instance, [50] proposes an LVRT algorithm for a two-stage 3-phase grid-connected PV system, where a fault detection block is required to ensure that the system can switch from an MPPT mode to a non-MPPT mode. However, a hard switch is needed for this approach, which can lead to a non-smooth transition and losses between the two modes. Moreover, [50] only investigates asymmetrical faults. Although asymmetrical fault is common, the fault current is much higher when a 
symmetrical fault occurs, which has to be limited properly. In [60], a control strategy for limiting the inverter current in islanded mode is studied. However, a constant DCvoltage source is connected to the inverter, which is not a precise representation of a renewable system. Obviously, the dynamics of the PV system, including the MPPT algorithm, the DC-link voltage control and the current loop controller can affect the operation of the entire system. For example, when an LVRT strategy is introduced, the desired approach must consider if the MPPT can be connected when a fault appears. When the method needs to switch from MPPT to non-MPPT mode, it must ensure that the system can provide a smooth transition. Moreover, in [60], the current is limited to 2 pu during both symmetrical and asymmetrical faults, which seems to be too high, especially for asymmetrical faults where voltage sags are relatively smaller. The PV inverter technical data in [61] clearly indicates that the maximum RMS value for the output fault current is $1.92 \mathrm{pu}$, which means that the method in [60] will activate the inverter overcurrent protection during the fault. Similarly, [62] proposes an LVRT control scheme using symmetrical components in the synchronous frame for gridconnected inverter without considering a renewable energy source, neither a PV nor a wind turbine. In [63], an instantaneous active power controller is presented, which results in non-sinusoidal inverter currents under asymmetrical faults. Thus, the load will consume more power (both active and reactive) during faults. Consequently, the consumer will have to pay more for the electricity. In [64], a control strategy is proposed using symmetrical components; however, the injected active power contains significant double frequency oscillation.

This thesis proposes an LVRT strategy for 3-phase grid-connected PV system in SYRF. The proposed method can limit the inverter current within the acceptable limits for both 
symmetrical and asymmetrical faults. Unlike the previous publication, the voltage compensation unit is designed, which do not need to switch from MPPT mode to nonMPPT mode; thus, a smooth response when faults occur is guaranteed. Moreover, the proposed method can reduce the inverter active power double grid frequency oscillation and provide sinusoidal inverter current during asymmetrical faults.

\subsection{Dynamic performance for LVRT strategy in STRF}

With the LVRT techniques attracting more and more research, only considering the current limitation for an LVRT strategy is not enough. The quality of the delivered power to the grid or upstream consumer during faults [65-68], the protection of the system at the instant of the fault and exactly after fault is cleared, and the post-fault recovery performance [69] are also needed to be considered when designing an LVRT technique. In addition, SYRF based methods have dominated the research and industries in both normal operation and LVRT techniques for many years. However, with the advancement in the implementation of Proportional-Resonant (PR) controllers, the STRF based control schemes for normal operation have been proposed in the last couple of years. Unfortunately, the research considering STRF based techniques for LVRT is limited due to some drawbacks or challenges of the PR controllers. There are three challenges for an STRF-based LVRT method:

1) The conventional equations used for reference currents calculation will make the current non-sinusoidal during asymmetrical faults, which will be demonstrated in Chapter 4.

2) The inherent coupling between the active and reactive powers deteriorates the performance of the system [70], especially during faults. 
3) The PR controller has a poor transient response compared to the PI controller [71], which becomes more problematic during faults.

On the other hand, the SYRF-based LVRT methods, which require the STRF to SYRF transformation and the commonly used positive and negative sequences separation methods for asymmetrical faults, create massive additional mathematical computation. Therefore, a well-designed STRF-based LVRT method provides a more straightforward structure to achieve a faster response [72]. Moreover, compared with the PI controllers, the PR controllers are more robust and can improve the steady-state error $[72,73]$. This is because a PR controller has a good capability to compensate for the harmonics and can provide the system with a very high or infinite gain at the resonance frequency, which can cancel out the steady-state error. To this extent, this work proposes an STRF based control scheme for LVRT.

\subsection{State-of-the-art on LVRT in STRF considering post-fault recovery}

Although different LVTR methods considering dynamic performance during faults have been proposed in the literature, there are deficiencies with the proposed methods. For example, [56] proposes a method to improve the post-fault performance of the converter. However, the method in [56], which is demonstrated only for the symmetrical fault, utilizes a damping resistor and a transistor (similar to a chopper circuit) which increases the costs and losses of the system. In [74], an LVRT technique for a grid-connected PV system is proposed. The result shows that it takes $1.4 \mathrm{~s}$ for the active power to recover to its nominal value when a 3-phase to ground fault is cleared, which seems too long for the post-fault recovery of a grid-connected PV system. In [50, 75, 76], the LVRT strategy for a grid-connected PV system is proposed, but the results 
do not show the post-fault recovery, which is an important criterion for an LVRT method. Moreover, [50] shows the results for only asymmetrical faults and the LVRT performance for symmetrical faults, which are more severe, is not discussed. Results show that the inverter current after the fault clearance contains harmonics components even for a voltage sag as small as $0.2 \mathrm{pu}$ in [77]. Similarly, in [78], the results show that it takes $0.1 \mathrm{~s}$ for the active and reactive power to recover from a $0.43 \mathrm{pu}$ voltage sag, which is not fast enough for a non-severe fault. In [79], an enhancement of a gridconnected PV system post-fault recovery performance method is proposed. However, the current after the fault clearance hits the upper limitation when subject to a single phase to ground fault. Moreover, almost the same amount of reactive power is injected to the grid for different voltage sags, which is not in compliance with the grid codes [50].

There are less than a handful of the papers that considered the abnormal performance of the RES system in the STRF [80-82]. A current circulating suppression for modular multilevel converter HVDC system using PR controller is proposed in [80]. Even though the inverter currents are suppressed through the approach, it can be observed that the currents are not kept sinusoidal during asymmetrical faults, which will have negative impacts on the loads connected to the healthy phases. Reference [81] proposes an LVRT control strategy for a virtual synchronous generator, and the results show that the current is higher than 2 pu even for a $0.5 \mathrm{pu} 3$-phase voltage sag, which will activate the overcurrent protection. Moreover, to avoid the disadvantages brought by the STRF based control scheme, the method proposed in [81] requires symmetrical components separation and SYRF to STRF transformation, which increases the computational efforts and undermines one of the advantages of using STRF in the first 
place. In [82], an LVRT for a 3-phase grid-connected PV system is proposed. However, the inverter currents are oscillatory at the instant of the fault and after the fault clearance, which will degrade the stability of the system.

In light of the above, this thesis proposes an STRF-based LVRT strategy for 3-phase grid-connected PV system, which uses a novel approach to produce the inverter reference currents. Compared with these state-of-the-art, the proposed method provides independent control of active and reactive power in STRF without the need for SYRF to STRF transformation. The proposed method can achieve fast, and smooth recovery after the fault is cleared. Moreover, this thesis proposes a transient reactive power suppression unit to reduce the inverter current after the fault clearance.

\subsection{Summary of Chapter 2}

This chapter reviews and discusses the following aspects:

1) The physical theory of a PV cell is introduced, and the mathematical model of a PV cell is explained.

2) The changing level of temperature and irradiance have an effect on the PV system, which is illustrated by $I-V$ and $P-V$ curves. This leads to the need for an MPPT algorithm, where P\&O method will be used in this work.

3) PV inverter-based system regarding the PLL scheme and current controller are presented.

4) Some of the LVRT methods are reviewed. Notably, the need of the symmetrical sequences' separation for LVRT in SYRF during unbalanced fault is explained. 
5) The main challenges facing LVRT for grid-connected PV system during both balanced and unbalanced faults in SYRF are highlighted, which include the current curtailment and elimination of the oscillatory terms in the system during the asymmetrical fault.

6) The need for improvement of the dynamic performance at the instant of fault, exactly after fault is cleared and post-fault recovery is emphasized. Also, the advantages of using the PR controller in STRF for LVRT is highlighted.

7) Analysis and comparison of the existing proposed methods are presented to illustrate the value of this work. 


\section{Chapter 3 AN LVRT Strategy for 3-phase grid-connected PV Systems in the SYRF}

\subsection{Introduction}

This chapter introduces an LVRT strategy for 3-phase grid-connected PV system in SYRF. As described in Chapter 2, many of the LVRT control algorithms require a hard switch to move from MPPT mode to non-MPPT mode when a fault is detected, which leads to losses and a non-smooth transient performance. To improve this disadvantage, a voltage compensation unit (VCU) is introduced in this chapter. The proposed method can limit the inverter current during both symmetrical and asymmetrical faults. Moreover, it provides sinusoidal inverter current and reduces the double grid frequency oscillation during the asymmetrical fault. Two different VCUs will be presented:

1) A simplified VCU is introduced to demonstrate that the proposed method can operate for both symmetrical and asymmetrical faults. The proposed simplified method uses two quadratic functions to define the variation of the inverter voltage and the compensation voltage during the faults, which will be using for the LVRT strategy.

2) The mixed potential function is used to improve the VCU, which defines how much PV output power should reduce for a voltage sag in order to comply with the Lyapunov criteria. 
The proposed control scheme in this chapter also includes a reactive power injection block to support the grid during faults. The proposed method is verified using MATLAB/Simulink simulations.

\subsection{Proposed LVRT for grid-connected PV system in SYRF}

Figure 3.1 shows a grid-connected PV system and the proposed LVRT structure. The average model of the inverter is used to simulate the PV converter. The inverter-based system is controlled by a cascaded voltage and current controller as mentioned in Chapter 2. As shown in Figure 3.1, the proposed VCU uses positive and negative sequence inverter voltages $\left(V_{d p}\right.$ and $\left.V_{d n}\right)$ to modify the input reference voltage for the voltage loop. Moreover, the proposed method uses $\Delta V_{d \mathrm{p}}, \Delta V_{d \mathrm{n}}$, which are the positive and negative voltage sags during the fault to control the reactive power.

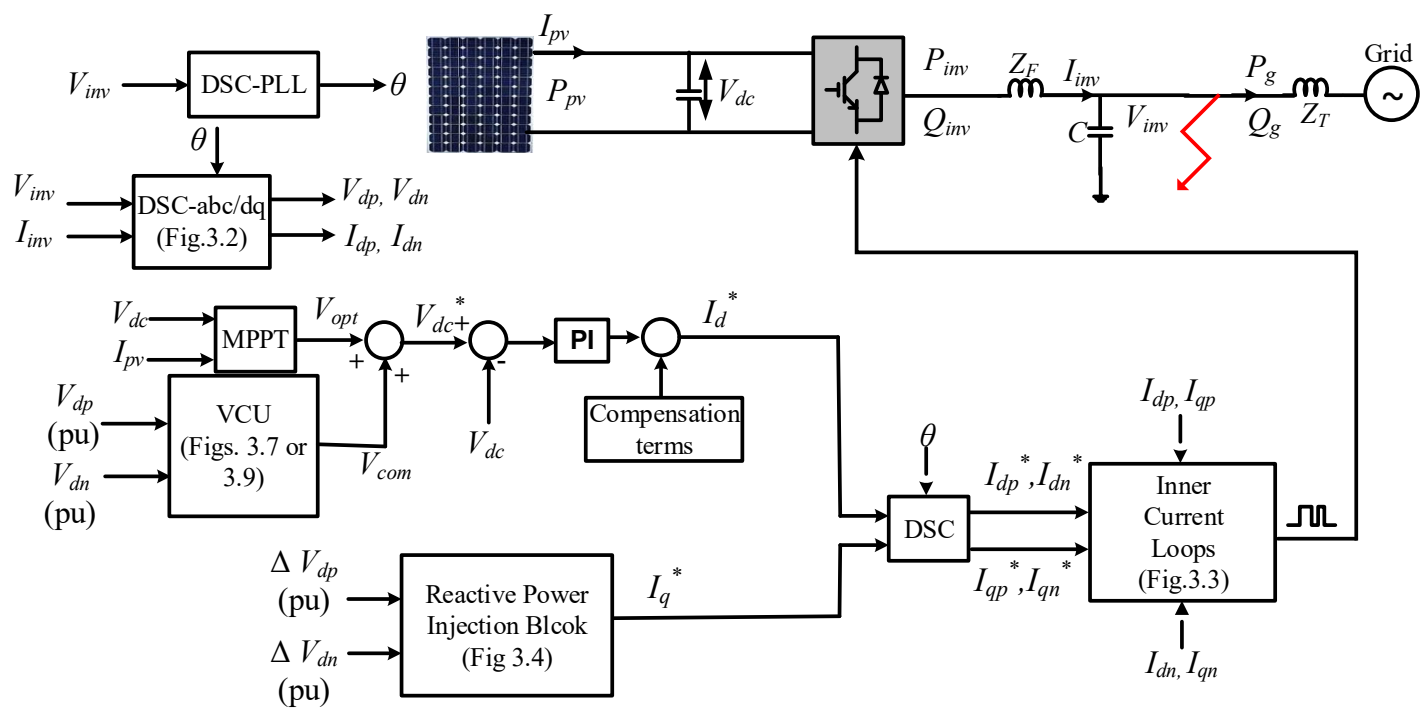

Figure 3.1: The grid-connected PV system under study 


\subsubsection{Symmetrical components generation}

As introduced in Chapter 2, this thesis uses the well-known method DSC to separate the symmetrical sequences. Through using equation (2.9), the symmetrical sequences separation block can be proposed, which is shown in Figure 3.2. $V_{a b c}$ and $I_{a b c}$ are the inverter output voltage and current. $V_{\alpha, \beta}$ and $I_{\alpha, \beta}$ are the inverter output voltages and currents in STRF, which is transformed by using Clarke's Transformation. $V_{(\alpha, \beta) p}, V_{(\alpha,}$ $\beta{ }_{\beta} n, I_{(\alpha, \beta) p}$ and $I_{(\alpha, \beta) n}$ are the estimations of the positive and negative sequence voltages and currents in STRF, and $T$ is the signal period, which is the same as the grid period (usually the grid frequency is $50 \mathrm{~Hz}$, which means, $T=0.02 \mathrm{~s}) . V_{(d, q) p}, V_{(d, q) n}, I_{(d, q) p}$ and $I_{(d, q) n}$ are the estimations of the positive and negative sequence voltages and currents in SYRF, which are transformed from the voltages and currents in STRF. Here, the Clarke's transformation is given in equation (3.1):

$$
V_{\alpha \beta}=\left[\begin{array}{c}
V_{\alpha} \\
V_{\beta}
\end{array}\right]=\frac{1}{3}\left[\begin{array}{ccc}
2 & -1 & -1 \\
0 & \sqrt{3} & -\sqrt{3}
\end{array}\right]\left[\begin{array}{l}
V_{a} \\
V_{b} \\
V_{c}
\end{array}\right]
$$

As illustrated in Chapter 2, during normal or balanced operation and symmetrical faults, the negative and zero sequences do not exist in a three wire-system. However, the negative sequences will appear in both voltages and currents, which generates oscillatory results for voltages and currents, under unbalanced conditions. Hence, a four-channel current loop (see Figure 3.3) based on the symmetrical sequences is used to reduce the oscillatory components under asymmetrical faults. 

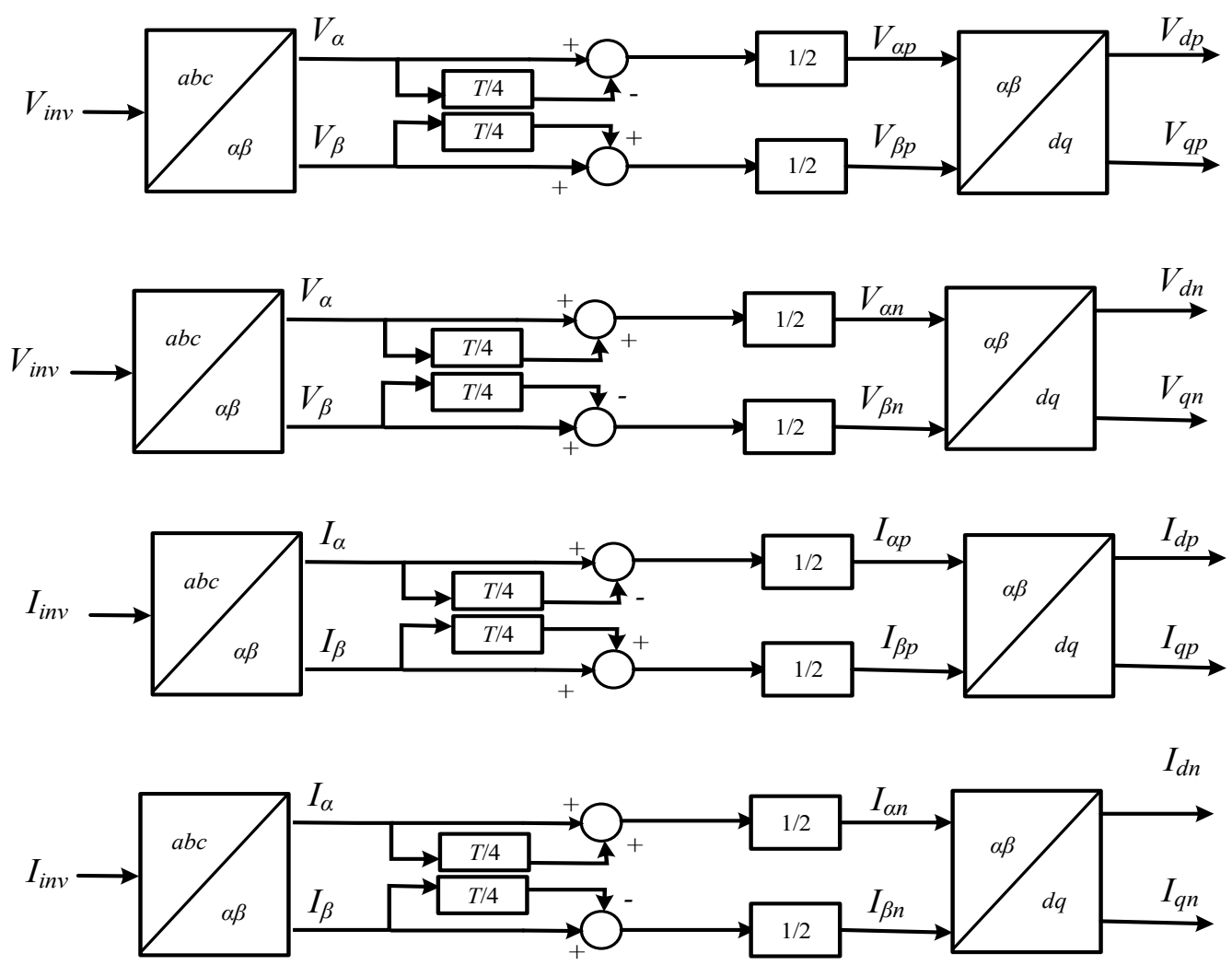

Figure 3.2: The symmetrical sequences separation block

\subsubsection{Current controller design}

Figure 3.3 shows the control scheme for a four-channel current controller. This controller consists of two classic current loops; one is the positive loop; another one is the negative loop. As discussed in Chapter 2, equation (2.12) is used for the current controller. The compensation terms for this four-channel current controller are $-I_{d p} \omega L_{f}$, $-I_{q p} \omega L_{f},-I_{d n} \omega L_{f},-I_{q n} \omega L_{f}, V_{d p}, V_{q p}, V_{d n}$ and $V_{q n}$. These feedforward compensation terms are used to decouple the dynamics of the inverter system; it can also improve the inverter start-up transients [70]. For an average model, equation (3.2) can be used to describe the variation between the $\mathrm{AC}$ side voltage and the $\mathrm{DC}$ side voltage.

$$
V_{a c}=\frac{1}{2} m V_{d c}
$$


Where $V_{a c}$ is the RMS inverter output phase voltage and $V_{d c}$ is the DC side input voltage, $m$ is the modulation index signal. Thus, equation (3.2) is used to estimate $m$. As shown in Figure 3.3, $m$ is the sum of the positive and negative modulation index signal $\left(m=m_{p}+m_{n}\right)$. Note that the phase angle used in the negative channel for inverse Park transformation is $-\theta$.

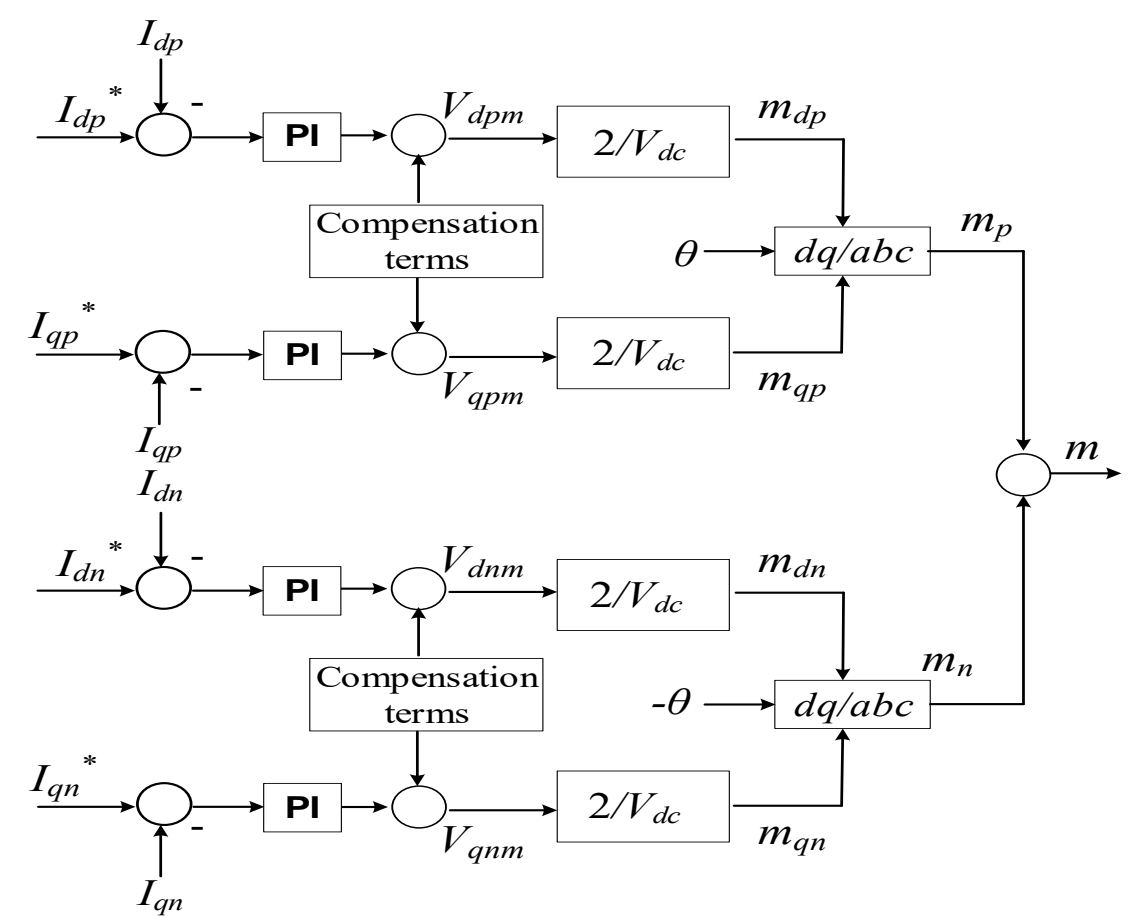

Figure 3.3: Current Loop

Since the PI controller is used in the current controller for the proposed LVRT strategy, the proportional gain and integral gain are designed to guarantee the controller is robust enough against the faults. The integral gain is designed using the characteristic equation. The detailed procedure for PI controller design is explained below:

Considering the LC filter is used in this work, the transfer function for the LC filter is written in equation (3.3): 


$$
T F_{(\text {filter })}=\frac{1}{R_{f}+s L_{f}}
$$

The transfer function for the PI controller is written in equation (3.4):

$$
T F_{(P I)}=K_{p}+\frac{K_{i}}{s}
$$

Thus, from equation (3.3) and (3.4), the characteristic equation for this control plant can be written in equation (3.5):

$$
s^{2}+\left(\frac{R_{f}+K_{p}}{L_{f}}\right) s+\frac{K_{i}}{L_{f}}=0
$$

Where $R_{f}$ and $L_{f}$ are the LC filter resistance and inductance. The standard characteristic equation for a control plant is:

$$
s^{2}+2 \omega_{n} \xi s+\omega_{n}^{2}=0
$$

Where $\omega_{n}$ is the bandwidth of the desired controller, $\zeta$ is the damping ratio. Comparing equation (3.5) with (3.6), one can be found that the integral gain $K_{i}$ can be calculated in equation (3.7):

$$
K_{i}=L_{f} \omega_{n}^{2}
$$

It can also be found that the proportional gain $K_{p}$ is determined by equation (3.8):

$$
K_{p}=2 \zeta L_{f} \omega_{n}-R_{f}
$$

When $\zeta=1$, which means the system is under a critically damped condition. Usually, the controller is designed underdamped, which means $\zeta<1$. However, according to [83], it is possible to make the system overdamped $(\zeta>1)$ without violate the system stability. Simulation results for irradiance variation will be presented to demonstrate the above 
claim. Therefore, by choosing $K_{p}>2 L_{f} \omega_{n}-R_{f}$, the controller's robustness can be improved. To investigate the effect of $K_{p}$ varies on the system root locus, one can rewritten the equation (3.5) in follow:

$$
\begin{gathered}
s^{2}+\frac{R_{f}}{L_{f}} s+\frac{K_{i}}{L_{f}}+\frac{K_{p}}{L_{f}} s=0 \\
1=\frac{-\frac{K_{p}}{L_{f}} s}{s^{2}+\frac{R_{f}}{L_{f}} s+\frac{K_{i}}{L_{f}}} \\
1+\frac{\frac{K_{p}}{L_{f}} s}{s^{2}+\frac{R_{f}}{L_{f}} s+\frac{K_{i}}{L_{f}}}=0
\end{gathered}
$$

Equation (3.11) is the characteristic equation; thus, from the definition of the characteristic equation, the equivalent Open-Loop Transfer Function (OLTF) for the control plant, which contains $K_{p}$, can be written in (3.12):

$$
O L T F=\frac{\frac{K_{p}}{L_{f}} s}{s^{2}+\frac{R_{f}}{L_{f}} s+\frac{K_{i}}{L_{f}}}
$$

Where $K_{i}=L_{f} \omega_{n}{ }^{2}$. Using equation (3.12), the root locus diagram can be drawn for $K_{p}$ variations. This method will be used in the simulation to design the current loops. 


\subsubsection{Reactive Power Injection}

This work proposes a reactive power injecting block, which calculates how much reactive power should be injected during a voltage sag. The proposed reactive power injection block fully complies with the grid code in China, which is shown in Figure 2.17.

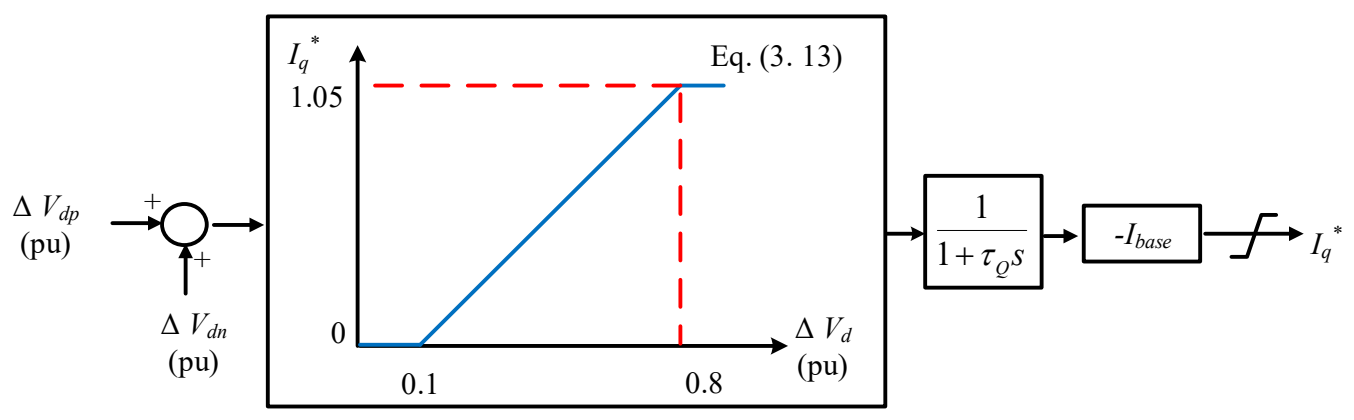

Figure 3.4: Reactive power injection block

The DSC-PLL keeps $V_{q p}$ (the q-component for the positive sequence of inverter output voltage) zero at steady-state. Moreover, since the negative sequence $V_{q n}$ is too small when the fault occurs, $\Delta V_{d p}+\Delta V_{q p}$ is proposed as the input signal of the reactive power injection block. Note that $\Delta V_{d p}=1-V_{d p}, \Delta V_{q p}=0-V_{q p}\left(V_{q p}\right.$ is zero during normal operation and 3-phase fault, while it goes to negative values under asymmetrical faults). Then, a low-pass filter is required to help improve the dynamic response of the reactive power injection block. Figure 3.4 shows the proposed reactive power injection block; the solid blue line represents equation (3.13), which is the Chinese standard.

$$
I_{q}^{*}=\left\{\begin{array}{cc}
0 & \Delta V_{d}<0.1 p u \\
1.5\left|\Delta V_{d}\right|-0.15 & 0.1<\Delta V_{d}<0.8 p u \\
1.05 & \Delta V_{d}>0.8 p u
\end{array}\right.
$$

Note that, the reactive power $Q=-1.5 V_{d} I_{q}$, therefore, the output signal $I_{q}{ }^{*}$ should be multiplied by the negative base current value $\left(-I_{\text {base }}\right)$. Then the positive and negative sequences in SYRF for $I_{q}{ }^{*}$ is separated by using the DSC method, which is the input signals for the current controller as shown in Figure 3.3. 


\subsubsection{Design of the proposed VCU}

The proposed LVRT control strategy in this thesis is aiming to limit the inverter current during balanced and unbalanced faults, while the PV array is still running without disconnecting the MPPT, enabling a smooth transition. To achieve that, Fault Operation Point (FOP) for the PV system needs to be defined. The VCU is used to calculate the FOP during faults. In order to reduce the inverter current during faults, the output power of the PV array need to be reduced, which leads to the reduction of the inverter output power. Thus, the inverter current will be limited. For this reason, the VCU is designed to force the PV array to produce less power during faults than the normal operation. The equal-area criterion [84] is used to illustrate the possibility of introducing a new operating point during faults:

Comparing a PV system to a synchronous generator, one can argue that the PV array input power $P_{p v}$ resembles the input mechanical power. In a synchronous generator, the mechanical power is assumed constant after a fault since it cannot be changed very quickly. $\delta_{1}$ is the power angle when the output power is $P_{p v-M P P T}$ and $\delta_{0}$ is the power angle when the output power is $P_{p v-V C U}$. At some peak value $\delta_{2}$, the power angle recovers to synchronous value, but the output power is higher than $P_{p v-M P P T}$. This divides the power vs power angle characteristic (see Figure 3.5) into accelerating (red shadow $\mathrm{A}_{1}$ ) and maximum decelerating (red shadow $\mathrm{A}_{2}$ ) areas. According to equalarea criterion, the system remains stable if $\mathrm{A}_{1} \leq \mathrm{A}_{2}$. As illustrated in Figure 3.5, in a PV system, reducing $P_{p v}$ after a fault (i.e. from $P_{p v-M P P T}$ to $P_{p v-V C U}$ ) reduces the 
accelerating area (purple shadow $\mathrm{A}_{4}$ ) and increases the maximum decelerating area (purple shadow $\mathrm{A}_{3}$ ), which in turns increases the stability margin.

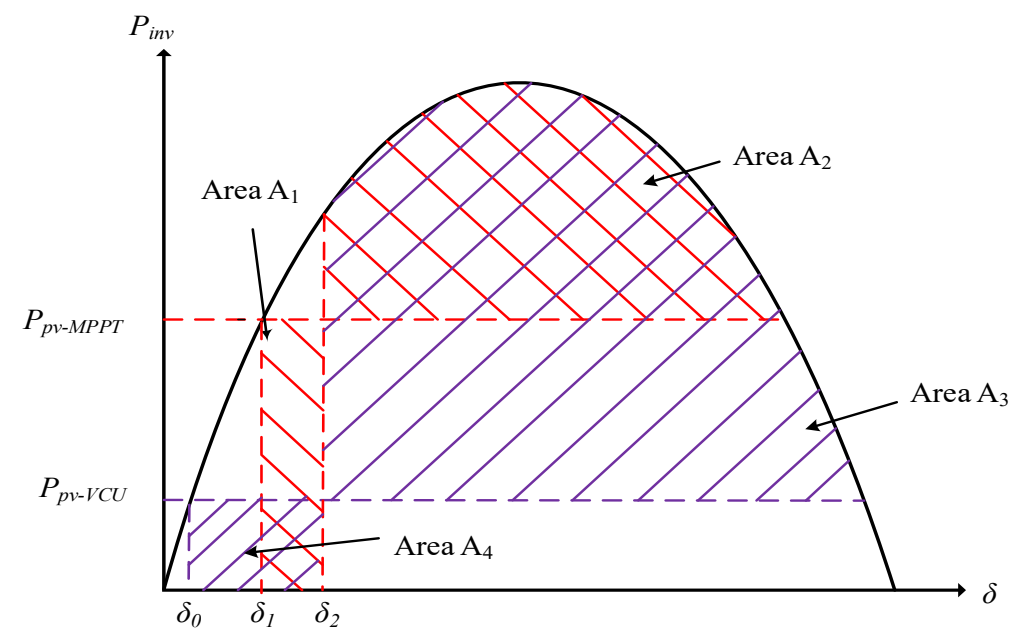

Figure 3.5: Inverter Power vs power angle characteristic

As it can be seen from the $P_{p v^{-}} V_{p v}$ characteristic in Figure 3.6, it is possible to reduce $P_{p v}$ through either adding the compensation voltage $V_{c o m}$ (from the VCU) to the optimum voltage $V_{\text {opt }}$ (from the MPPT algorithm) or subtracting $V_{\text {com }}$ from $V_{\text {opt }}$. However, considering the $I_{p v^{-}} V_{p v}$ curve (the dashed blue line), it can be found that only when the PV is operating at the right-hand side of the MPP (e.g. FOP), the output current of the PV can be reduced. Thus, as illustrated in Figure 3.1, the VCU determines the reference DC-link voltage $V_{d c}{ }^{*}$ by adding $V_{c o m}$ to $V_{o p t}$. By doing this, both the inverter current and power will be reduced under symmetrical and asymmetrical faults, and there is also no need to switch the PV system from MPPT mode to a non-MPPT mode. Obviously, as the voltage sag increases, $V_{\text {com }}$ should also increase to reduce the PV output current. Thus, two functions are proposed to define the variation of $V_{c o m}$ and $V_{d}$, where $V_{d}$ is the sum of the d-component positive and negative bus voltage $\left(V_{d p}, V_{d n}\right)$ during the faults. 


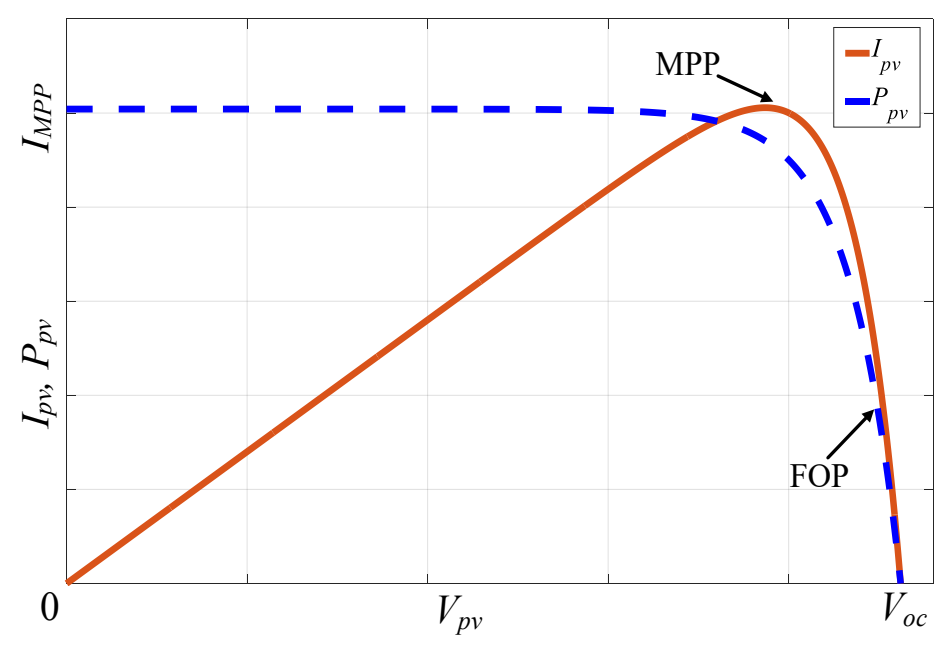

Figure 3.6: $P_{p v^{-}} V_{p v} \& I_{p v^{-}} V_{p v}$ characteristic curves

Two different approaches to estimate the variation of $V_{c o m}$ and $V_{d}$ are proposed, which are the main contributions of this chapter:

1) The simplified VCU, which is straightforward, but it is not sensitive to the voltage sag and cannot further reduce the double grid frequency oscillation during asymmetrical faults.

2) Mixed potential function based VCU, which is more complex, however, reduces the double grid frequency oscillations. Note that, both methods operate with the MPPT connected to the system during faults. In other words, other schemes lead to hard switching from an MPPT mode to a non-MPPT mode of operation. Both methods will be introduced in the next two sections.

\subsubsection{The simplified model of VCU}

The simplified VCU has the following main characteristics and advantages:

1) The simplified VCU should help the PV reduce the active power generated during the fault; thus, the inverter current is reduced. 
2) The output power of the PV array should be able to track the MPP at normal operation.

3) The VCU should be able to obtain the FOP located at the right side of the MPP.

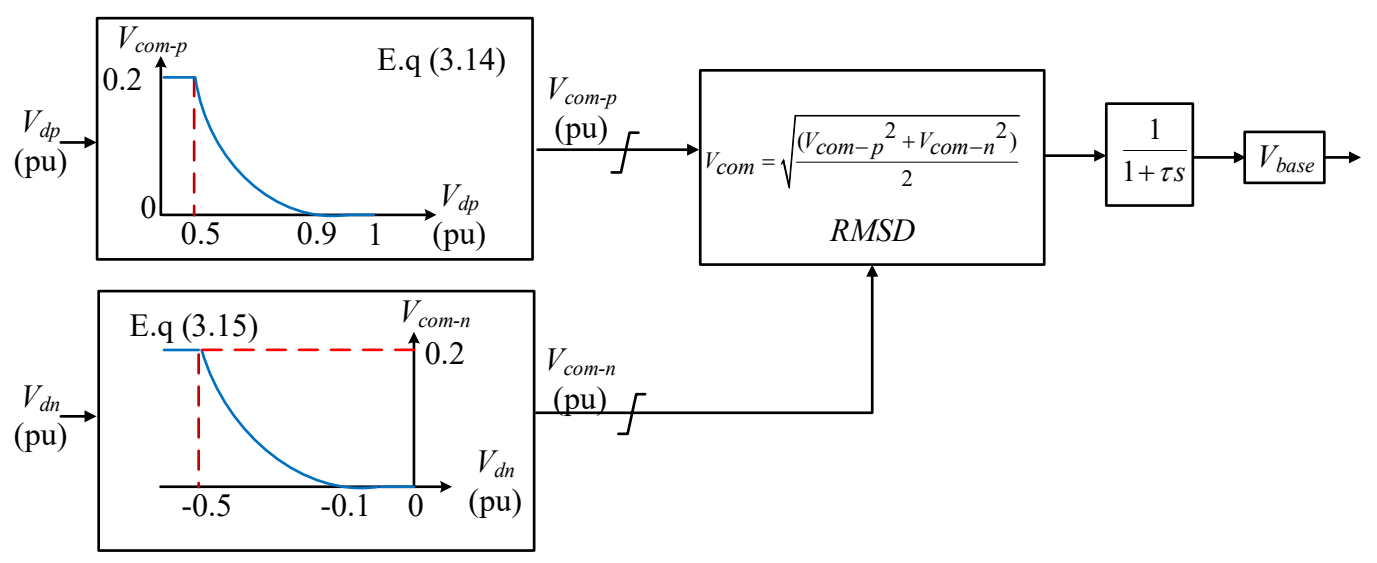

Figure 3.7: The proposed simplified VCU

As explained above, the proposed VCU should be able to reduce the active power of the inverter during faults to limit the inverter current. This is achieved by introducing the quadratic functions illustrated in Figure 3.7. As shown in Figure 3.7, both positive and negative sequences d-component $V_{d p}, V_{d n}$ are used in this proposed method. $V_{c o m}$ is calculated by both $V_{c o m-p}$ and $V_{c o m-n}$, where $V_{c o m-p}$ and $V_{c o m-n}$ are generated by $V_{d p}$ and $V_{d n}$ variations, respectively.

$V_{d p}$ is 1 pu during normal operation and reduces after both symmetrical and asymmetrical faults. Thus, as $V_{d p}$ becomes less than $0.9 \mathrm{pu}$ (a $10 \%$ tolerance is applied as a voltage disturbance), $V_{\text {com-p }}$ is calculated in equation (3.14):

$$
V_{c o m-p}=-\Delta V_{d p}\left(V_{d p}-0.9\right)
$$

Where $\Delta V_{d p}$ is the voltage sag of $V_{d p}$. Using equation (3.14) leads to a higher rate of increase in $V_{\text {com-p }}$ as $\Delta V_{d p}$ increases (this is simply the quadratic curve shown in Figure 
3.7). On the other hand, $V_{d n}$, which is zero during normal operation, decreases following only asymmetrical faults. Thus, as $V_{d n}$ becomes less than $-0.1 \mathrm{pu}(10 \%$ tolerant for voltage disturbance), $V_{\text {com-n }}$ is calculated in equation (3.15):

$$
V_{c o m-n}=\Delta V_{d n}\left(-V_{d n}-0.1\right)
$$

Where $\Delta V_{d n}$ is the voltage sag of $V_{d n}$. Using equation (3.15) leads to a higher rate of increase in $V_{c o m-n}$ as $\Delta V_{d n}$ reduces. Note that $V_{d n}$ is negative. Both $V_{c o m-p}$ and $V_{c o m-n}$ are limited to $V_{o c}-V_{o p t-m a x}$, where $V_{o c}$ is the PV array open-circuit voltage and $V_{o p t-m a x}$ is the $V_{\text {opt }}$ at 1 pu solar power. By doing this, it is ensured that $V_{d c}{ }^{*}$, which is the reference DC-link voltage, remains smaller than $V_{o c}$. Since in the simulated model $V_{o c}-V_{o p t-m a x}$ $=0.2 \mathrm{pu}, 0.2 \mathrm{pu}$ is used in Figure 3.7. Thus, from equation (3.14) and (3.15), when both $V_{d p}$ and $V_{d n}$ sag depth under $0.5 \mathrm{pu}, V_{c o m-p}$ and $V_{c o m-n}$ will reach the limitation $(0.2 \mathrm{pu})$. By using Root-Mean-Square Deviation of the positive and negative sequence compensation terms $V_{\text {com-p }}$ and $V_{c o m-n}, V_{\text {com }}$ will be kept under 0.2 pu as well. A low-pass-filter is used to add dynamics to the system, which reduces the oscillations at fault occurring and clearing instances. As shown in Figure 3.1, a classic PI controller is used for the voltage loop to get $I_{d}{ }^{*}$, which is the reference signal for the current controller. Considering that the simplified VCU have some shortcomings, which are discussed above, a more comprehensive approach is proposed to design the VCU. The mixed potential function is used to calculate the variation of $V_{c o m}$ vs $V_{d}$, which will improve the performances of the VCU. Note that the results based on the simplified VCU will be shown in the simulation section. 


\subsubsection{The mixed potential function based VCU}

As mentioned above, in order to overcome the drawbacks of the simplified VCU, the mixed potential function is used to help to estimate the mixed potential function based VCU (MPF-VCU). The MPF-VCU has the following advantages compared with the simplified VCU:

1) The MPF-VCU can achieve faster current limitation during a server fault (e.g. 3-phase fault).

2) The MPF-VCU is sensitive even to a small voltage sag.

3) The MPF-VCU can reduce the inverter active power double grid frequency oscillation during the asymmetrical fault.

4) The inverter current is kept pure sinusoidal during the asymmetrical faults.

The mixed potential function, which first stated in Brayton-Moser's mixed potential theory $[85,86]$, can be used to describe the dynamics of a large class of nonlinear RLC network with two-terminal elements. The mixed potential function is used to investigate the stability of the network's equilibrium point, and to describe the noise of the network (here the noise is the double grid frequency oscillation of the active power and the DC-link voltage) [85-87].

The mixed potential function $P_{p}$ is constructed from the resistors, capacitors and inductors in the nonlinear network. According to the mixed-potential theory, if $v_{\mu}$ and $i_{\mu}$ denote the voltage and current of all the non-energy storage elements of the system 
and $v_{\sigma}$ and $i_{\sigma}$ denote the voltage, and current of all capacitors of the system, the potential function $P$ can be written in equation (3.16):

$$
P_{p}(i, v)=\sum \int v_{\mu} d i_{\mu}+\sum i_{\sigma} v_{\sigma}
$$

where the first term on the right-hand side of the equal mark represents the current potential of all the non-energy storage elements, and the second term is the sum of the capacitors' energy [88]. Since the proposed system is a nonlinear dynamic model under fault conditions, the mixed-potential function can be used to describe the system [89].

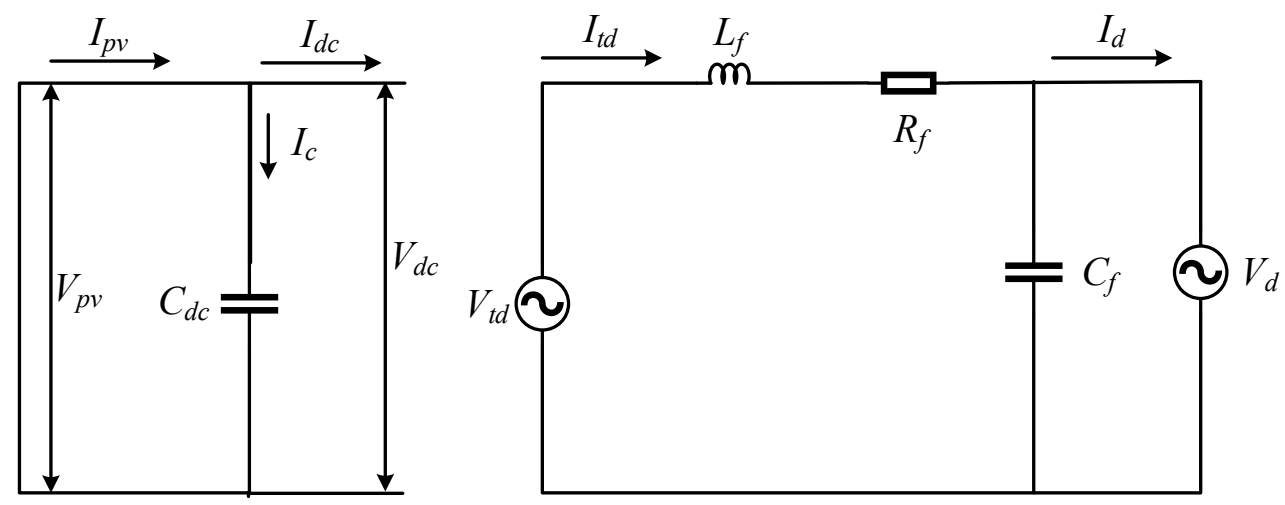

Figure 3.8: The simplified model of the proposed PV system

Figure 3.8 shows the simplified model of a grid-connected PV system while the inverter is represented by $V_{t d}$ on the AC-side, and by $C_{d c}$ on the DC-side. As mentioned above, all of the d-components are the sum of the positive and negative sequence components. The mixed potential function for the proposed model can be written in equation (3.17):

$$
P(i, v)=\int_{0}^{i_{p v}} v_{p v} d i_{p v}-i_{c} v_{p v}-\int_{0}^{i_{d c}} v_{d c} d i_{d c}+\int_{0}^{i_{t d}} v_{t d} d i_{t d}-\int_{0}^{i_{d d}} i_{t d} R_{f} d i_{t d}-\int_{0}^{i_{d}} v_{d} d i_{d}-\left(i_{t d}-i_{d}\right) v_{d}
$$


In steady-state (neglecting the losses):

$$
P=\frac{3}{2} V_{d} I_{d}=V_{p v} I_{p v}=P_{p v}
$$

where $P$ is the grid active power, $V_{d}$ and $I_{d}$ are the voltage and current after the LC filter. Since the capacitor voltage is constant at steady-state, $I_{p v}$ should be equal to $I_{d c}$. Considering $V_{p v}=V_{d c}, I_{p v}=I_{d c}$, where $I_{c}$ is a small value. Thus, equation (3.17) can be rewritten in equation (3.19):

$$
P(i, v)=-i_{c} v_{p v}+\int_{0}^{i_{d d}} v_{t d} d i_{t d}-\int_{0}^{i_{d d}} i_{t d} R_{f} d i_{t d}-\int_{0}^{i_{d}} \frac{2 p}{3 i_{d}} d i_{d}-\left(i_{t d}-\frac{2 p}{3 v_{d}}\right) v_{d}
$$

where the first term on the right hand of the equal mark represents the DC-link capacitor's energy, the second term is the current potential of the inverter output voltage, the third term is the current potential of the filter resistor, the fourth term is the current potential of the grid side voltage, and the last term is the filter capacitor's energy.

Since the grid side voltage $V_{d}$ is not a single-valued function of the grid side current $I_{d}$, one can write (3.20):

$$
\int_{0}^{i_{d}} \frac{2 p}{3 i_{d}} d i_{d}=\frac{2 p}{3 i_{d}} I_{d}-\int_{0}^{v_{d}} \frac{2 p}{3 v_{d}} d v_{d}
$$

Substituting equation (3.20) into (3.19), gives:

$$
P(i, v)=v_{t d} i_{t d}-\frac{1}{2} R_{f} i_{t d}^{2}+\int_{0}^{v_{d}} \frac{2 p}{3 v_{d}} d v_{d}-i_{t d} v_{d}-i_{c} v_{p v}
$$


Equation (3.21) is the mixed-potential function of the proposed model. To verify whether equation (3.21) is the correct mixed-potential function, the partial derivatives of equation (3.21) must comply with equation (3.22) [85-88]:

$$
\begin{aligned}
& \frac{\partial p}{\partial v_{\sigma}}=-C \frac{d v_{\sigma}}{d t} \\
& \frac{\partial p}{\partial i_{\mu}}=L \frac{d i_{\mu}}{d t}
\end{aligned}
$$

Equation (3.22) is the only criterion to verify the validity of the mixed-potential function. Using equation (3.21), the following differential equations of the proposed model can be obtained:

$$
\begin{aligned}
& \frac{\partial p}{\partial v_{p v}}=-i_{c}=-C_{d c} \frac{d v_{p v}}{d t} \\
& \frac{\partial p}{\partial v_{d}}=\frac{2 p}{3 v_{d}}-i_{t d}=-\left(i_{t d}-i_{d}\right)=-C_{f} \frac{d v_{d}}{d t} \\
& \frac{\partial p}{\partial I_{t d}}=v_{t d}-R_{f} i_{t d}-v_{d}=L_{f} \frac{d i_{t d}}{d t}
\end{aligned}
$$

As noted, equation (3.23) is in accordance with equation (3.22), and consequently, equation (3.21) corresponds to the system state equations, and it is the correct mixedpotential function of the system. In general, the unified form of $P_{u}$ is given in equation (3.24) [85-88]:

$$
P_{u}(i, v)=-A(i)+B(v)+(i, \gamma v-\alpha)
$$

Thus, in this model, $P_{u}(i, v)$ can be written in equation (3.25):

$$
P_{u}(i, v)=-\frac{1}{2} R_{f} i_{t d}^{2}+\int_{0}^{V_{d}} \frac{2 p}{3 v_{d}} d v_{d}+\left(\begin{array}{ll}
i_{c} & i_{t d}
\end{array}\right) \times\left(\left(\begin{array}{cc}
-1 & 0 \\
0 & -1
\end{array}\right)\left(\begin{array}{c}
v_{p v} \\
v_{d}
\end{array}\right)-\left(\begin{array}{c}
0 \\
-v_{t d}
\end{array}\right)\right)
$$


The proposed method is to use the mixed potential function to determine for a certain $V_{d}$ drop, how much $P_{p v}$ should be reduced (i.e. $\left.P_{p v}=\mathrm{Fcn}\left(V_{d}\right)\right)$ to comply with the Lyapunov criterion. One can define $\mu_{1}$ and $\mu_{2}$ as the minimum eigenvalue of the matrices $L^{-1 / 2} A_{i i}(i) L^{-1 / 2}$ and $C^{-1 / 2} B_{v v}(v) C^{-1 / 2}$, respectively, where, $A_{i i}(i)$ and $B_{v v}(v)$ are the second-order partial derivative of $A(i)$ and $B(v)$. According to the fifth theorem of the mixed-potential theory [85] and Lyapunov criterion [90], if for all $i$ and $v$ :

$$
\mu_{1}+\mu_{2}>0 \text { and } P_{u}(i, v) \rightarrow \infty, a s|i|+|v| \rightarrow \infty
$$

then all the solutions of equation (3.23) approach the equilibrium point, which means the oscillation is minimized [89]. To calculate $\mu_{1}$ and $\mu_{2}, A_{i i}(i)$ and $B_{v v}(v)$ are calculated first.

From equation (3.25), $A(i)$ and $B(v)$ can be written in equation (3.27):

$$
\begin{aligned}
& A(i)=\frac{1}{2} R_{f} i_{t d}^{2} \\
& B(v)=\int_{0}^{p_{d}} \frac{2 p}{3 v_{d}} d v_{d}
\end{aligned}
$$

Then from equation (3.27), $A_{i i}(i)$ and $B_{v v}(v)$ can be written in equation (3.28):

$$
\begin{aligned}
& A_{i i}(i)=\frac{\partial^{2} A(i)}{\partial i^{2}}=R_{f} \\
& B_{v v}(v)=\frac{\partial^{2} B(v)}{\partial v^{2}}=-\frac{2 p}{3 v_{d}^{2}}
\end{aligned}
$$

Thus, $\mu_{1}$ and $\mu_{2}$ can be derived:

$$
\begin{aligned}
& \mu_{1}=\frac{R_{f}}{L} \\
& \mu_{2}=-\frac{2 P}{3 C V_{d}^{2}}
\end{aligned}
$$


Since the proposed model is grid-connected, $P=P_{p v}$ (neglecting the losses). Equation (3.26) can be rewritten in equation (3.30):

$$
\mu_{1}+\mu_{2}=\frac{R_{f}}{L_{f}}-\frac{2 P_{p v}}{3 C_{d c} V_{d}^{2}}>0
$$

Thus, the Lyapunov criterion of the proposed model is equation (3.30). From this criterion, the variation of $P_{p v}$ vs $V_{d}$ can be derived:

$$
P_{p v}<\frac{3 R_{f} C_{d c}}{2 L_{f}} V_{d}^{2}
$$

where, $V_{d}$ is the grid voltage, which will drop when a fault occurs. Equation (3.31) approximately determines the maximum $P_{p v}$ for a $V_{d}$ such that system complies with the Lyapunov criterion. Equation (3.31) will be used to define the variation of $V_{\text {com }}$ and $V_{d}$ in the proposed VCU:

Using equation (3.31) for $V_{d}=0: 0.1: 1 \mathrm{pu}$ (i.e. for $0.1 \mathrm{pu}$ steps of $V_{d}$ ), $P_{p v-l i m i t}$ is calculated:

$$
P_{p v-\text { limit }}=\frac{3 R_{f} C_{d c}}{2 L_{f}} V_{d}^{2}
$$

Obviously, $P_{p v}<P_{p v-l i m i t}$ in order to comply with the Lyapunov criterion. Then, the calculated $P_{p v-l i m i t}$ (for each $V_{d}$ ) is used in (the right-hand side of) the $P_{p v}$ vs $V_{p v}$ characteristic (see Figure 3.6) to get the desirable $V_{\text {com }}$. Doing this for each 0.1 pu step of $V_{d}$, and using the MATLAB 'polyfit' function (for the calculated $V_{c o m}$ vs $V_{d}$ points), equation (3.33) can be formed:

$$
V_{\text {com }}=k_{m}\left(a V_{d}^{5}+b V_{d}^{4}+c V_{d}^{3}+d V_{d}^{2}+e V_{d}+f\right)
$$


Where $k_{m}$ is a safety margin coefficient (e.g. $k_{m}=1.05$ ) to make sure that the $P_{p v}$ associated with the calculated $V_{\text {com }}$ from equation (3.33) complies with Equation (3.31), i.e. is less than $P_{p v-l i m i t}$. A hard limit of $V_{\text {limit }}=V_{o c}-V_{o p t-m a x}$, where $V_{o c}$ is the open-circuit voltage of the PV array and $V_{\text {opt-max }}$ is the optimum voltage from the MPPT at $1 \mathrm{pu}$ solar irradiance, is applied to make sure that $V_{c o m}$ will not become more than $V_{o c}$ (which is $0.2 \mathrm{pu}$ in the model simulated in this thesis). Note that with the solar irradiance varies, both $V_{o c}$ and $V_{o p t}$ vary almost proportionally; thus, $V_{\text {limit }}$ can be a fixed value. The calculated $V_{\text {com }}$ is added to $V_{o p t}$ to get $V_{d c}{ }^{*}$. Then, exactly the same as the simplified VCU, a classic PI controller (see Figure 3.1) is used for the voltage loop to determine $I_{d}{ }^{*}$. Figure 3.9 shows the structure of the proposed MPF-VCU.

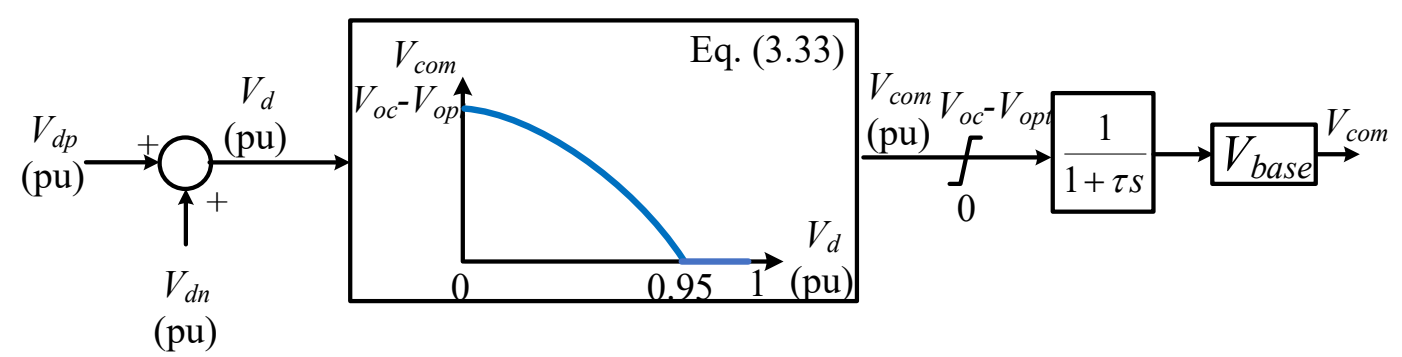

Figure 3.9: Structure of the proposed MPF-VCU

\subsection{Simulation Results}

Figure 3.1, which is simulated by MATLA/Simulink, shows the system under study, which considers grid-connected PV system with the proposed LVRT control scheme. The PI controllers for the current loops are designed as follows:

By using equation (3.7), the integral gain of the PI-based current controller can be calculated. Considering the bandwidth of a current controller can be from to 100 to $1000 \mathrm{~Hz}$. Choosing the natural frequency $\omega_{n}=730 \mathrm{rad} / \mathrm{s}\left(f_{n}=116 \mathrm{~Hz}\right)$, the integral gain $K_{i}$ is calculated: 


$$
K_{i}=L_{f} \omega_{n}^{2}=1598.7
$$

Then substituting $K_{i}=1598.7$ into equation (3.12), the current loop root locus with the proportional gain $K_{p}$ varies for the simulated system is illustrated in Figure 3.10.

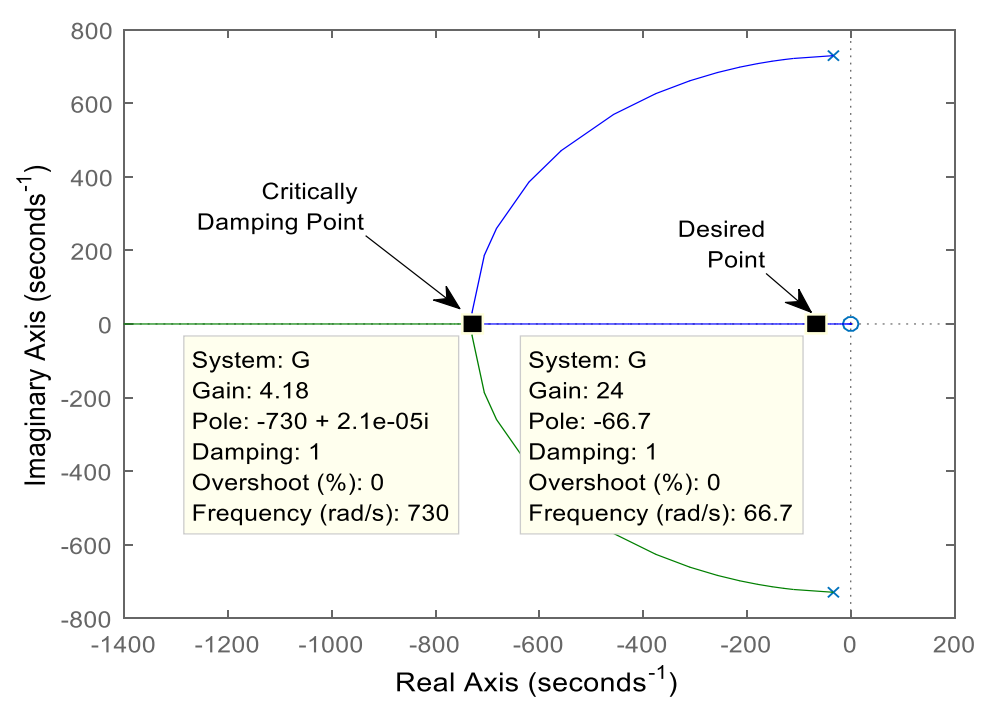

Figure 3.10: Root locus diagram of the proposed current loop

As shown in Figure 3.10, when the gain is 4.18 , which means $K_{p}=4.18$, the system is critical damped. As mentioned in section 3.2.2, it is possible to select $K_{p}>4.18$, which makes the system overdamped without affecting the stability of the system but provides good robustness. Hence, the desired point shown in Figure 3.10 is used for this thesis $\left(K_{p}=24\right)$. It should be noted that when $K_{p}=24$, the pole of the controller is located at the left-hand side plane in the real axis, which means the system is stable.

In this section, the two different VCUs are simulated in MATLAB/Simulink to compare the two VCUs. Different scenarios are tested to prove the need for the proposed VCUs. The grid frequency is $f=50 \mathrm{~Hz}$. The rest of the system's parameters are shown in Table A-2 in the appendix. Note that all the results are shown in per unit value based on the rating power of the proposed system, where $P_{\text {base }}=11 \mathrm{~kW}$. 


\subsubsection{Normal operation}

It is important to demonstrate that the proposed LVRT strategies (both simplified VCU and MPF-VCU) will not affect the normal operation. Therefore, this section considers the normal operation of the proposed system. Since the main difference between these two VCUs is the variation of $V_{c o m}$ vs $V_{d}$, it is possible to test only one VCU to show the effect during the normal operation. Figure 3.11 shows the active power $P_{i n v}$ (solid blue line) and the reactive power $Q_{i n v}$ (dotted orange line) when the solar irradiance is changing as $0.8,0.6,0.4,0.2$ and $0.8 \mathrm{pu}$. It can be observed from the result that when $P_{i n v}$ is changing, $Q_{i n v}$ remains at $0.2 \mathrm{pu}$. The result proves that the proposed LVRT strategy will not affect the operation when active power changes with solar irradiance changes. The result also shows that the designed current loop provides a good dynamic response. Similarly, when $Q_{i n v}$ changes, the proposed LVRT strategy will not affect the operating of the system. As it can be seen from Figure 3.12, $P_{\text {inv }}$ remains at $0.4 \mathrm{pu}$ while $Q_{i n v}$ varies as $0,0.2,0.4,0.8$ and $0 \mathrm{pu}$. Then, different types of faults will be investigated with the proposed LVRT strategies. For the sake of simplicity, it is assumed that $Q_{i n v}=0$ pu before and after the fault under all scenarios.

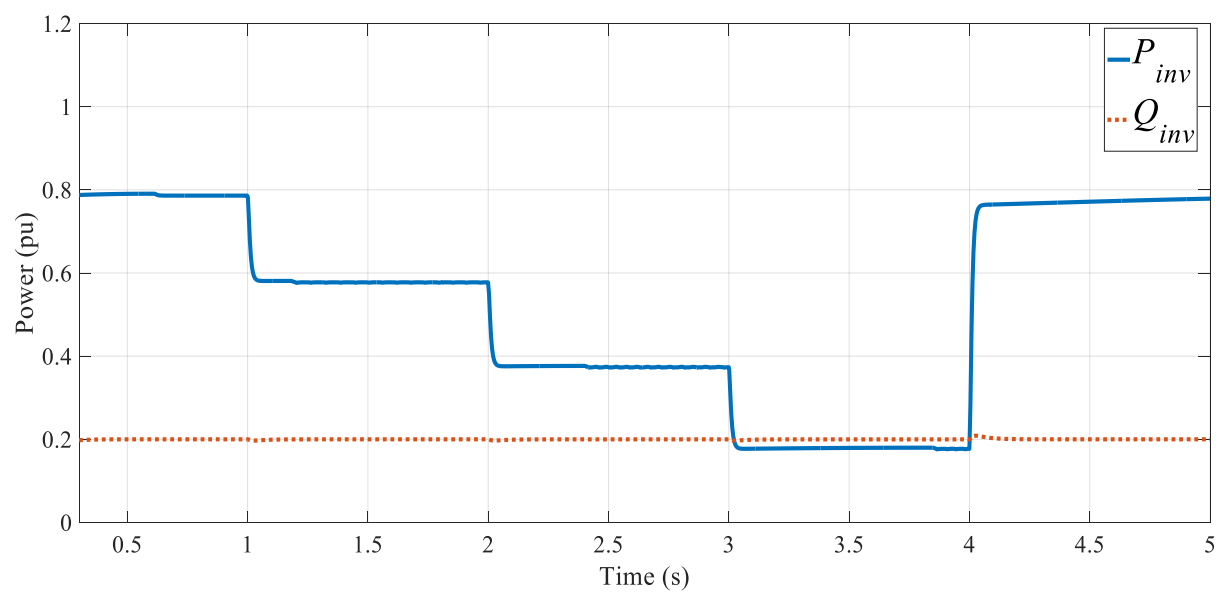

Figure 3.11: Active and reactive power when irradiance changes 


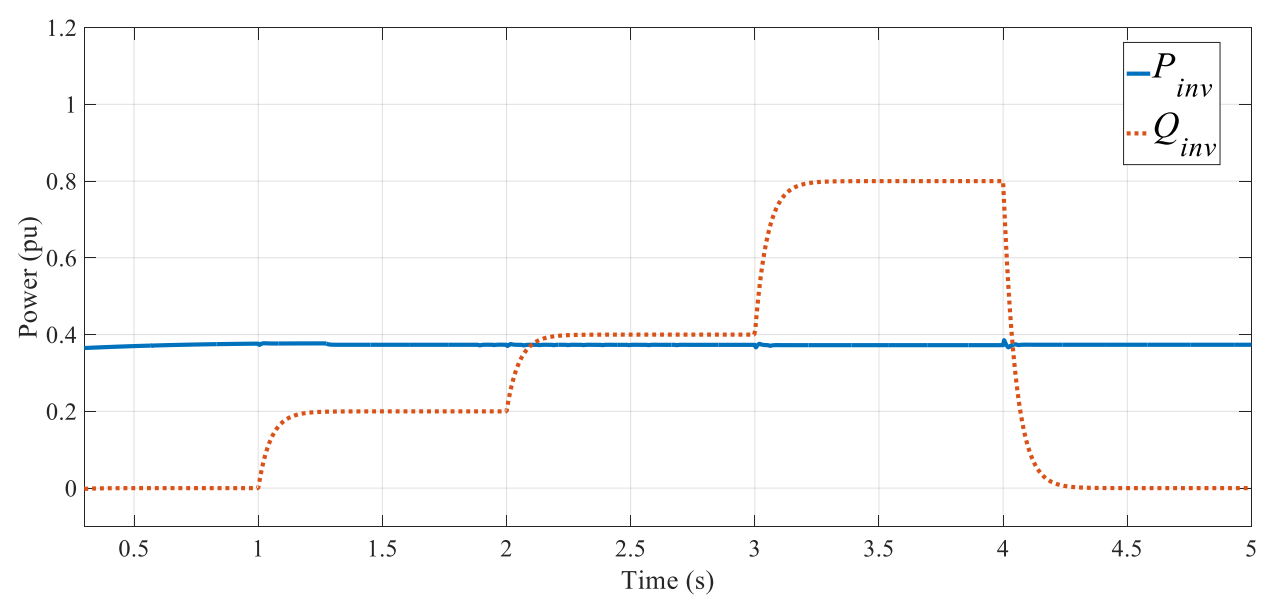

Figure 3.12: Active and reactive power when reactive power changes

\subsubsection{Simulation results for the simplified $V C U$}

\section{(a) Results under 3-phase fault}

Figure 3.13 shows the results for the 3-phase fault without VCU. $V_{i n v}$ drops to less than $0.2 \mathrm{pu}$. As it can be seen, the fault appears at $t=1 \mathrm{~s}$, and it is removed at $t=1.2 \mathrm{~s}$ (the fault lasts for $0.2 \mathrm{~s}$ for all types of fault). Since it is a symmetrical fault, there is no double grid frequency oscillation for the inverter active power and DC-link voltage. Although $I_{\text {inv }}$ remains pure sinusoidal even without an LVRT strategy, it increases to 4 pu during the fault, which will hit the hard limit during the whole fault period; thus, the inverter overcurrent protection will trip the PV system.

Meanwhile, Figure 3.14 shows the simulation results with the simplified VCU for a 3phase fault. It can be found in Figure 3.14 that the proposed method reducing the 3phase currents $I_{i n v}$ (see Figure 3.14 (b)) by increasing the DC-link voltage (see Figure 3.14 (c)) $\left(V_{d c}\right.$ increases to almost $\left.V_{o c}=1.2 \mathrm{pu}\right)$ during the fault. Therefore, the power generated by the PV array $P_{p v}$ is reduced to almost $0.2 \mathrm{pu}$ (see Figure 3.14 (e)), consequently, the inverter active power $P_{\text {inv }}$ is reduced to $0.2 \mathrm{pu}$ (see Figure 3.14 (d)). Moreover, $I_{i n v}$ hit the hard limit for two cycles as shown in Figure 3.14 (b), i.e. less 
than $0.04 \mathrm{~s}$, then it reduces to less than $1.5 \mathrm{pu}$. After the fault is cleared, the PV system restores to its normal operation. The proposed system generates 1.05 pu reactive power during fault to support the grid, which is in compliance with the grid code shown in Figure 2.17. It can be concluded that the proposed simplified VCU can limit the inverter current during the 3-phase fault.

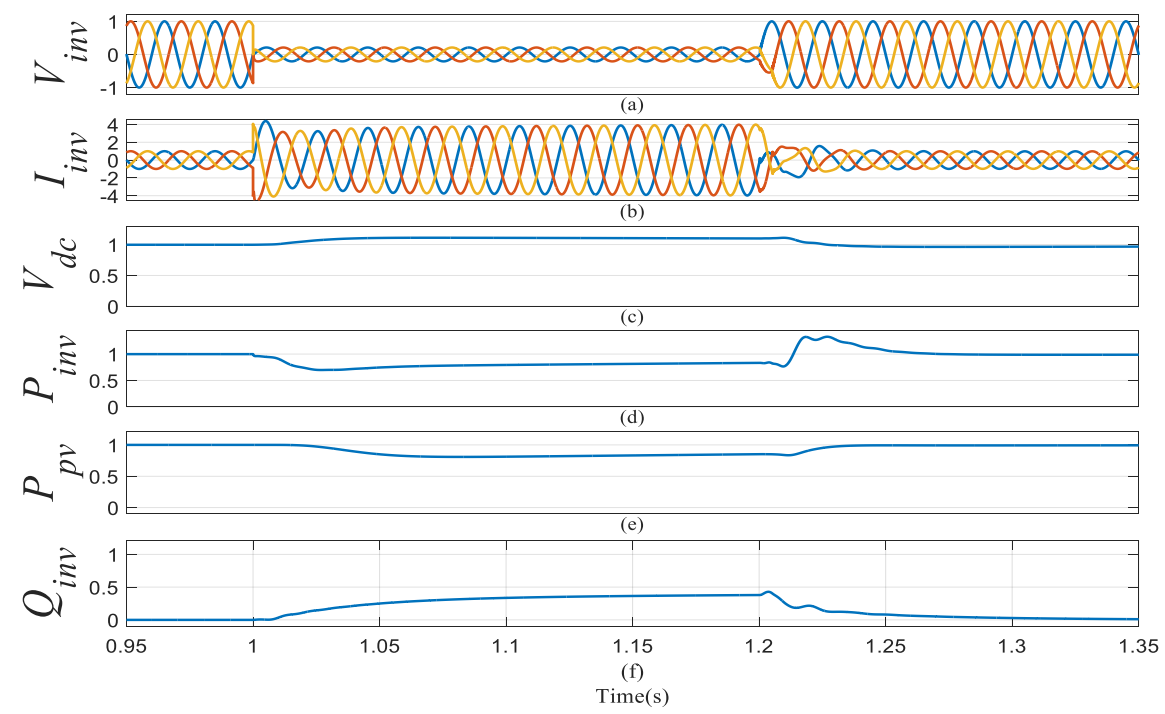

Figure 3.13: Simulation results under 3-phase fault without VCU (all in pu): (a) inverter voltage, (b) inverter current, (c) DC-link voltage, (d) inverter side active power, (e) PV power, (f) reactive power

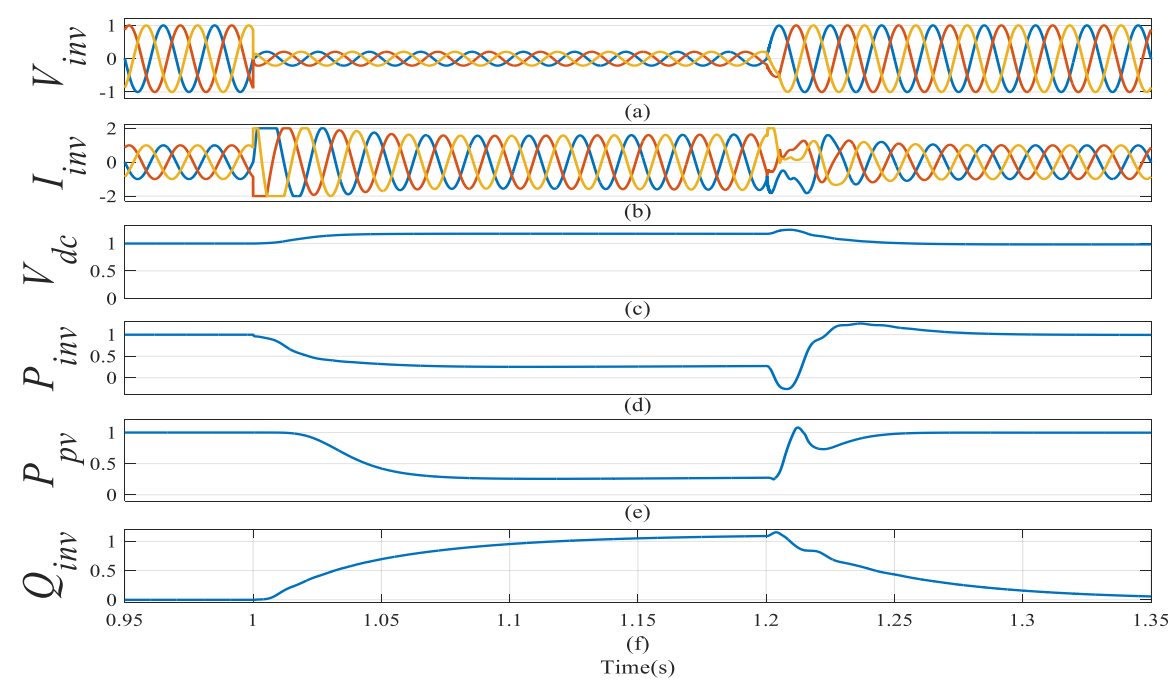

Figure 3.14: Simulation results under 3-phase fault with simplified VCU (all in pu): (a) inverter voltage, (b) inverter current, (c) DC-link voltage, (d) inverter side active power, (e) PV power, (f) reactive power 
(b) Results under Double Line to Ground (DLG) fault

Figure 3.15 shows the simulation results for a DLG fault using the proposed simplified VCU. Two phase voltages drop to $0.2 \mathrm{pu}$. $P_{i n v}$ is reduced to $0.5 \mathrm{pu}$ during the fault. Meanwhile, $I_{i n v}$ is limited around 1.5 pu during the fault. Since the voltage on the healthy phase remains at $1 \mathrm{pu}$ and both $V_{i n v}$ and $I_{i n v}$ remain sinusoidal during the fault, it is possible to keep feeding the loads connected to the healthy phase. Moreover, 0.8 pu reactive power is injected to the grid during the fault. The normal operation is restored after the fault is cleared. Meanwhile, Figure 3.16 shows the results without VCU. It can be observed from Figure 3.16 (b) that $I_{i n v}$ is more than 2 pu during the fault, and the current is not sinusoidal. It can be also observed that the inverter active power's double grid oscillation is reduced by applying the simplified VCU.

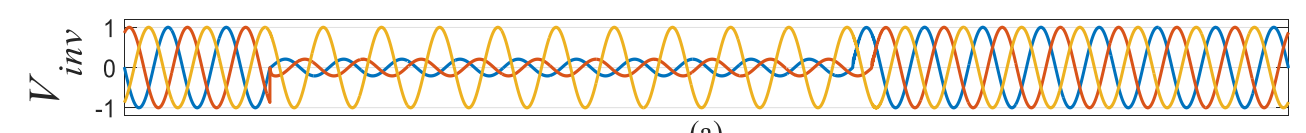

(a)
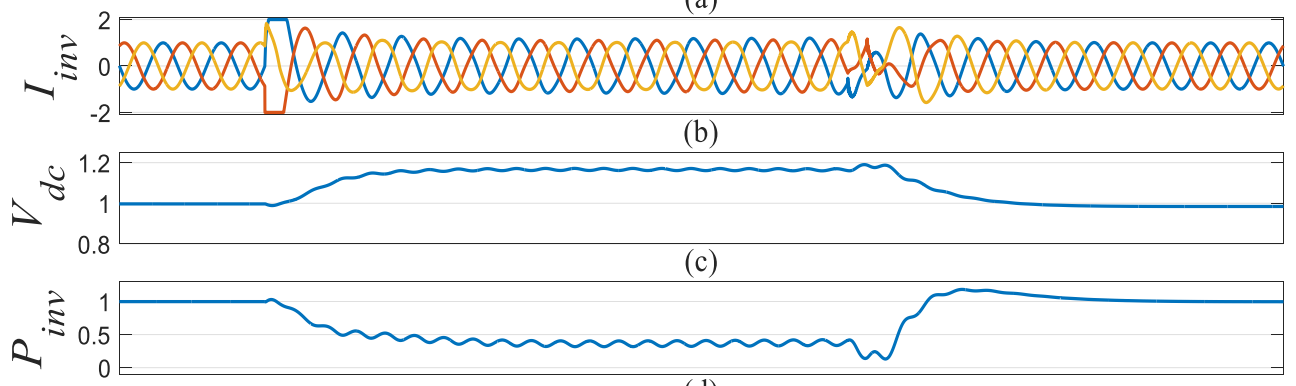

(d)

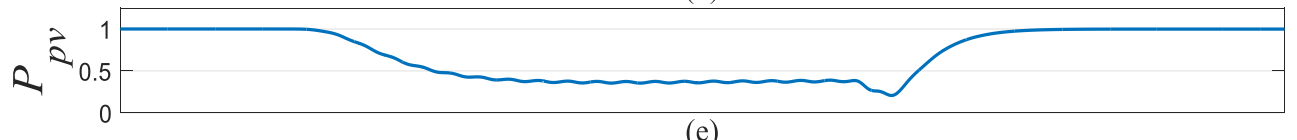

(e)

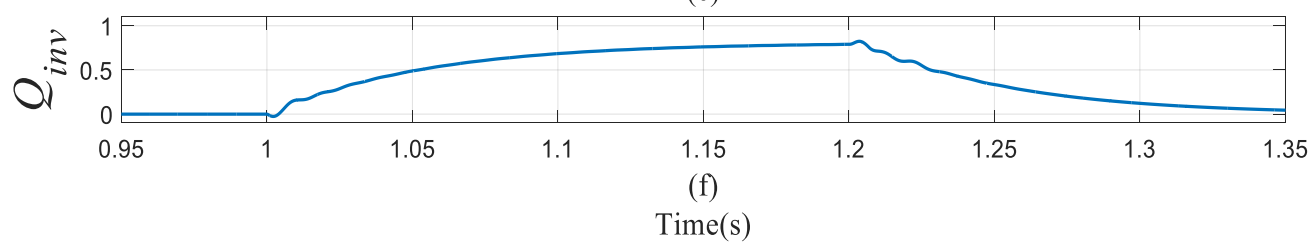

Figure 3.15: Simulation results under DLG fault with simplified VCU (all in pu): (a) inverter voltage, (b) inverter current, (c) DC-link voltage, (d) inverter side active power, (e) PV power, (f) reactive power 


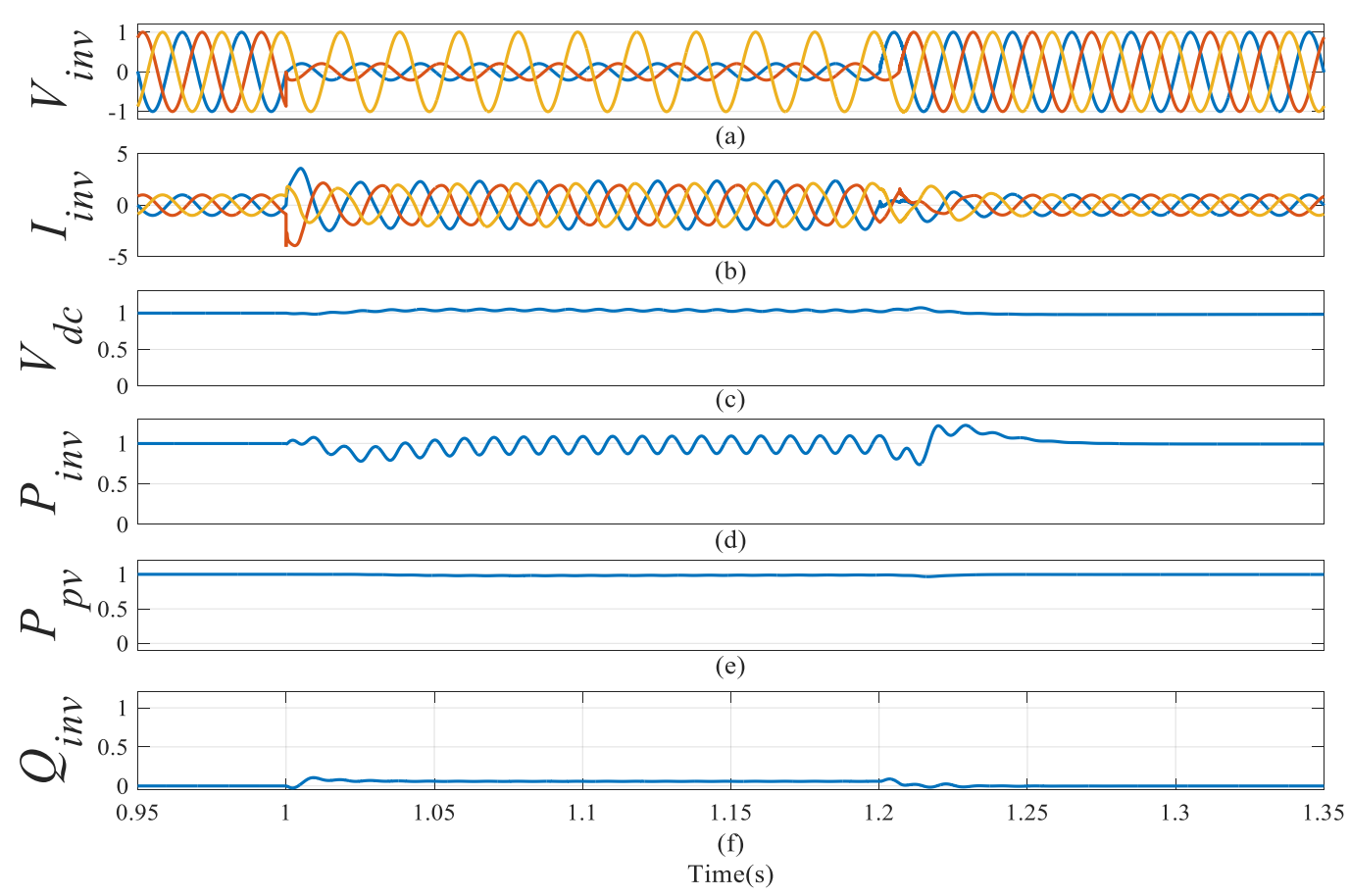

Figure 3.16: Simulation results under DLG fault without VCU (all in pu): (a) inverter voltage, (b) inverter current, (c) DC-link voltage, (d) inverter side active power, (e) PV power, (f) reactive power

\section{(c) Results under Double Line (DL) fault}

Figure 3.17 shows the simulation results for a DL fault using the proposed method. It can be found that in Figure 3.17 (a) the two faulted voltages are not identical. This is because there is some internal impedance inside the fault block, which is used in the simulation. Since the voltage sag is not as deep as it is during DLG fault, there is relatively less reduction in PV power and less increase in DC-link voltage. Comparing Figure 3.17 (d) with Figure 3.18 (d) (which is the result without VCU), it can be found that $P_{i n v}$ reduces to just less than 1 pu during the fault, which is because the simplified VCU is not sensitive to a small voltage sag. Therefore, $I_{i n v}$ with and without the VCU is almost the same (see Figure 3.17 (b) and Figure 3.18 (b)). Meanwhile, $0.6 \mathrm{pu}$ reactive power is injected to the grid. Moreover, it can be found in Figure 3.17 (d), that the inverter active power's double grid frequency oscillation still exists and is not negligible, which will be improved by MPF-VCU. 

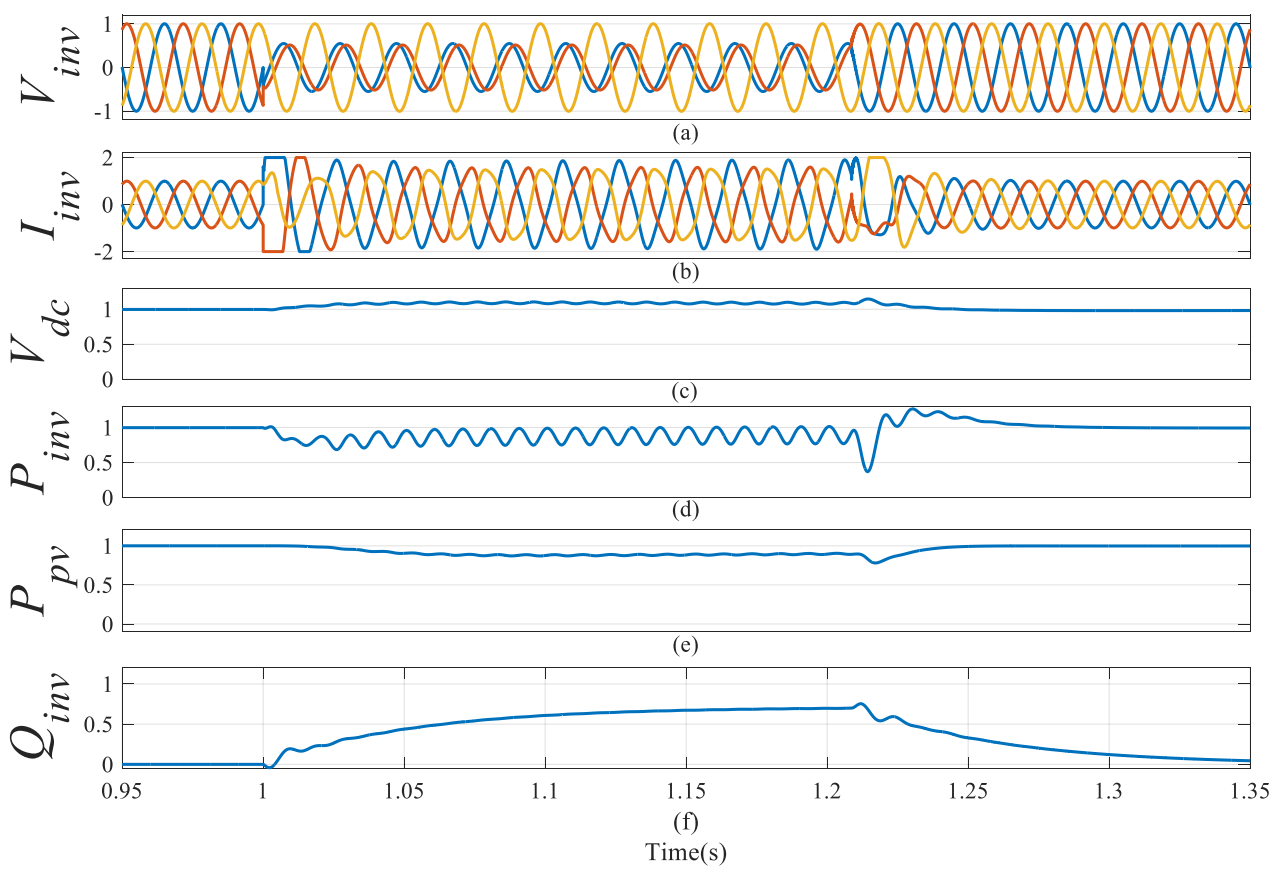

Figure 3.17: Simulation results under DL fault with simplified VCU (all in pu): (a) inverter voltage, (b) inverter current, (c) DC-link voltage, (d) inverter side active power, (e) PV power, (f) reactive power

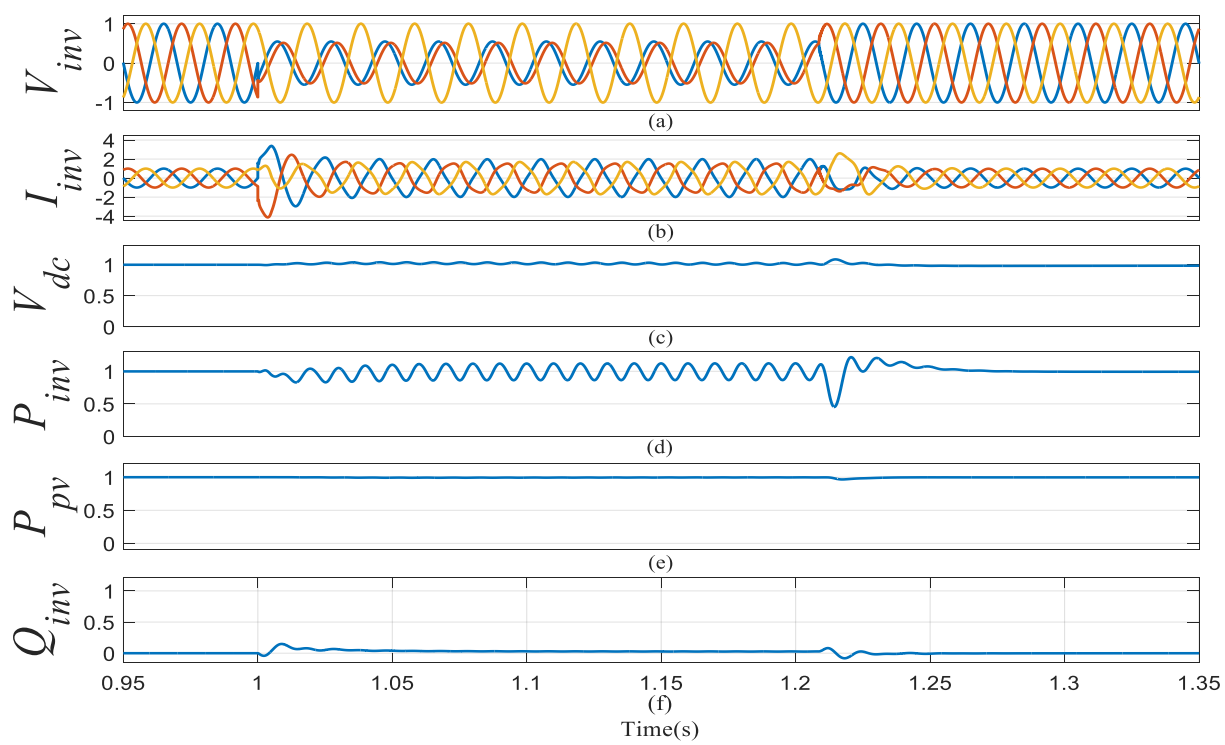

Figure 3.18: Simulation results under DL fault without VCU (all in pu): (a) inverter voltage, (b) inverter current, (c) DC-link voltage, (d) inverter side active power, (e) PV power, (f) reactive power 


\section{(d) Results under Single Line to Ground (SLG) fault}

Figure 3.19 shows the simulation results for a SLG fault using the proposed strategy. Since the voltages on the two healthy phases remain at $1 \mathrm{pu}$ during the fault, the 3phase voltage drop is slightly less than the DL fault. Similar to the DLG fault, $V_{\text {com }}$, which is calculated by the VCU, is very small, which leads to $P_{i n v}$ almost remains at 1 pu; consequently, $P_{p v}$ is almost $1 \mathrm{pu}$ as well. Hence, $I_{i n v}$ is almost the same with and without the simplified VCU (less than 2pu). The results demonstrate that the simplified VCU is not sensitive to the fault when the voltage sag is small (compared with Figure 3.20 , which is the results without simplified VCU).

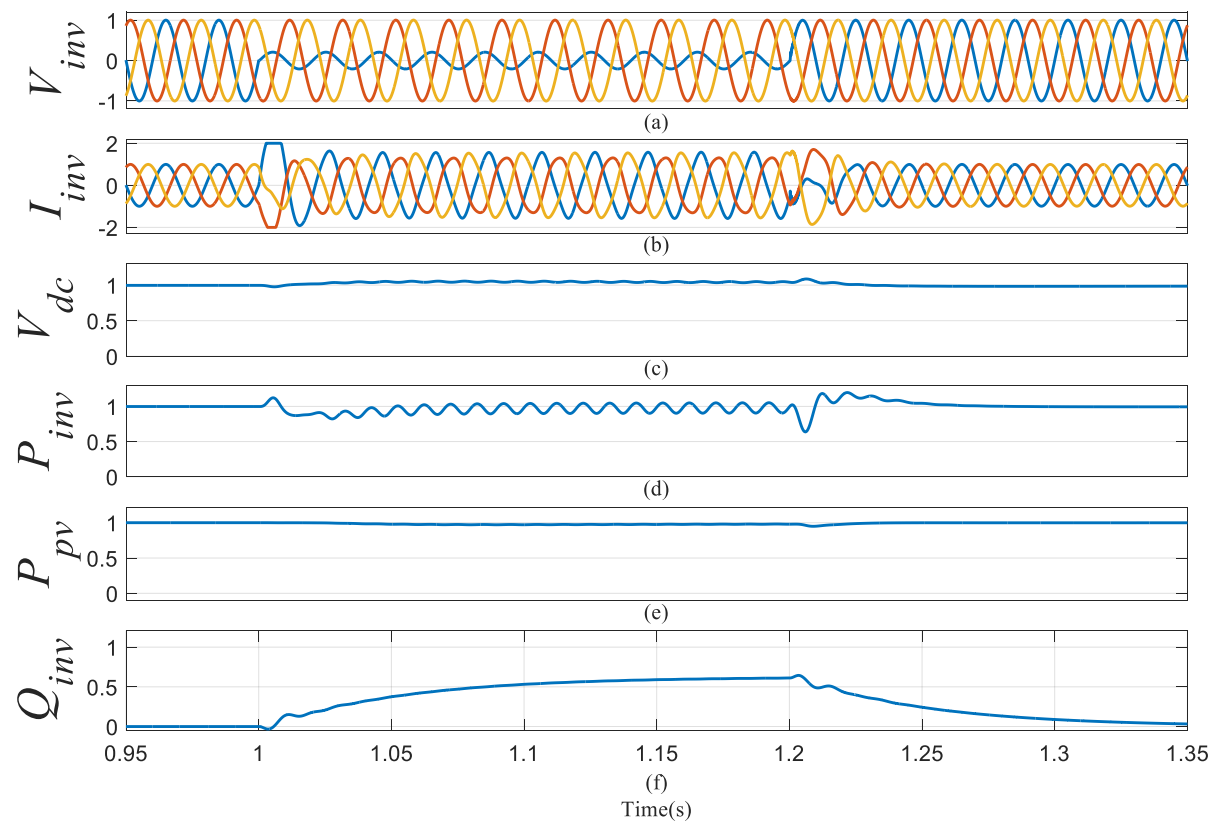

Figure 3.19: Simulation results under SLG fault with simplified VCU (all in pu): (a) inverter voltage, (b) inverter current, (c) DC-link voltage, (d) inverter side active power, (e) PV power, (f) reactive power 


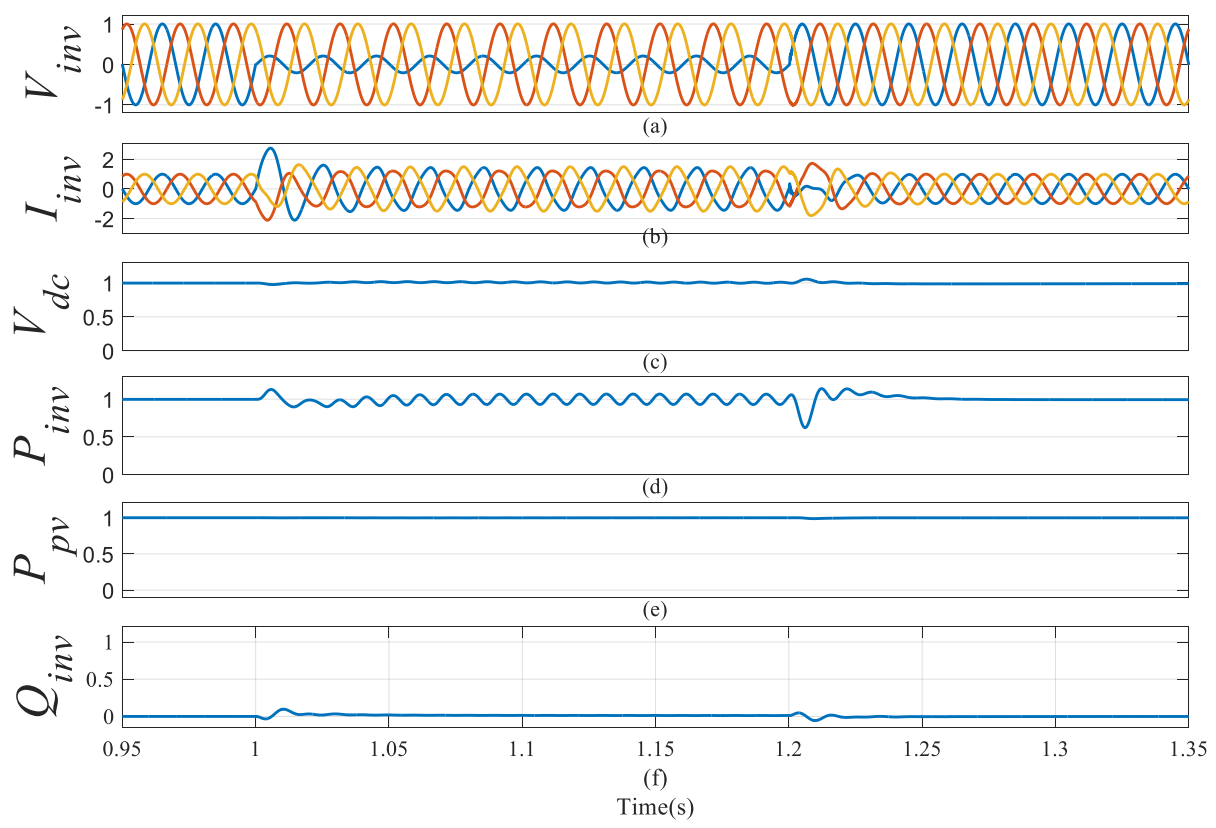

Figure 3.20: Simulation results under SLG fault without VCU (all in pu): (a) inverter voltage, (b) inverter current, (c) DC-link voltage, (d) inverter side active power, (e) PV power, (f) reactive power

\subsubsection{Simulation results for $M P F-V C U$}

Using the data provided in Table 3-1, equation (3.31) for the simulated system is:

$$
P_{p v}<0.021 V_{d}^{2}
$$

Considering $k_{m}=1.05$, equation (3.33) for the simulated system is:

$$
V_{\text {com }}=-3.6771 V_{d}^{5}+7.0739 V_{d}^{4}-4.6767 V_{d}^{3}+1.5089 V_{d}^{2}-0.5786 V_{d}+0.3496
$$

The results shown in this section are used to illustrate the need for MPF-VCU. In order to emphasize the improvement, the results for different types of faults are compared with the results shown in the previous section.

\section{(a) Results under 3-phase fault}

Figure 3.21 shows the result of a 3-phase fault using the MPF-VCU. It can be found that the inverter current $I_{i n v}$ only hit the hard limit for less than one cycle, i.e. $\mathrm{t}=1.02 \mathrm{~s}$, 
which is one cycle faster than the result using simplified VCU (see Figure 3.14 (b)). This demonstrates that the proposed MPF-VCU can improve the dynamic response during the fault.

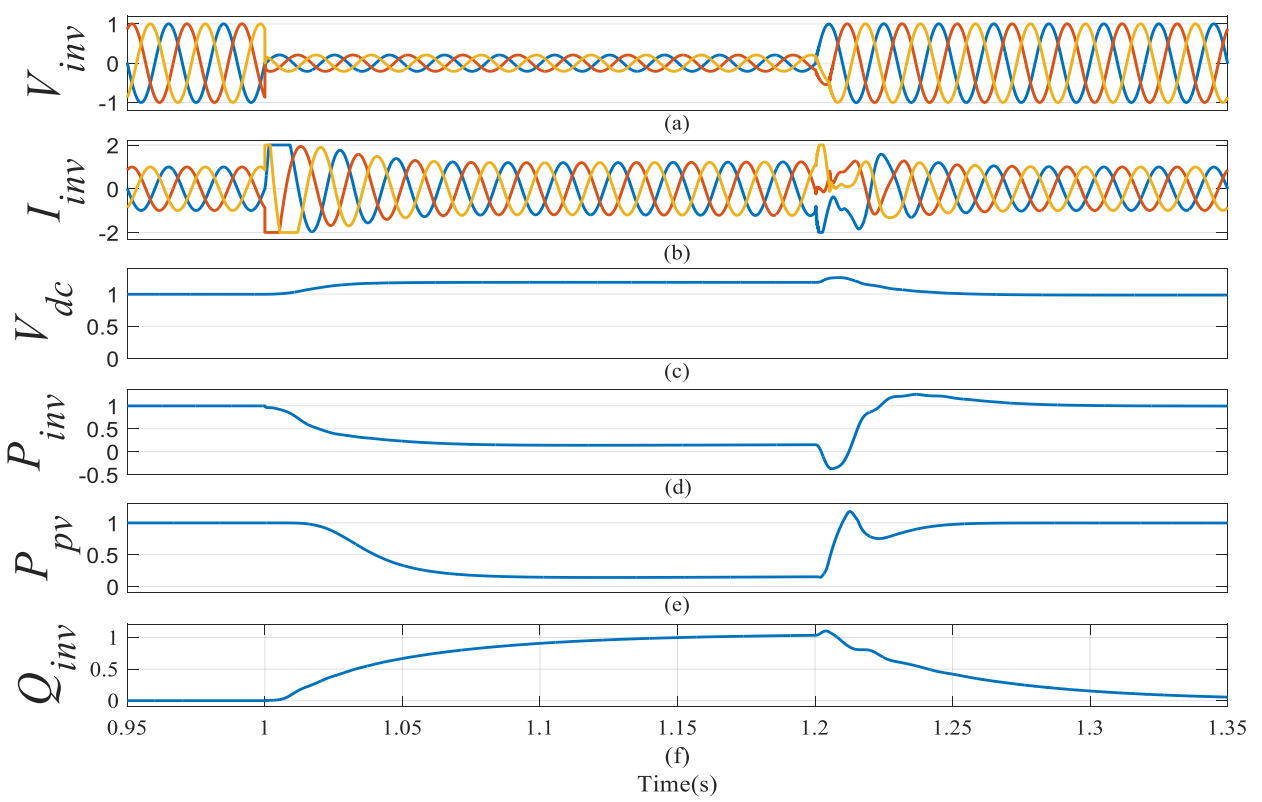

Figure 3.21: Simulation results under 3-phase fault with MPF-VCU (all in pu): (a) inverter voltage, (b) inverter current, (c) DC-link voltage, (d) inverter side active power, (e) PV power, (f) reactive power

\section{(b) Results under DLG fault}

Figure 3.22 shows the results with the MPF-VCU under a DLG fault. The $P_{i n v}$ fluctuation (see Figure 3.22 (d)) is almost the same compared with the result shown in Figure 3.15 (d), which is because $V_{\text {com }}$ is almost the same as for the simplified VCU. Similarly, it can be found that the inverter active power is reduced to slightly less than $0.5 \mathrm{pu}$, which leads to $I_{\text {inv }}$ is limited to less $1.5 \mathrm{pu}$ during the fault. 


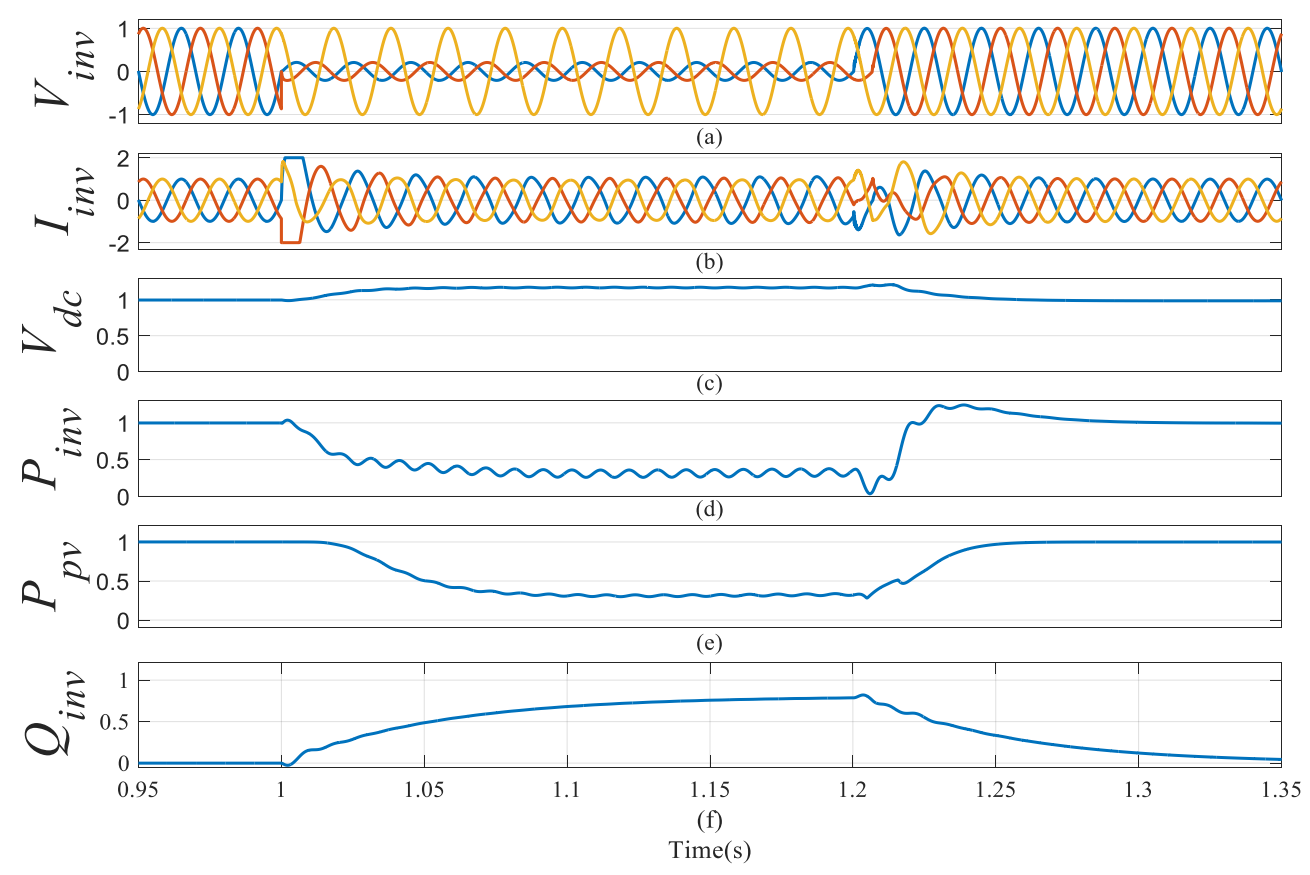

Figure 3.22: Simulation results under DLG fault with MPF-VCU (all in pu): (a) inverter voltage, (b) inverter current, (c) DC-link voltage, (d) inverter side active power, (e) PV power, (f) reactive power

\section{(c) Results under DL fault}

Figure 3.23 shows the results with the proposed MPF-VCU for a DL fault. Comparing Figure 3.23 with Figure 3.17, it can be found that under the same voltage sag, the proposed MPF-VCU increases $V_{d c}$ to about 1.15 pu (see Figure 3.23 (c)), while $V_{d c}$ remains almost the same for the simplified VCU (see Figure 3.17 (c)). This leads to $P_{i n v}$ reduces to 0.5 pu by using the MPF-VCU (see Figure $3.23(\mathrm{~d})$ ), while $P_{i n v}$ is just less than 1 pu by applying the simplified VCU (see Figure 3.17 (d)). As a result, the PV power is reduced to 0.5 pu by using MPF-VCU. It can be observed that $I_{i n v}$ is pure sinusoidal during the fault (see Figure 3.23 (b)) while $I_{\text {inv }}$ is not pure sinusoidal in Figure 3.17 (b). 


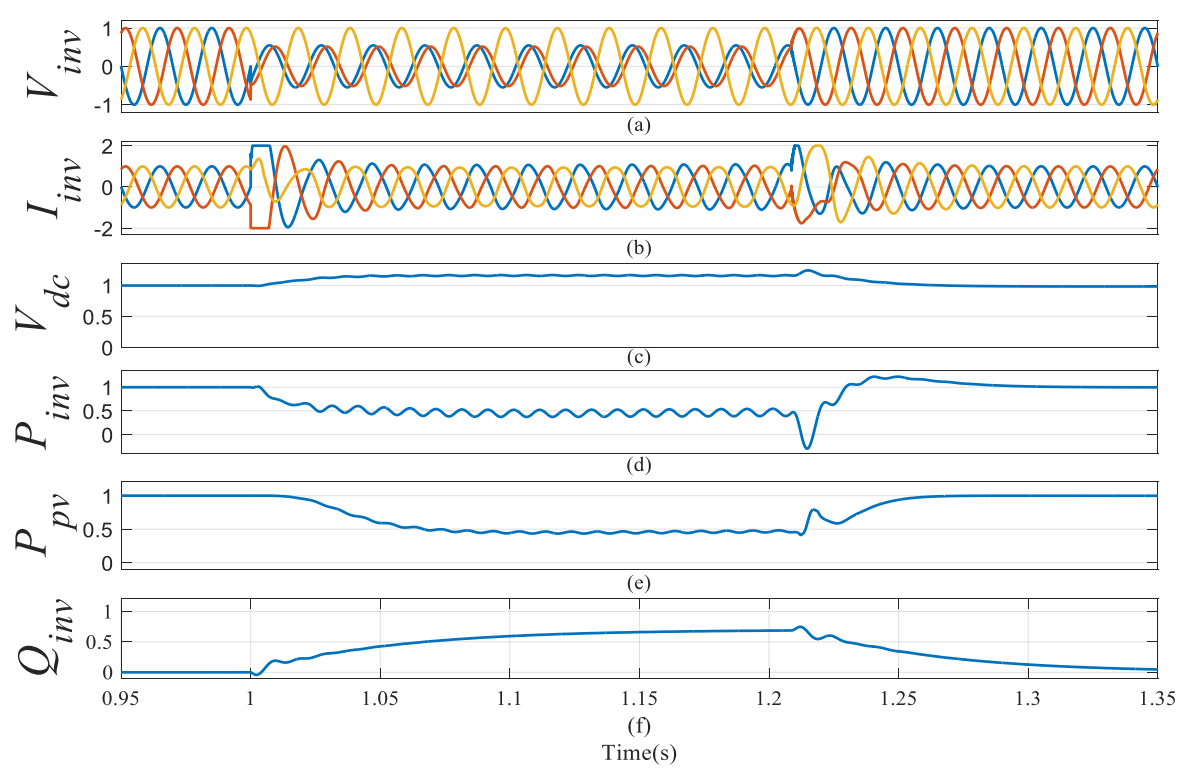

Figure 3.23: Simulation results under DL fault with MPF-VCU (all in pu): (a) inverter voltage, (b) inverter current, (c) DC-link voltage, (d) inverter side active power, (e) PV power, (f) reactive power

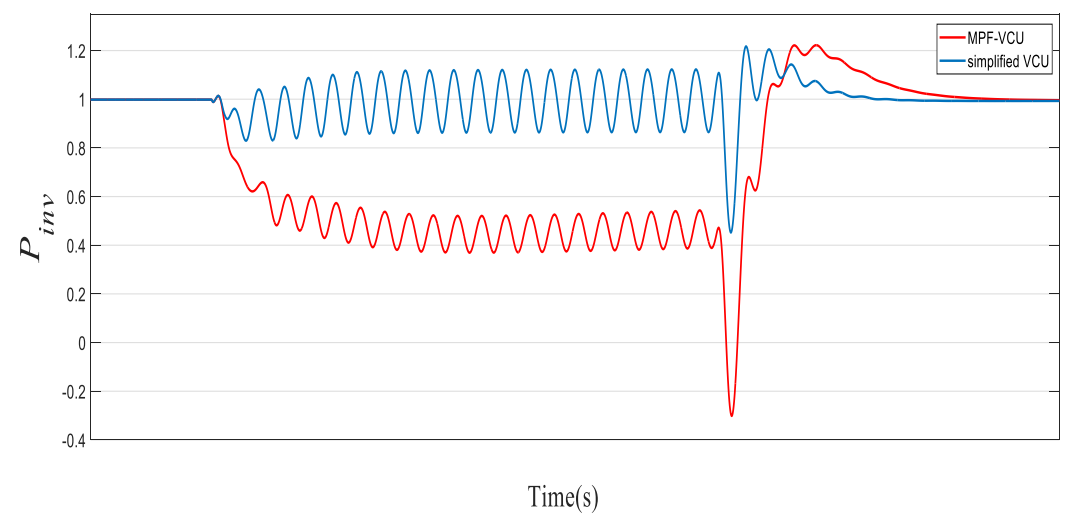

Figure 3.24: Inverter power comparison between simplified VCU and MPF-VCU under DL fault

Figure 3.24 shows the direct comparison of inverter power between simplified VCU and MPF-VCU for a DL fault. The red line is $P_{i n v}$ using MPF-VCU, and the blue line is $P_{i n v}$ using simplified VCU. It shows that the double grid oscillation is reduced with the MPF-VCU, which will also be illustrated by the Fast Fourier Transformation (FFT) analysis. Figure 3.25 (with MPF-VCU) and Figure 3.26 (simplified VCU) show the FFT analysis for $P_{i n v}$ under the DL fault. In order to emphasize the improvement of the MPF-VCU, the FFT analysis is used to show the magnitude of the double grid 
frequency oscillatory waveform. The fundamental frequency for the FFT analysis is set to be $100 \mathrm{~Hz}$, such that the magnitude of the double grid frequency oscillatory waveform will be calculated. As shown on the top of the diagram, the magnitude of $P_{i n v}$ at the fundamental frequency is 0.3897 with the MPF-VCU (see Figure 3.25), while, the magnitude of $P_{i n v}$ is 0.6137 at the same frequency (see Figure 3.26). The results demonstrate the proposed MPF-VCU can further reduce the double grid frequency oscillation during asymmetrical faults.

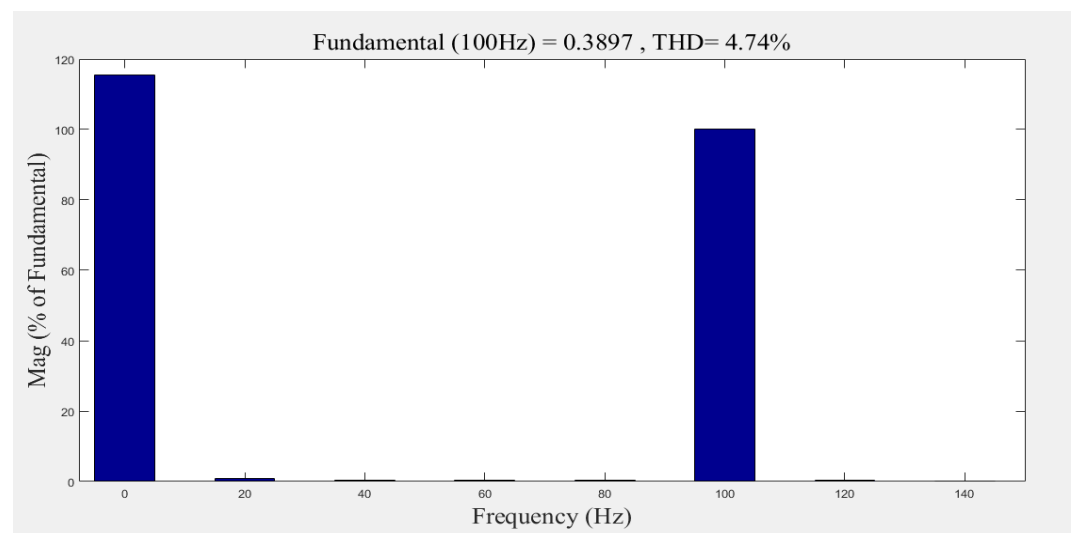

Figure 3.25: FFT analysis for the inverter power under DL fault with MPF-VCU

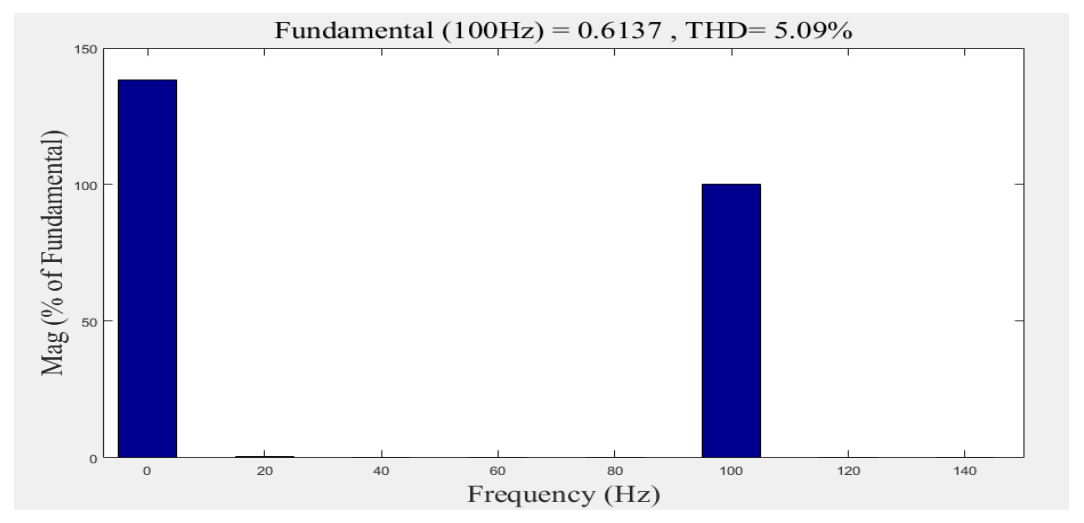

Figure 3.26: FFT analysis for the inverter power under DL fault with simplified VCU

\section{(d) Results under SLG fault}

Figure 3.27 shows the results for a SLG fault with the MPF-VCU. Since the voltage sag is smaller than the other types of asymmetrical fault, the MPF-VCU reduces $P_{p v}$ less than DLG fault and DL fault. However, it can be found that $I_{i n v}$ is pure sinusoidal 
and limited to less than 1 pu with the proposed MPF-VCU (see Figure 3.27 (b)). Moreover, $P_{p v}$ (see Figure 3.27 (d)) and $P_{i n v}$ (see Figure 3.27 (e)) with the MPF-VCU are reduced compared with Figure 3.19 (d) and (e). From Figure 3.28, it can be observed that the magnitude $P_{i n v}$ is 0.242 at the fundamental frequency with the MPFVCU, while the magnitude of $P_{i n v}$ is 0.3806 with the simplified VCU (see Figure 3.29). The results show illustrate that the MPF-VCU can help reduce the double grid frequency oscillation.

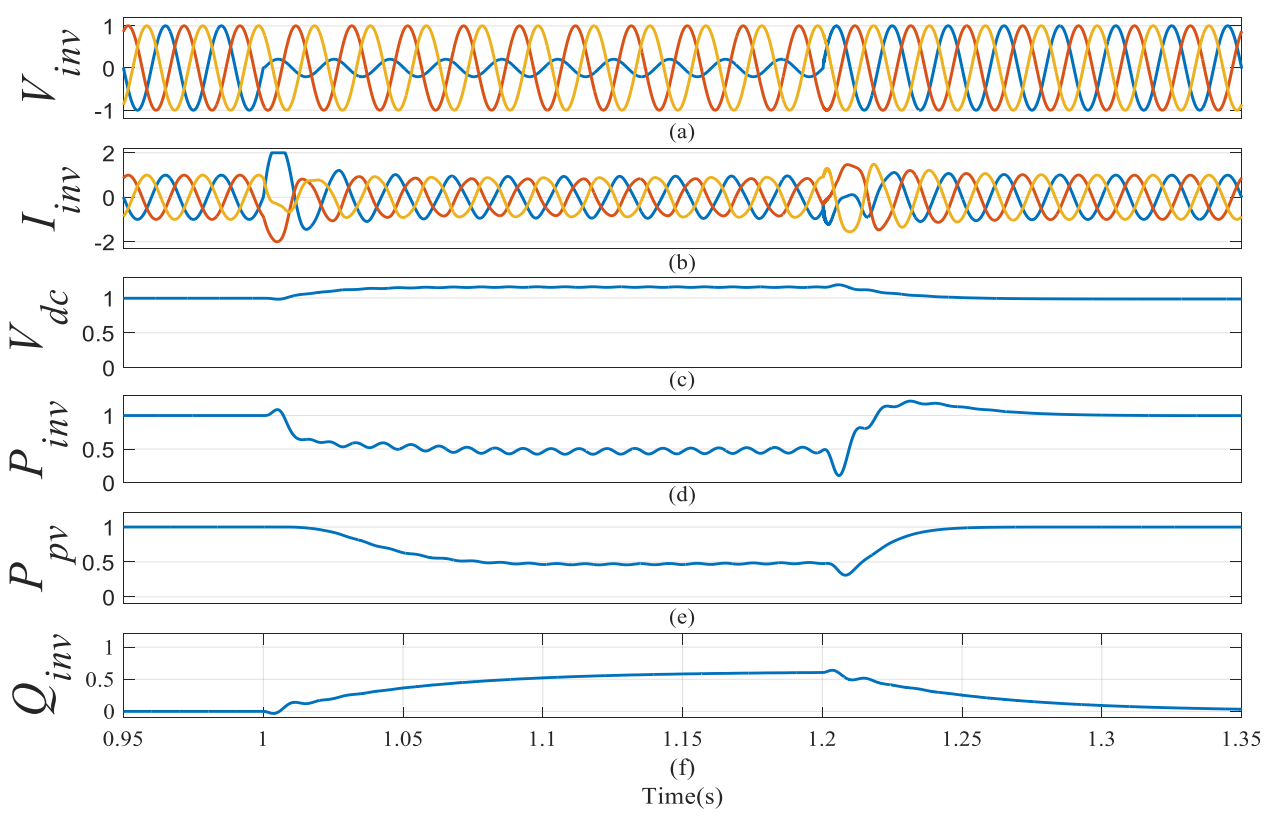

Figure 3.27: Simulation results under SLG fault with MPF-VCU (all in pu): (a) inverter voltage, (b) inverter current, (c) DC-link voltage, (d) inverter side active power, (e) PV power, (f) reactive power 


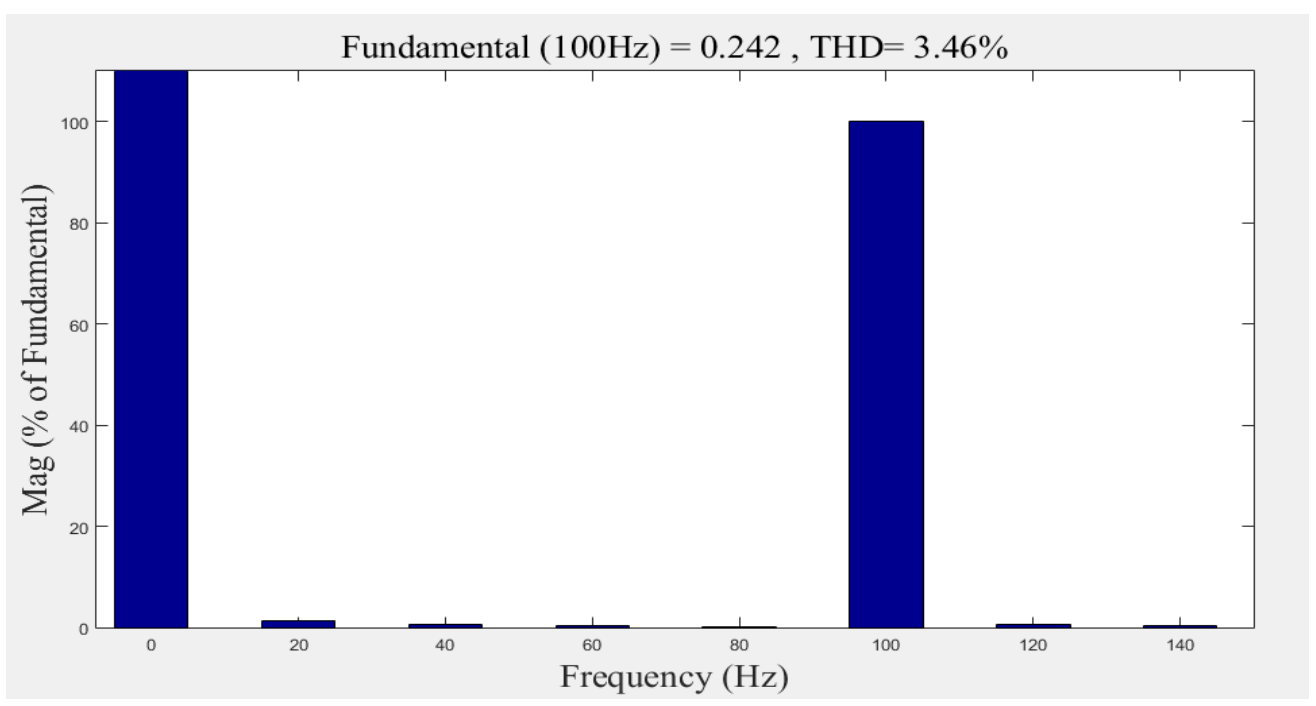

Figure 3.28: FFT analysis for the inverter power under SLG fault with MPF-VCU

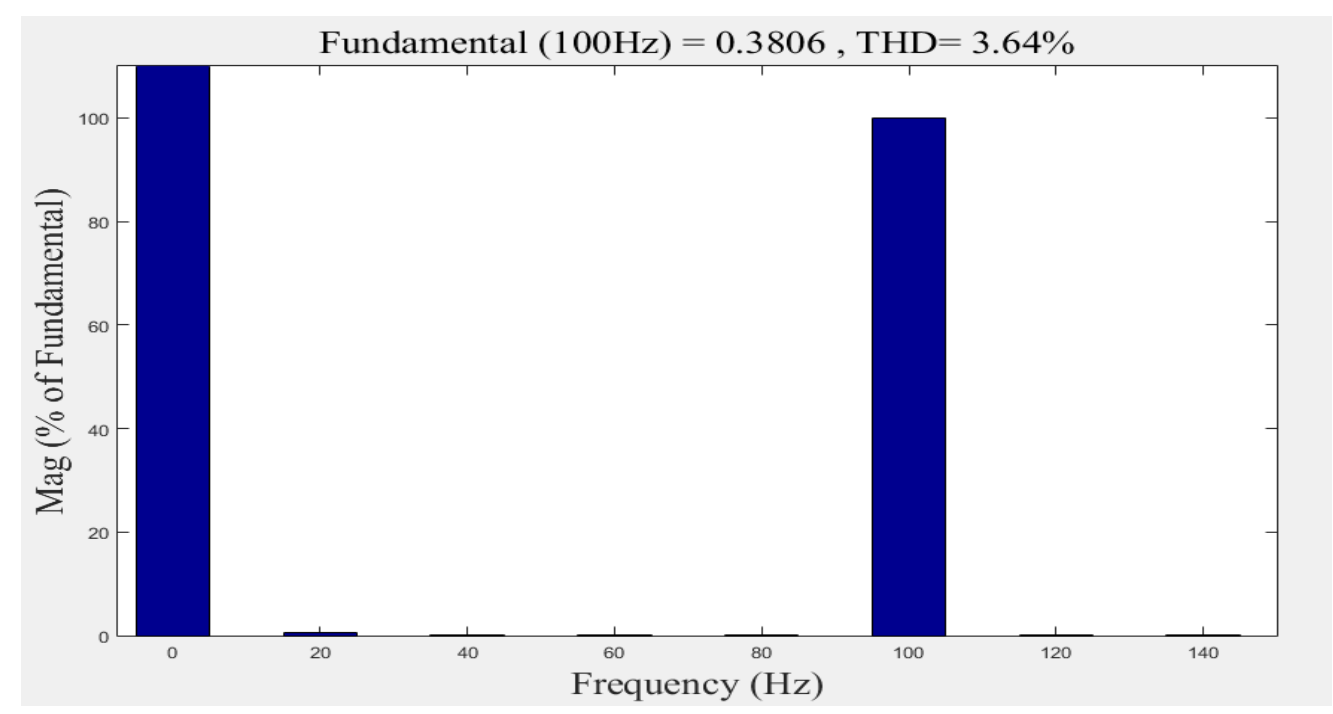

Figure 3.29: FFT analysis for the inverter power under SLG fault with simplified VCU

\subsection{Summary of Chapter 3}

The LVRT strategy for a grid-connected PV system based on SYRF frame is presented in this chapter. The proposed method is based on the classic cascaded voltage and current loops in SYRF, which includes a reactive power injection block and a VCU. The reactive power is injected to the grid during the faults to support the grid while the proposed VCU uses the positive and negative sequences to modify the reference 
DC-link voltage to limit the inverter current during the grid faults. Two different VCUs are proposed, which use different functions to define the variation of $V_{c o m}$ and $V_{d}$. The first VCU (simplified VCU) uses two quadratic functions while the other one (MPFVCU) uses the mixed potential function.

The simplified VCU is designed to limit the inverter current during different types of faults without the need for switch from the MPPT to a non-MPPT mode. The simplified VCU is validated in MATLAB/Simulink for different types of faults. For 3-phase and DLG fault, the simplified VCU can limit the inverter current through reducing the power generated by the PV array. However, for a not server voltage sag, e.g. DL or SLG fault, the simplified VCU contributes less to the current curtailment, which is because the quadratic functions are not sensitive to the voltage sags.

The MPF-VCU is proposed to reduce the inverter active power's double grid frequency oscillation and provides pure sinusoidal inverter current during asymmetrical faults, which is illustrated by the simulation results for different types of faults. Results also show that the MPF-VCU is sensitive to even small voltage sags and can achieve faster current curtailment. In summary, the proposed LVRT strategy with the MPF-VCU in this chapter has the following advantages:

1) It can limit the inverter current for both symmetrical and asymmetrical faults.

2) It provides high-quality sinusoidal inverter voltage and current during faults.

3) The proposed LVRT strategy can reduce the double grid frequency oscillation during the asymmetrical fault.

4) The proposed method eliminates the need to switch from the MPPT mode to a non-MPPT mode. 
5) The proposed method has a reactive power injection block, which can support the grid voltage during faults.

It should be noted that the normal operation of the proposed methods has been also investigated. Results show that the methods do not affect the system's normal operation. In choosing the DC-link capacitor, this should be taken into account that the proposed method increases the DC-link voltage during the faults. However, since the protection systems must operate within a fraction of a second, this should not be a massive burden on an appropriate capacitor. 


\section{Chapter 4 AN LVRT Strategy for 3-phase grid-connected PV Systems in the STRF}

\subsection{Introduction}

This chapter presents an enhancement of LVRT strategy and post-fault recovery for a 3-phase grid-connected PV system in the STRF. The proposed control scheme for the LVRT strategy in this chapter avoids using symmetrical sequences separation and the STRF to the SYRF transformation. The proposed method in this chapter contains a novel approach for the calculation of the reference current of the inverter to overcome the drawbacks of the inherent coupling between the active and reactive powers in an STRF controller, which enables independent control of active and reactive power during normal operation. Similar to the methodology proposed in Chapter 3, this method can maintain the inverter current within acceptable limitation during all types of faults and produce sinusoidal currents during asymmetrical faults. Moreover, a transient reactive power suppression unit is proposed to reduce the inverter current after the fault clearance for a severe 3-phase fault. The proposed method also provides a fast and smooth recovery after the fault is being cleared. Frequency analysis is used to design the proportional and resonant gains of the PR controller, which improves the transient response for the PR controller. The proposed method is validated using MATLAB/Simulink simulations. 


\subsection{Proposed LVRT for grid-connected PV system in the STRF}

The grid-connected PV system under study with the proposed method is illustrated in Figure 4.1. The same as the LVRT strategy presented in Chapter 3; it uses the classic cascaded voltage and current loops. The voltage loop includes the MPF-VCU, which produces the peak amplitude of the inverter current $\left(\left|I_{\text {peak }}{ }^{*}\right|\right)$, which will be used for the reference current calculation. The method also considers a the reactive power calculation block (see Figure 4.2), which consists of a transient reactive power suppression unit to adjust $\theta^{*}$ during the faults. $\theta^{*}$ is the reference angle between the active power and the apparent power (known as power factor angle). An SYRF-PLL is used to estimate the grid frequency. Then $\left|I_{\text {peak }}{ }^{*}\right|, \theta^{*}$ and the grid frequency are used for reference currents calculation (see Figure 4.1). The current loop consists of two non-ideal PR controllers.

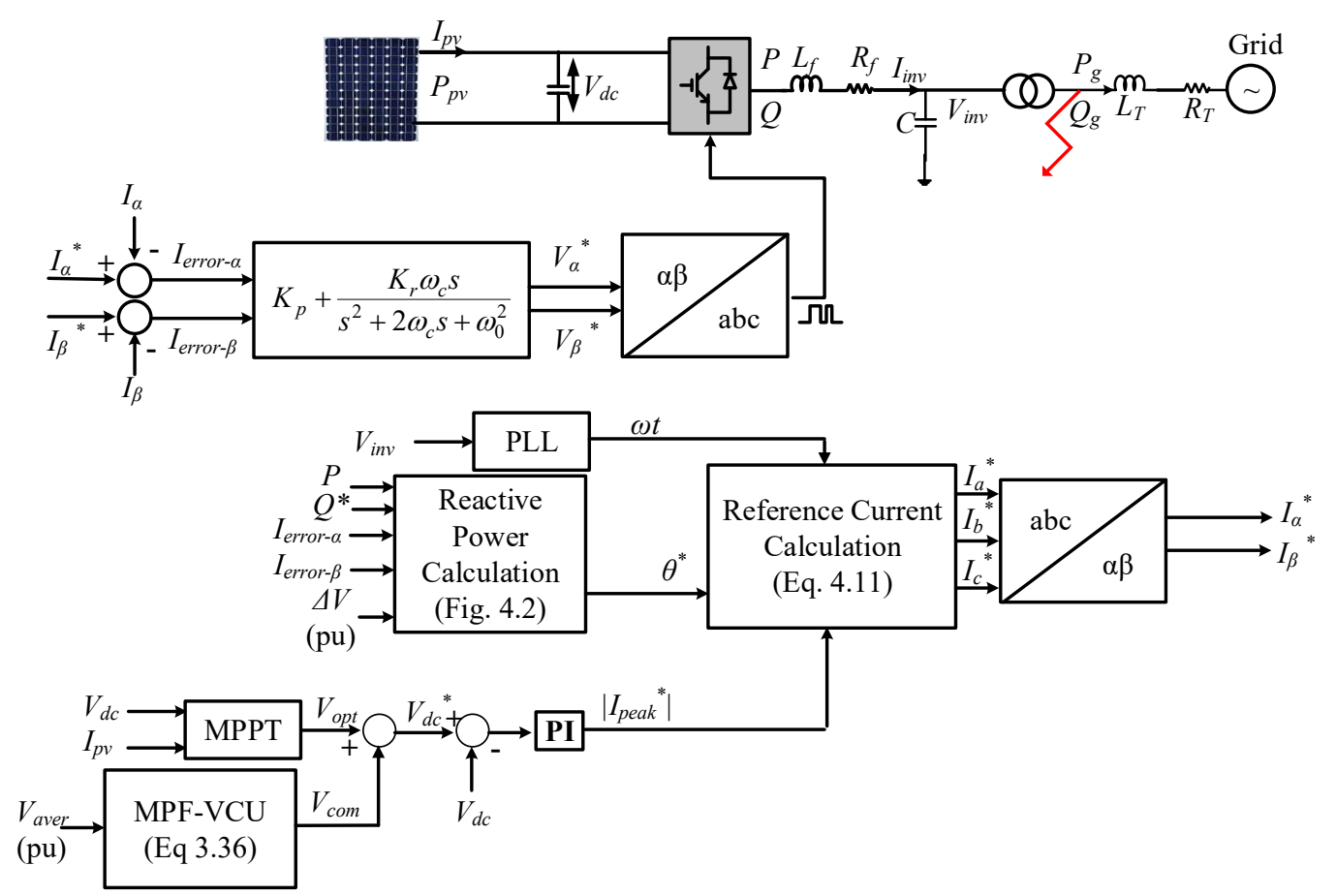

Figure 4.1: The proposed control scheme for the system under study 


\subsubsection{Reference Current Calculation}

The conventional equation for the calculation of reference currents in the STRF will make the inverter current non sinusoidal and will contain double grid frequency oscillation during the asymmetrical faults. The reason for this drawback in the conventional equations for the inverter reference current calculation is explained next. Similar to the active and reactive power calculation in the SYRF, the equations for inverter reference active and reactive power calculation in the STRF are stated in equation (4.1) [70]:

$$
\begin{aligned}
P^{*} & =\frac{3}{2}\left(v_{\alpha} i_{\alpha}^{*}+v_{\beta} i_{\beta}^{*}\right) \\
Q^{*} & =-\frac{3}{2}\left(v_{\alpha} i_{\beta}^{*}-v_{\beta} i_{\alpha}^{*}\right)
\end{aligned}
$$

Where $i_{\alpha}{ }^{*}$ and $i_{\beta}{ }^{*}$ are the inverter reference currents in the STRF, $P^{*}$ and $Q^{*}$ are the inverters reference active and reactive power, and $v_{\alpha}$ and $v_{\beta}$ are the measured instantaneous inverter AC-side voltages in the STRF. From equation (4.1), the equations used to calculate the reference current $\left(i_{\alpha}{ }^{*}\right.$ and $\left.i_{\beta}{ }^{*}\right)$ in the STRF can be written in (4.2):

$$
\begin{aligned}
& i_{\alpha}^{*}=\frac{P^{*} v_{\alpha}+Q^{*} v_{\beta}}{1.5\left(v_{\alpha}^{2}+v_{\beta}^{2}\right)} \\
& i_{\beta}^{*}=\frac{P^{*} v_{\beta}-Q^{*} v_{\alpha}}{1.5\left(v_{\alpha}^{2}+v_{\beta}^{2}\right)}
\end{aligned}
$$

From equation (4.2), it can be concluded that there is a coupling between the active and reactive power, which will deteriorate the system's performance. $v_{\alpha}$ and $v_{\beta}$ can be written in equation (4.3): 


$$
\begin{aligned}
& v_{\alpha}=\left|V_{\alpha}\right| \sin \omega t \\
& v_{\beta}=\left|V_{\beta}\right| \cos \omega t
\end{aligned}
$$

Where $\left|V_{\alpha}\right|$ and $\left|V_{\beta}\right|$ are the magnitudes of the voltages in the STRF. Substituting equation (4.3) into (4.2), $i_{\alpha}{ }^{*}$ and $i_{\beta}{ }^{*}$ can be given in equation (4.4):

$$
\begin{aligned}
& i_{\alpha}^{*}=\frac{P^{*}\left|V_{\alpha}\right| \sin \omega t}{1.5\left(\left|V_{\alpha}\right|^{2} \sin ^{2} \omega t+\left|V_{\beta}\right|^{2} \cos ^{2} \omega t\right)}+\frac{Q^{*}\left|V_{\beta}\right| \cos \omega t}{1.5\left(\left|V_{\alpha}\right|^{2} \sin ^{2} \omega t+\left|V_{\beta}\right|^{2} \cos ^{2} \omega t\right)} \\
& i_{\beta}^{*}=\frac{P^{*}\left|V_{\beta}\right| \cos \omega t}{1.5\left(\left|V_{\alpha}\right|^{2} \sin ^{2} \omega t+\left|V_{\beta}\right|^{2} \cos ^{2} \omega t\right)}-\frac{Q^{*}\left|V_{\alpha}\right| \sin \omega t}{1.5\left(\left|V_{\alpha}\right|^{2} \sin ^{2} \omega t+\left|V_{\beta}\right|^{2} \cos ^{2} \omega t\right)}
\end{aligned}
$$

During a symmetrical fault, $\left|V_{\alpha}\right|=\left|V_{\beta}\right|=|V|$. Therefore, $i_{\alpha}{ }^{*}$ and $i_{\beta}{ }^{*}$ can be written in equation (4.5):

$$
\begin{aligned}
& i_{\alpha}^{*}=\frac{P^{*}|V| \sin \omega t+Q^{*}|V| \cos \omega t}{1.5\left(|V|^{2}\left(\sin ^{2} \omega t+\cos ^{2} \omega t\right)\right)}=\frac{P^{*}|V| \sin \omega t+Q^{*}|V| \cos \omega t}{1.5\left(|V|^{2}\right)} \\
& i_{\beta}^{*}=\frac{P^{*}\left|V_{\beta}\right| \cos \omega t-Q^{*}|V| \sin \omega t}{1.5\left(|V|^{2}\left(\sin ^{2} \omega t+\cos ^{2} \omega t\right)\right)}=\frac{P^{*}|V| \cos \omega t-Q^{*}|V| \sin \omega t}{1.5\left(|V|^{2}\right)}
\end{aligned}
$$

Thus, $i_{\alpha}{ }^{*}$ and $i_{\beta}{ }^{*}$ will be sinusoidal. However, it is not the case during an asymmetrical fault. Since $\left|V_{\alpha}\right| \neq\left|V_{\beta}\right|$, by using the calculation of the symmetrical components, and assuming $Q^{*}=0 \mathrm{pu}, i_{\alpha}{ }^{*}$ and $i_{\beta}{ }^{*}$ is written in equation (4.6):

$$
\begin{aligned}
& i_{\alpha}^{*}=\frac{P^{*} v_{\alpha}^{+}+P^{*} v_{\alpha}^{-}}{1.5\left(\left(v_{\alpha}^{+}+v_{\alpha}^{-}\right)^{2}+\left(v_{\beta}^{+}+v_{\beta}^{-}\right)^{2}\right)} \\
& i_{\beta}^{*}=\frac{P^{*} v_{\beta}^{+}+P^{*} v_{\beta}^{-}}{1.5\left(\left(v_{\alpha}^{+}+v_{\alpha}^{-}\right)^{2}+\left(v_{\beta}^{+}+v_{\beta}^{-}\right)^{2}\right)}
\end{aligned}
$$

Where $v_{\alpha}{ }^{+}, v_{\alpha}^{-}, v_{\beta}{ }^{+}, v_{\beta}{ }^{-}$are the positive and negative sequences of instantaneous inverter AC-side voltages. Then, $i_{\alpha}{ }^{*}$ and $i_{\beta}{ }^{*}$ are written in equation (4.7): 


$$
\begin{gathered}
i_{\alpha}^{*}=\frac{P^{*}\left(V_{\alpha}^{+}|\sin \omega t+| V_{\alpha}^{-} \mid \cos \omega t\right)}{1.5\left(\begin{array}{l}
\left.\left|V_{\alpha}^{+}\right|^{2} \sin ^{2} \omega t+\left|V_{\alpha}^{-}\right|^{2} \cos ^{2} \omega t+2\left|V_{\alpha}^{+}\right| \sin \omega t\left|V_{\alpha}^{-}\right| \cos \omega t+\right) \\
\left|V_{\beta}^{+}\right|^{2} \cos ^{2} \omega t+\left|V_{\beta}^{-}\right|^{2} \sin ^{2} \omega t+2\left|V_{\beta}^{+}\right| \sin \omega t\left|V_{\beta}^{-}\right| \cos \omega t
\end{array}\right)} \\
i_{\beta}^{*}=\frac{P^{*}\left(\left|V_{\beta}^{+}\right| \cos \omega t+\left|V_{\beta}^{-}\right| \sin \omega t\right)}{1.5\left(\begin{array}{l}
\left|V_{\alpha}^{+}\right|^{2} \sin ^{2} \omega t+\left|V_{\alpha}^{-}\right|^{2} \cos ^{2} \omega t+2\left|V_{\alpha}^{+}\right| \sin \omega t\left|V_{\alpha}^{-}\right| \cos \omega t+ \\
\left|V_{\beta}^{+}\right|^{2} \cos ^{2} \omega t+\left|V_{\beta}^{-}\right|^{2} \sin ^{2} \omega t+2\left|V_{\beta}^{+}\right| \sin \omega t\left|V_{\beta}^{-}\right| \cos \omega t
\end{array}\right)}
\end{gathered}
$$

Where $\left|V_{\alpha}^{+}\right|,\left|V_{\alpha}^{-}\right|,\left|V_{\beta}^{+}\right|,\left|V_{\beta}^{-}\right|$are the magnitude of the positive and negative sequences voltages. Since $\left|V_{\alpha}^{+}\right|=\left|V_{\beta}^{+}\right|=\left|V^{+}\right|$and $\left|V_{\alpha}^{-}\right|=\left|V_{\beta^{-}}\right|=\left|V^{-}\right|$during asymmetrical faults, $i_{\alpha}{ }^{*}$ and $i_{\beta}{ }^{*}$ can be written in equation (4.8):

$$
\begin{aligned}
& i_{\alpha}^{*}=\frac{P^{*}\left(\left|V^{+}\right| \sin \omega t+\left|V^{-}\right| \cos \omega t\right)}{\left.1.5\left(\left|V^{+}\right|^{2}+\left|V^{-}\right|^{2}+4\left|V^{+}\right|\left|V^{-}\right| \sin \omega t \cos \omega t\right)\right)} \\
& i_{\beta}^{*}=\frac{P^{*}\left(\left|V^{+}\right| \cos \omega t+\left|V^{-}\right| \sin \omega t\right)}{\left.1.5\left(\left|V^{+}\right|^{2}+\left|V^{-}\right|^{2}+4\left|V^{+}\right|\left|V^{-}\right| \sin \omega t \cos \omega t\right)\right)}
\end{aligned}
$$

By applying the sum trigonometric function, equation (4.9) can be derived from equation (4.8):

$$
\begin{aligned}
& i_{\alpha}^{*}=\frac{P^{*}\left(\left|V^{+}\right| \sin \omega t+\left|V^{-}\right| \cos \omega t\right)}{1.5\left(\left|V^{+}\right|^{2}+\left|V^{-}\right|^{2}+2\left|V^{+}\right|\left|V^{-}\right| \sin 2 \omega t\right)} \\
& i_{\beta}^{*}=\frac{P^{*}\left(\left|V^{+}\right| \cos \omega t+\left|V^{-}\right| \sin \omega t\right)}{1.5\left(\left|V^{+}\right|^{2}+\left|V^{-}\right|^{2}+2\left|V^{+}\right|\left|V^{-}\right| \sin 2 \omega t\right)}
\end{aligned}
$$

As can be seen from equation (4.9), the denominator contains the double grid frequency components. Moreover, the numerator contains both sine and cosine expressions, which have different magnitude $\left(V^{+}, V^{-}\right)$. Thus, the reference currents will not be sinusoidal during asymmetrical faults. Considering $Q^{*} \neq 0 \mathrm{pu}$, equation (4.10) 
can be derived from equation (4.2) by following similar steps from equation (4.6) to (4.9):

$$
\begin{aligned}
& i_{\alpha}^{*}=\frac{P^{*}\left(\left|V^{+}\right| \sin \omega t+\left|V^{-}\right| \cos \omega t\right)}{1.5\left(\left|V^{+}\right|^{2}+\left|V^{-}\right|^{2}+2\left|V^{+}\right|\left|V^{-}\right| \sin 2 \omega t\right)}+\frac{\left.Q^{*}\left|V^{+}\right| \cos \omega t+\left|V^{-}\right| \sin \omega t\right)}{1.5\left(\left|V^{+}\right|^{2}+\left|V^{-}\right|^{2}+2\left|V^{+}\right|\left|V^{-}\right| \sin 2 \omega t\right)} \\
& i_{\beta}^{*}=\frac{P^{*}\left(\left|V^{+}\right| \cos \omega t+\left|V^{-}\right| \sin \omega t\right)}{1.5\left(\left|V^{+}\right|^{2}+\left|V^{-}\right|^{2}+2\left|V^{+}\right|\left|V^{-}\right| \sin 2 \omega t\right)}-\frac{\left.Q^{*}\left|V^{+}\right| \sin \omega t+\left|V^{-}\right| \cos \omega t\right)}{1.5\left(\left|V^{+}\right|^{2}+\left|V^{-}\right|^{2}+2\left|V^{+}\right|\left|V^{-}\right| \sin 2 \omega t\right)}
\end{aligned}
$$

Similar to equation (4.9), the same conclusion can be made from equation (4.10). Therefore, the conventional reference currents calculation method that is being commonly used in the STRF based control systems, cannot be used for the LVRT control strategy during asymmetrical faults. Therefore, an inverter reference currents calculation block is proposed to solve this problem. As illustrated in Figure 4.1, equation (4.11) is used to define the reference currents.

$$
\begin{aligned}
& I_{a}^{*}=\left|I_{\text {peak }}^{*}\right| \cos \left(\omega t+\theta^{*}\right) \\
& I_{b}^{*}=\left|I_{\text {peak }}^{*}\right| \cos \left(\omega t+\theta^{*}-120^{\circ}\right) \\
& I_{c}^{*}=\left|I_{\text {peak }}^{*}\right| \cos \left(\omega t+\theta^{*}+120^{\circ}\right)
\end{aligned}
$$

Where $I_{a}{ }^{*}, I_{b}{ }^{*}$ and $I_{c}{ }^{*}$ are the 3 -phase inverter reference currents. $\left|I_{\text {peak }}{ }^{*}\right|$ is the peak value of the inverter reference current, which comes from the voltage loop, $\omega$ is the grid frequency, which comes from the PLL. $\theta^{*}$ is the reference angle between the active power and the apparent power (Power Factor $=\cos (\theta)$ ), which is calculated by the reactive power calculation block. By using this reference currents calculation, the active and reactive power can be independently controlled, which will be proved by the simulation results. Since the reference currents are produced in 3-phase, during 
asymmetrical faults the phase currents will remain sinusoidal. Then the phase reference currents are transferred to the STRF.

\subsubsection{Reactive Power Calculation Block}

Similar to the reactive power injection block proposed in Chapter 3, the Chinese standard is used to define the required reactive power $Q_{0}$ :

$$
Q_{o}=\left\{\begin{array}{cc}
0 & \Delta V<0.1 p u \\
1.5|\Delta V|-0.15 & 0.1<\Delta V<0.8 p u \\
1.05 & \Delta V>0.8 p u
\end{array}\right.
$$

Equation (4.12) determines how much reactive power should be injected to the grid for different voltage sags during the faults. However, the transient performance of a PR controller after the fault clearance is not as good as a PI controller [71]. This is due to the frequency changes after the fault clearance, which means for a PR controller, the gain of the controller will significantly drop, such that it cannot cancel out the steadystate error. It can be found that right after the fault clearance (for those faults with severe voltage sags), the measured currents are larger than the reference currents. It means that there will be some extra power produced by the error currents which need to be eliminated. Thus, a transient reactive power suppression unit is introduced to minimize the power produced by the error currents. The proposed method reduces the extra reactive power, which is produced by the error currents (equation (4.13)) to reduce the inverter currents after the fault clearance.

$$
\begin{aligned}
& I_{\text {error- } \alpha}=I_{\alpha}^{*}-I_{\alpha} \\
& I_{\text {error }-\beta}=I_{\beta}^{*}-I_{\beta}
\end{aligned}
$$

In equation (4.13), $I_{\alpha}$ and $I_{\beta}$ are the measured currents, $I_{\alpha}{ }^{*}$ and $I_{\beta}{ }^{*}$ are the reference currents, $I_{\text {error- } \alpha}$ and $I_{\text {error }-\beta}$ are the error currents. Note that during normal operation, $I_{\text {error- }}$ 
${ }_{\alpha}=I_{\text {error }-\beta}=0$, which means that the error reactive power $\left(Q_{\text {error }}\right)$ produced by the error currents only exist exactly after the fault is cleared. Thus, it is possible to reduce the inverter currents after the fault clearance by reducing the reactive power generated by the error current. $Q_{\text {error }}$ can be calculated by equation (4.14):

$$
Q_{\text {error }}=-\frac{3}{2}\left(V_{\alpha} I_{\text {error }-\beta}-V_{\beta} I_{\text {error }-\alpha}\right)
$$

By subtracting $Q_{\text {error }}$ from $Q_{o}$, the reference reactive power during the faults $Q_{F}{ }^{*}$, which should be injected to the system during a fault is calculated (see Figure 4.2). It is noted that $Q_{F}{ }^{*} \neq Q_{o}$ only when $I_{\text {error- } \alpha \beta} \neq 0$, which happens at the clearance of severe faults. Knowing active and reactive power, angle $\theta_{F}$ can be calculated by equation (4.15):

$$
\theta_{F}=\cos ^{-1} \frac{P}{S}=\cos ^{-1}\left(\frac{P}{\sqrt{P^{2}+Q_{F}^{* 2}}}\right)
$$

where, $S$ is the apparent power of the inverter and $P$ is the inverter active power. To calculate $\theta^{*}$, the reactive power calculation block, which consists of the normal operation reactive power $\left(Q^{*}\right)$ calculation block and the fault operation reactive power $\left(Q_{F}{ }^{*}\right)$ calculation block is used as shown in Figure 4.2. The proposed method ensures that the PV system supplies $Q^{*}$ and $Q^{*}+Q_{F}$ during, respectively, normal and abnormal operations. As shown in Figure 4.2, $\theta^{*}=\theta_{F}+\theta_{N}$, where $\theta_{N}$ is calculated by $Q^{*}$ and $P$. $\theta^{*}$ is used to determine how much reactive power can be generated. During normal operation, since $\Delta V<0.1 \mathrm{pu}$, according to equation (4.12) and (4.15), $\theta_{F}=0$, which means only normal operation block contributes to the reactive power calculation. When $\Delta V>0.1 \mathrm{pu}$, $\theta_{F}$ varies as $\Delta V$ changes, thus, both normal operation and fault operation blocks contribute to the reactive power during faults. Then, $\theta^{*}$ is used for the reference current calculation. 


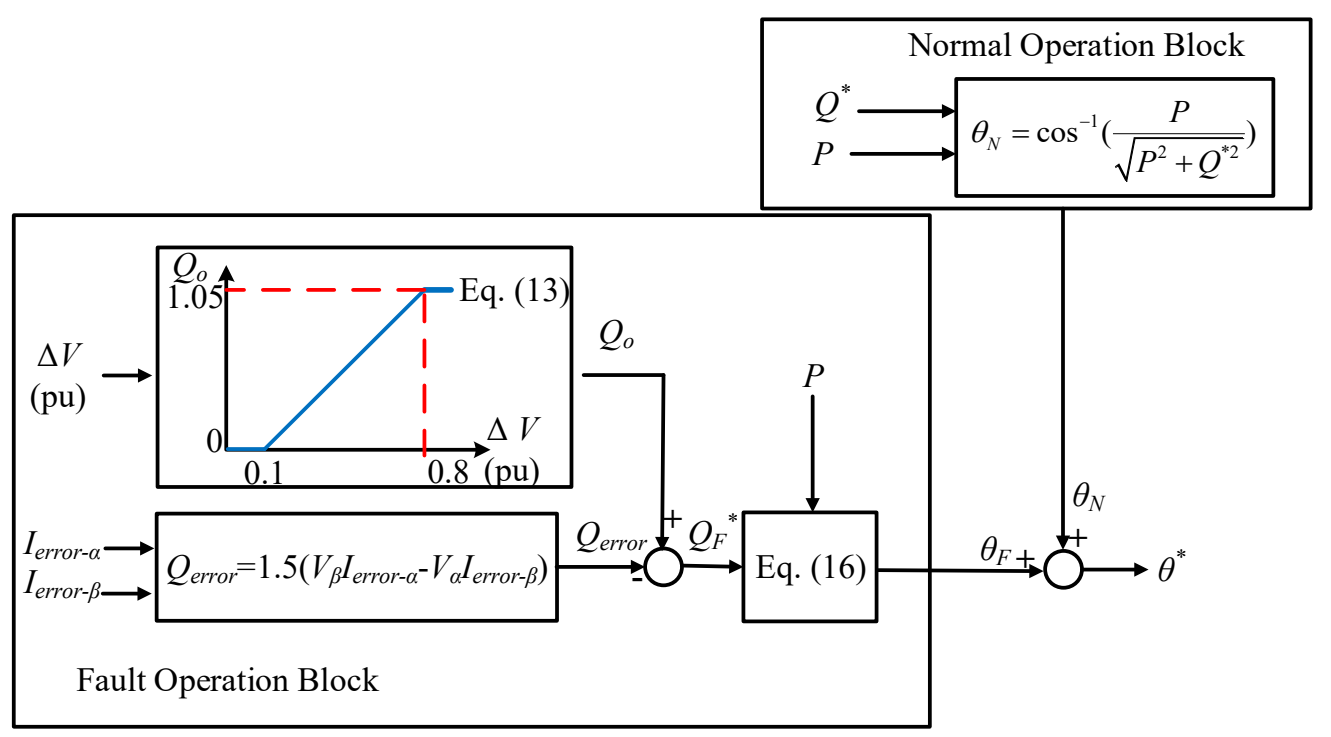

Figure 4.2: The control scheme for the reactive power calculation block

\subsubsection{Design of PR controller}

Equation (4.16) is the transfer function for a non-ideal PR controller [93], where $K_{p}$ is the proportional gain, $K_{r}$ is the resonant gain, $\omega_{c}$ is the cut-off frequency, and $\omega_{0}$ is the resonant (nominal) frequency.

$$
T F=K_{p}+\frac{K_{r} \omega_{c} s}{s^{2}+2 \omega_{c} s+\omega_{0}^{2}}
$$

A PR controller has a high gain (ideally infinity) around the resonant frequency. Compared with the non-ideal PR controller, the gain of the ideal PR controller will significantly reduce at other frequencies. It can be found from the simulation results that when a fault occurs, the frequency at the point of common coupling will oscillate. It means if an ideal PR controller is used, the controller may have poor performance during the faults. Thus, the non-ideal PR controller is chosen. In order to proposes a control scheme which can be widely used and make the most use of the existing regulations. The grid codes in the U.K. considering the frequency disturbances is used. In the latest grid codes [92], the controller should withstand $1 \%$ disturbance of the grid 
frequency. Thus, the cut-off frequency is set to be $0.5 \mathrm{~Hz}$. Furthermore, when a fault occurs, the frequency will disturb even more depending on how severe the fault is. According to the technical criteria in [93], the controller is expected to operate at least across the range $48-52 \mathrm{~Hz}$. Thus, the resonant gain is selected as discussed below:

Figure 4.3 shows the Bode plot for the open-loop transfer function of the current loop when $K_{r}$ varies. As it can be seen, for $K_{r}=1000$, the gain is about $34.5 \mathrm{~dB}$, which is not high enough to reject disturbances. However, for $K_{r}=20000$, the gain of the controller is $58 \mathrm{~dB}$, which is high enough to minimize the error between the reference currents and the measured currents during a fault. Note that the phase margin for $K_{r}=20000$ and $K_{r}=1000$ are almost the same. Thus, $K_{r}=20000$ is chosen.

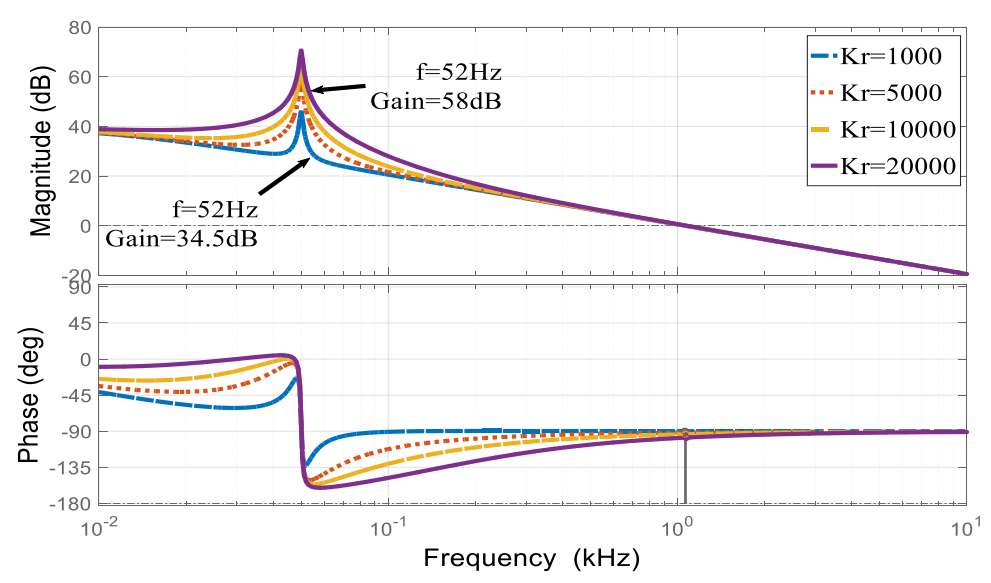

Figure 4.3: The Bode Plot for the control plant under study when $\mathrm{K}_{\mathrm{r}}$ varies

Figure 4.4 shows the Bode plot when $K_{p}$ varies. As it can be seen, when $K_{p}$ increases, the gain magnitude at the resonant frequency remains almost the same, but the phase margin increases. It means that higher $K_{p}$ can improve the stability of the system. Thus, $K_{p}=20$ is chosen. 


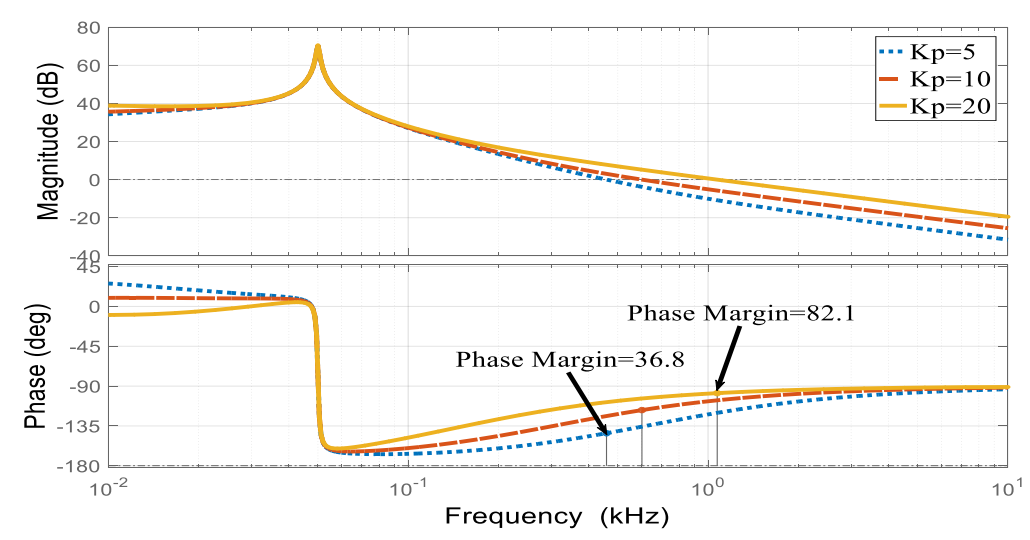

Figure 4.4: The Bode Plot for the under study control plant when $\mathrm{K}_{\mathrm{p}}$ varies

\subsubsection{MPF-VCU in the STRF}

Figure 4.5 shows the control scheme for the MPF-VSU used in this chapter. Similar to the method presented in Chapter 3, equation (3.36) is used to define how much voltage $\left(V_{c o m}\right)$ should be added into the DC-link voltage $\left(V_{d c}\right)$ for different voltage sags. However, it is slightly different from the proposed method in Chapter 3. Since the method is proposed in STRF, there is no $V_{d}$. Thus, to simplify the calculation, $V_{\text {aver }}$, which is the 3-phase average root mean square (RMS) voltage is used in this chapter.

$$
V_{\text {aver }}=\frac{1}{3}\left(V_{a-r m s}+V_{b-r m s}+V_{c-r m s}\right)
$$

Then, as shown in Figure 4.1, a classic PI controller is used for the voltage loop to get $\left|I_{\text {peak }}{ }^{*}\right|$, which is used for the inverter reference current calculation.

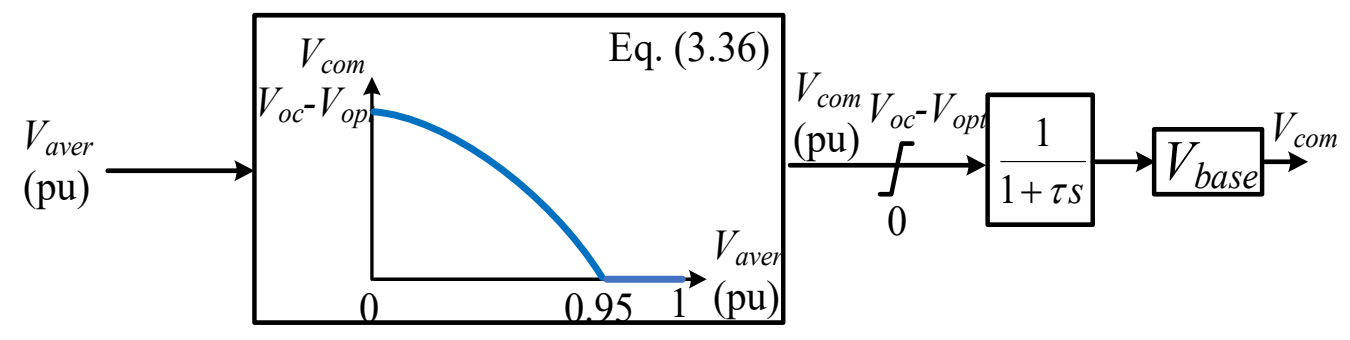

Figure 4.5: Structure of the proposed MPF-VCU 


\subsection{Simulation Results}

In this section, the proposed control strategy is simulated in MATLAB/SIMULINK environment. The grid frequency is $f=50 \mathrm{~Hz}$. Table A-3 shows the parameters used in the proposed model in this chapter. Note that all results are presented in per unit value. The system under study is tested under the normal operation and different types of faults to validate the proposed method works well for all scenarios. Where appropriate, the results are compared with state-of-the-art to demonstrate the improved performance of the proposed method.

\subsubsection{Normal Operation}

Similar to Chapter 3, it is essential to demonstrate that an LVRT scheme does not affect the normal operation. Besides, it is important to demonstrate that the proposed method provides independent active and reactive powers control. In this section, the normal operation of the system is considered. The results in Figure 4.6 shows that when the irradiance varies as $0.8,0.6,0.2$ and $0.8 \mathrm{pu}, P$ changes accordingly while $Q$ remains constant at $Q^{*}=0.2 \mathrm{pu}$. This is simply because e.g. when solar irradiance $=0.8 \mathrm{pu}$ and $Q^{*}=0.2 \mathrm{pu}, \theta_{N}$ is $14.04^{\circ}$ and when solar irradiance $=0.6 \mathrm{pu}$ and $Q^{*}=0.2 \mathrm{pu}, \theta_{N}$ is $18.43^{\circ}$. It means when irradiance reduces, $P$ will reduce accordingly, which leads to $\theta_{N}$ increase (according to equation (4.15)) and therefore reactive power will remain constant (note that $\theta_{F}=0$, during normal operation as $\Delta V<0.1 \mathrm{pu}$ ). Similarly, when $Q^{*}$ changes, $\theta_{N}$ will change accordingly and the active power will remain constant. As it can be seen from 
Figure 4.7, the active power remains at 0.4 pu while the reactive power varies as $0,0.4$, 0.8 and $0 \mathrm{pu}$.

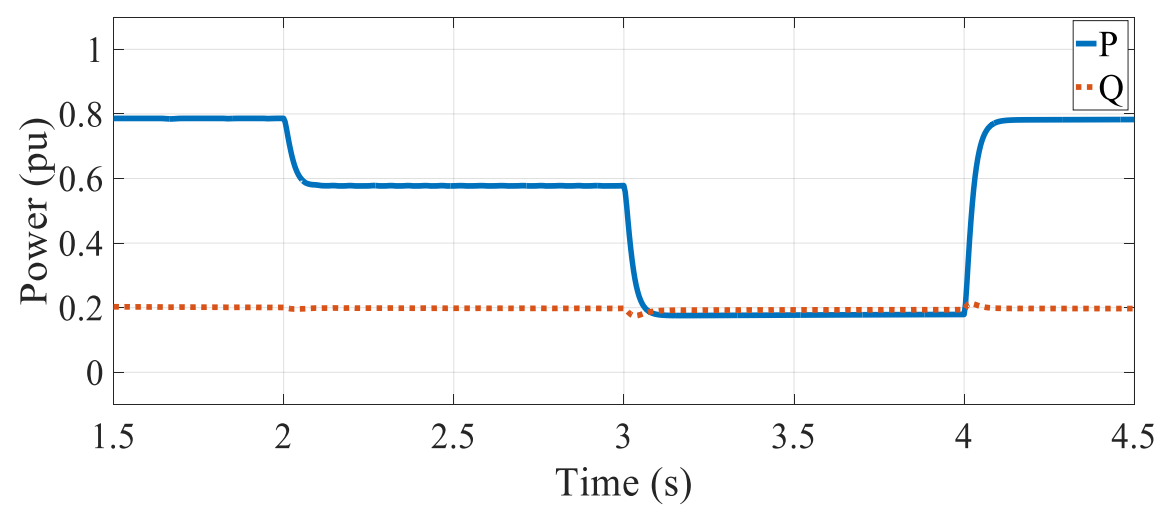

Figure 4.6: Active and reactive power performances with irradiance vary

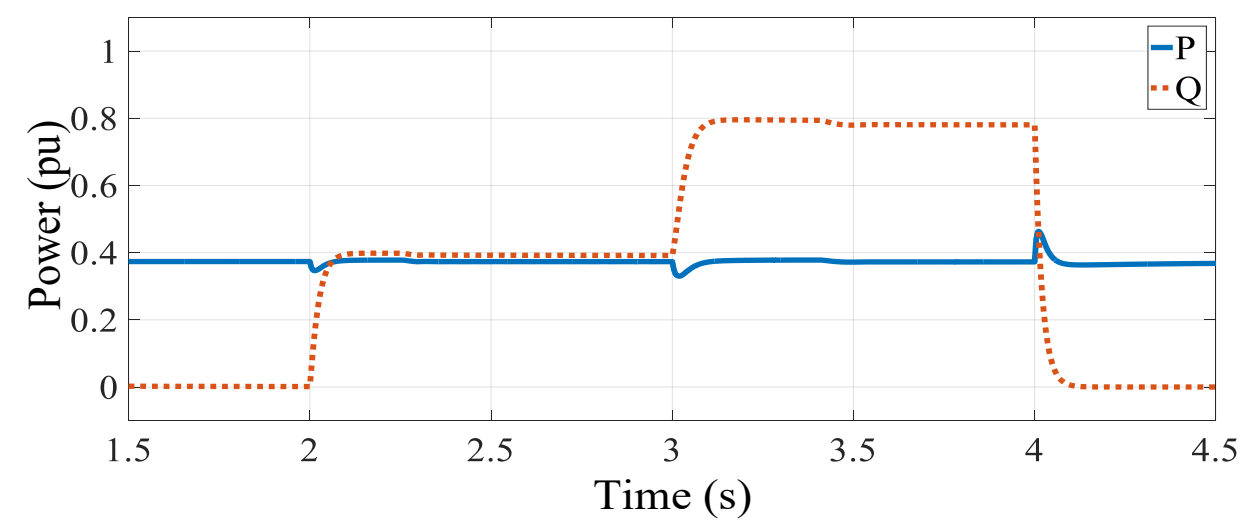

Figure 4.7: Active and reactive power performances with reactive power vary

These results demonstrate that the proposed LVRT strategy in STRF have the following advantages:

1) The proposed method does not interfere with normal operation.

2) The proposed LVRT strategy provides independent active and reactive power control. 


\subsubsection{Simulation results under different faults}

Now different types of faults will be investigated. For the sake of simplicity, it is assumed that $Q^{*}=0 \mathrm{pu}$ for all types of faults test. The simulation results are compared with the results in Chapter 3 and other state-of-the-art to illustrate the improvement and the need for this method.

\section{(a) 3-phase fault}

Figure Figure 4.8, Figure 4.9 and Figure 4.10 show the results for a 3-phase fault. The fault occurs at $\mathrm{t}=1 \mathrm{~s}$ and lasts for $0.2 \mathrm{~s}$. Figure 4.8 (a), which depicts the 3 -phase voltage, shows that the voltages drop to $0.2 \mathrm{pu}$. As shown in Figure 4.8 (b), which illustrates the average of the RMS inverter phase currents, the proposed method helps to reduce the current after the fault is cleared. It shows that the inverter current is limited to almost $1.3 \mathrm{pu}$ after the fault clearance with the proposed method. It also can be observed from Figure 4.8 (b), the proposed transient reactive power suppression unit reduces the inverter current from $1.9 \mathrm{pu}$ (solid blue line) to $1.7 \mathrm{pu}$ (dotted red line) exactly after the fault clearance for a severe fault. Figure 4.9 (a) shows that almost no active power is produced, and the proposed transient reactive power suppression unit will not affect the active power. From Figure 4.9 (b), it can be found that the transient reactive power suppression unit reduces the peak value of $Q_{i n v}$ exactly after the fault clearance from $1.25 \mathrm{pu}$ to $1 \mathrm{pu}$, while about $1.05 \mathrm{pu}$ reactive power is injected to the grid during the fault. As shown in Figure 4.8 (b) and Figure 4.9 (a), the inverter current and the active power recover to $1 \mathrm{pu}$ in almost $0.05 \mathrm{~s}$ after the fault clearance. Figure 4.10 shows the 3-phase currents are within acceptable limits during the whole of the fault period. 


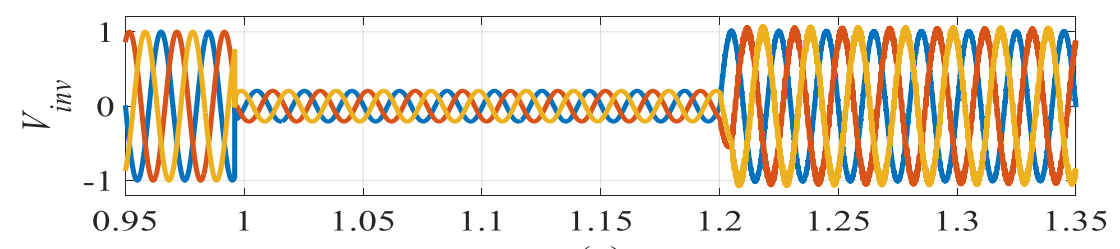

(a)

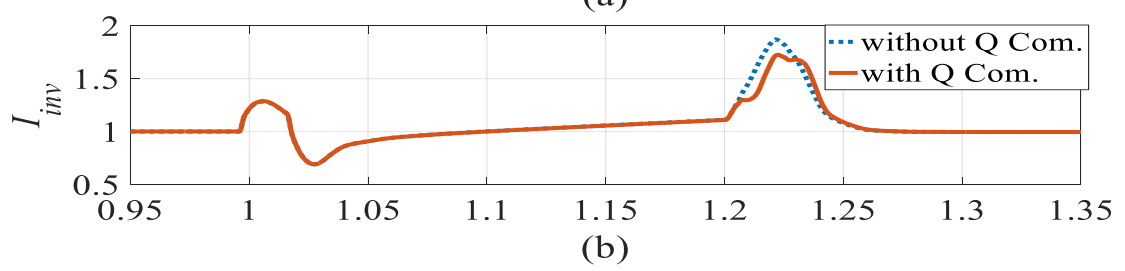

Time (s)

Figure 4.8: 3-phase fault (all results in pu) (a) The 3-phase voltage. (b) The average of the RMS inverter phase currents

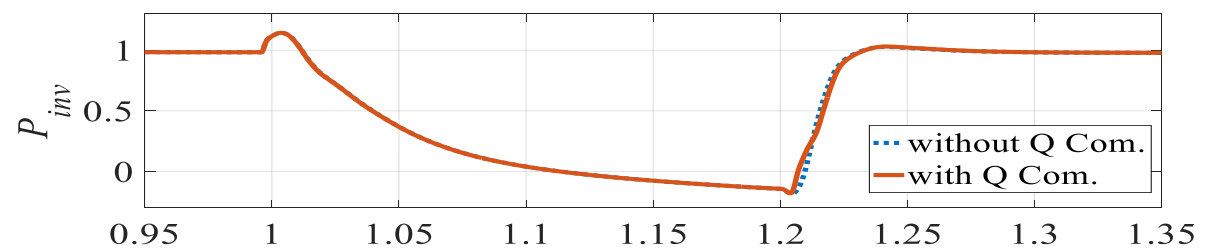

(a)

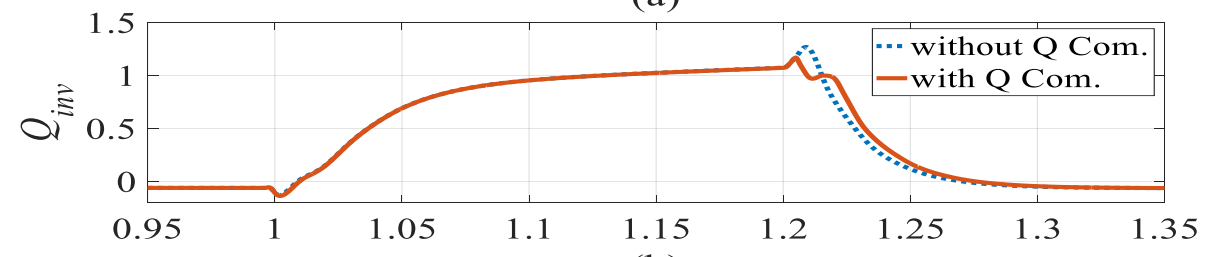

(b)

Time (s)

Figure 4.9: 3-phase fault (all results in pu) (a) The active power. (b) The reactive power

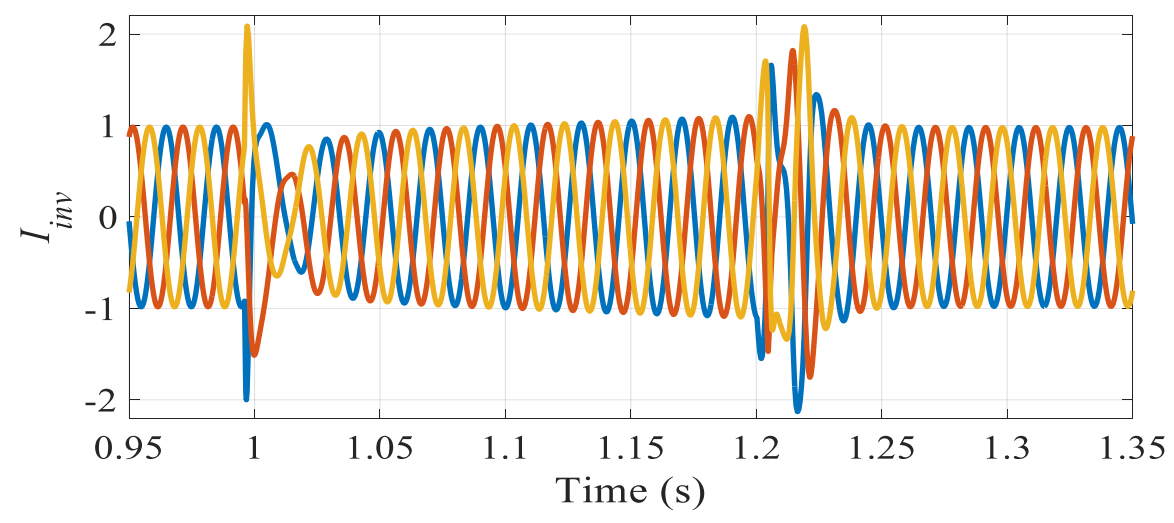

Figure 4.10: The 3-phase inverter currents under 3-phase fault (result in pu) 
Since [79] elaborates on the post-fault recovery performance under a 3-phase fault, it is chosen as the benchmark to highlight the improvement on post-fault recovery caused by the proposed method in. In order to make the comparison justifiable, the method is tested under the same configuration and conditions as [79].

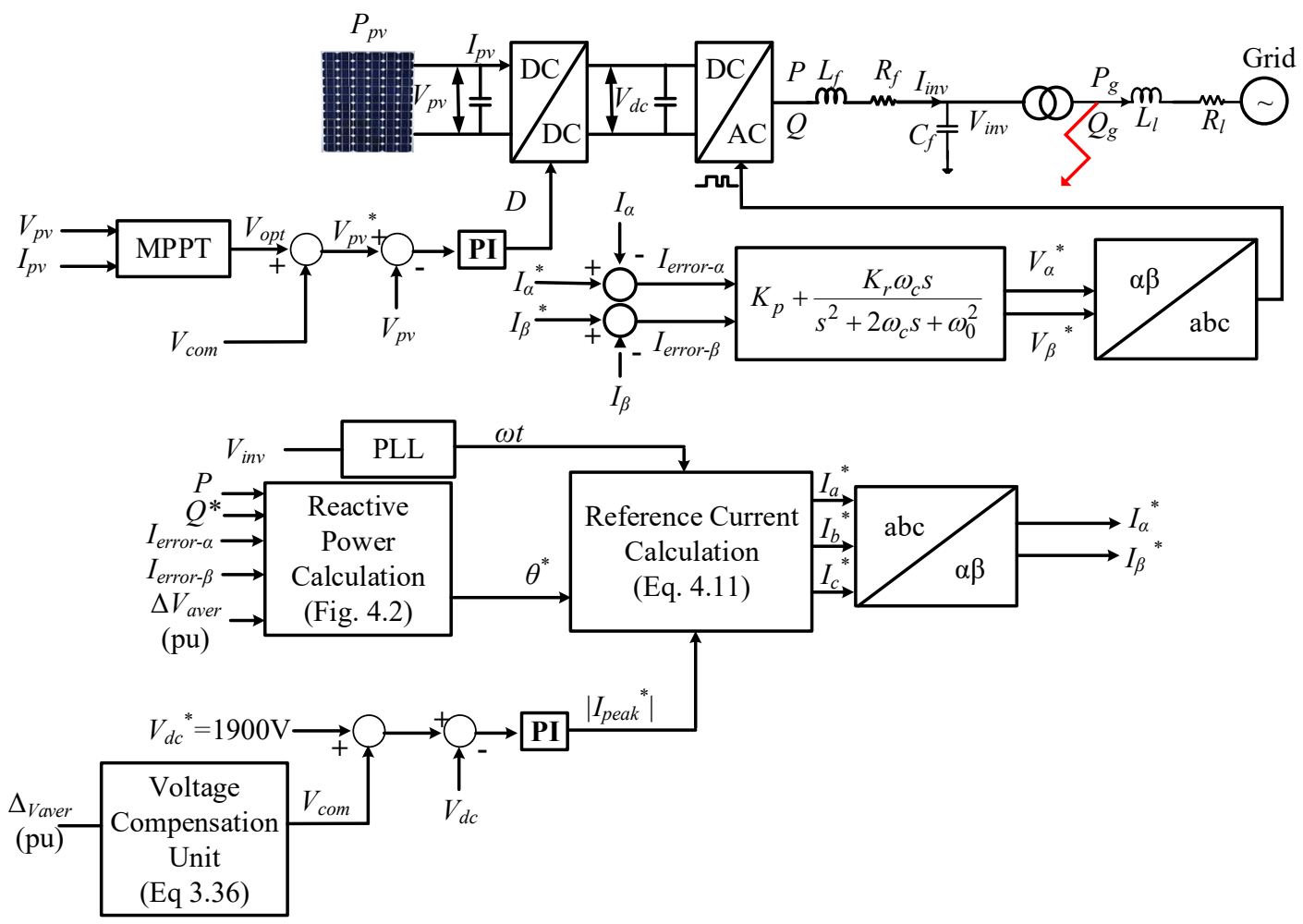

Figure 4.11: The proposed control scheme for the system under study which is the same as [79]

Figure 4.11 illustrates the proposed control scheme for a two-stage PV system, which is the same structure/parameter as [79]. From Figure 4.12 (b), it can be found that the inverter current is reduced to $0.7 \mathrm{pu}$ during the fault, and it is limited under $1.75 \mathrm{pu}$ after the fault is cleared. Meanwhile, the current seems to be much larger than $1.75 \mathrm{pu}$ in [79] (note that in [79] both $I_{d}$ and $I_{q}$ hit the $1.25 \mathrm{pu}$ limits after the fault clearance, which means the peak value of the inverter current will be even larger than $1.76 \mathrm{pu}$ ). The results show that the performances of the proposed LVRT method applied to a 
two-stage PV system (which is the same as [79]) are even better than that of the singlestage PV system (i.e. Figure 4.8).
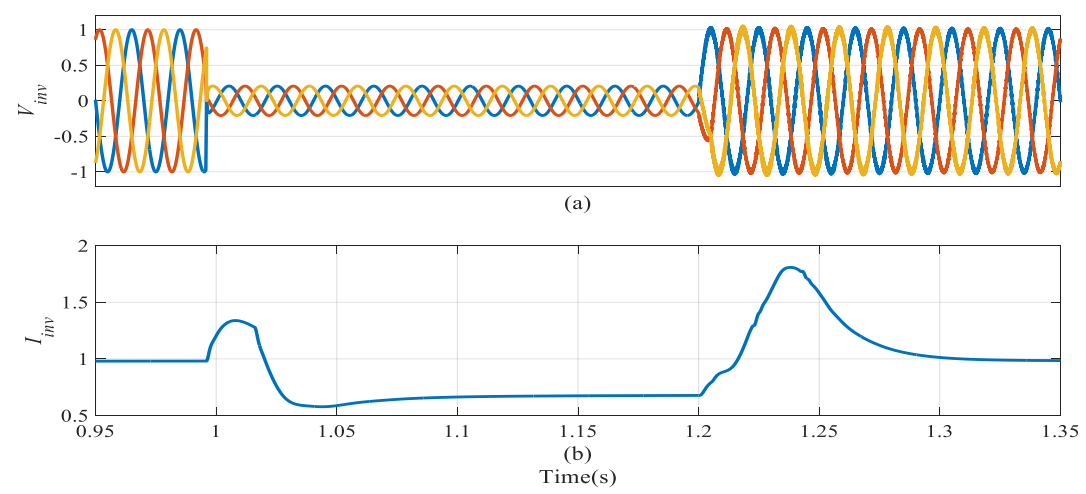

Figure 4.12: 3-phase fault with LVRT applied to [79] (all results in pu) (a) The 3phase voltage. (b) The average of the RMS inverter phase currents
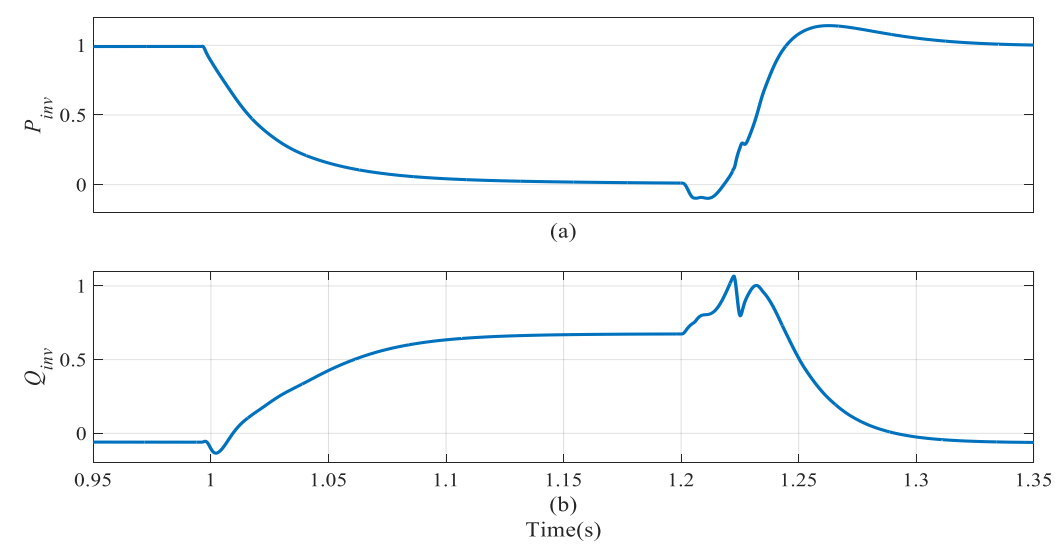

Figure 4.13: 3-phase fault with LVRT applied to [79] (all results in pu) (a) The active power. (b) The reactive power

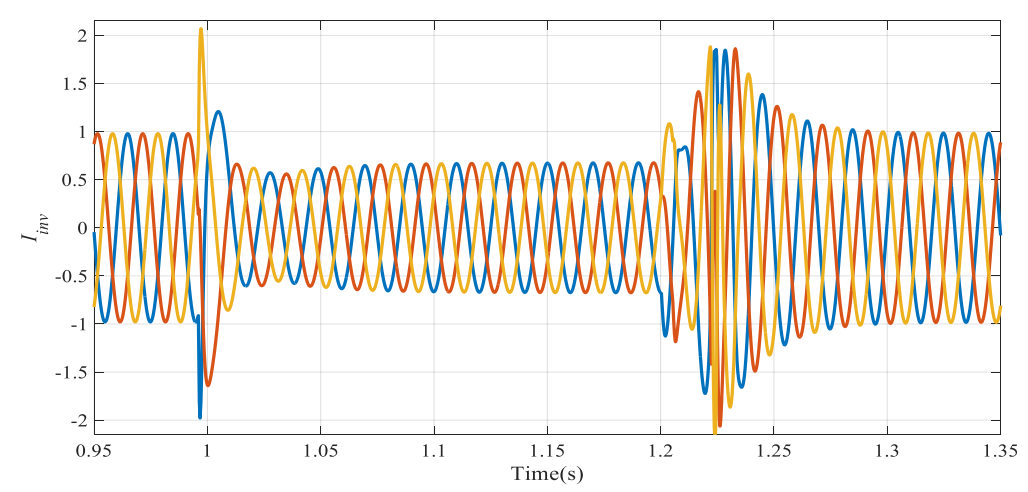

Figure 4.14: The 3-phase inverter currents under 3-phase fault with LVRT applied to [79] (result in pu) 
To demonstrate the effect of the transient reactive power suppression unit, another 3phase fault is simulated, where the voltage sag is 0.6 pu (see Figure 4.15 (a)). Result in Figure 4.15(b) shows the average of the RMS inverter phase currents is limited to 1.5 pu after the fault clearance with proposed method, while, the current is about 1.7 pu after the fault clearance without the proposed method. Similarly, Figure 4.16 (b) shows the reactive power is reduced exactly after the fault is being cleared with the transient reactive power suppression unit. As a result, it can claim that the proposed transient reactive power suppression unit can reduce the inverter current after the fault clearance for a severe 3-phase fault. Investigation for other types of asymmetrical fault is discussed below.

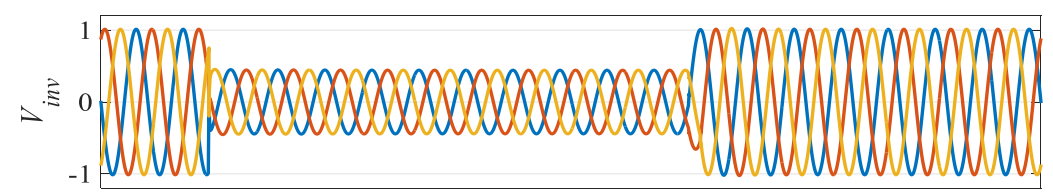

(a)

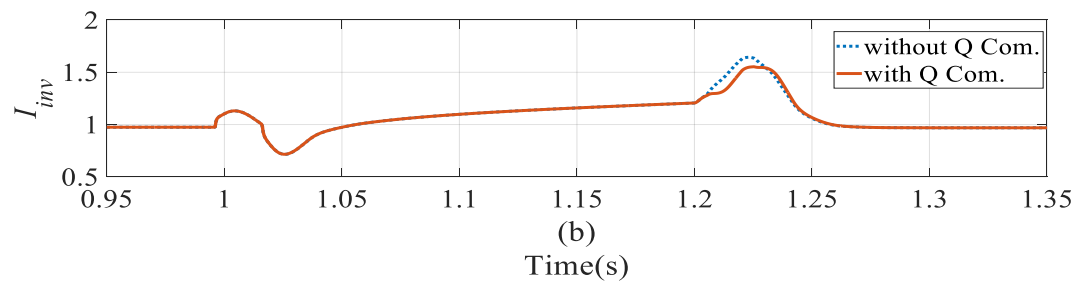

Figure 4.15: Light 3-phase fault (all results in pu) (a) The 3-phase voltage. (b) The average of the RMS inverter phase currents

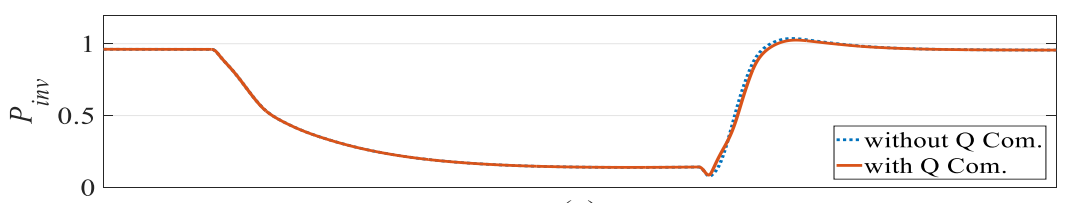

(a)

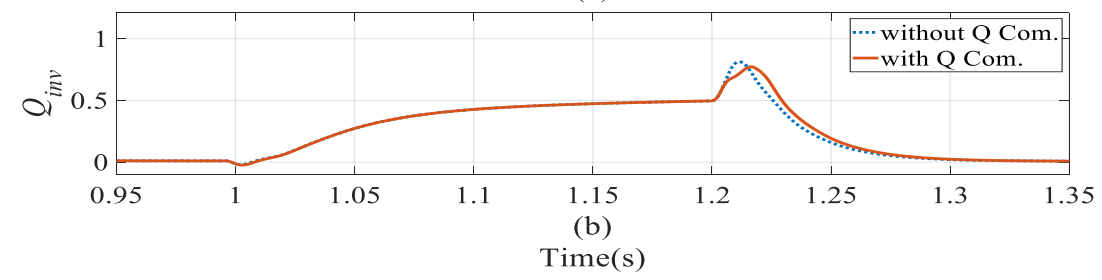

Figure 4.16: Light 3-phase fault (all results in pu) (a) The active power. (b) The reactive power 


\section{(b) DLG fault}

Figure 4.17 and Figure 4.18 show the results for a DLG fault. Figure 4.17 (a) shows the voltage of Phase A and B drops to $0.2 \mathrm{pu}$ at $\mathrm{t}=1 \mathrm{~s}$ and lasts for $0.2 \mathrm{~s}$. From Figure 4.17 (b), it can be observed that the inverter current is limited to 1.25 pu during the fault and about 1.4 pu exactly after the fault clearance. Figure 4.18 (a) shows the inverter active power is reduced to almost 0.3 pu during the fault. The average voltage sag is about $0.54 \mathrm{pu}$, thus, the system is injecting 0.7 pu reactive power during the fault (according to the Chinese grid code), which is shown in Figure 4.18 (b). Since the voltage sag is not as deep as a 3-phase fault, the transient reactive power suppression unit has almost no effect to the results. Figure 4.19 shows that the 3 -phase currents remain sinusoidal during the DLG fault, which proves that the proposed reference currents generation can produce sinusoidal reference currents under an asymmetrical fault. Moreover, the reactive power recovery is $0.05 \mathrm{~s}$ faster than the results shown in Chapter 3 (see Figure 3.22) and the currents recover in two cycles, which is much faster than the results in [82] and the results shown in Figure 3.22 (where the inverter current recover in four cycles).

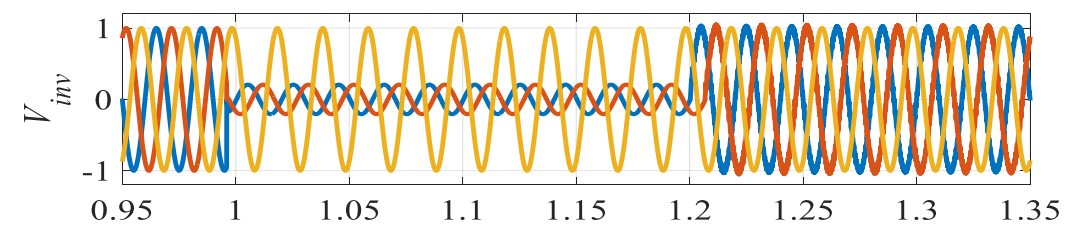

(a)

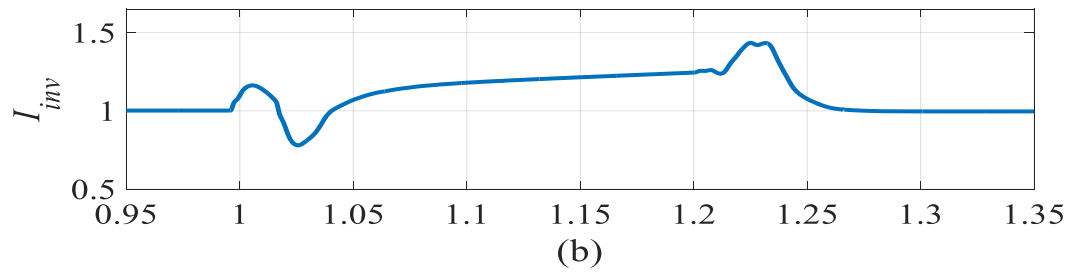

Time (s)

Figure 4.17: DLG fault (all results in pu) (a) The 3-phase voltage. (b) The average of the RMS inverter phase currents 


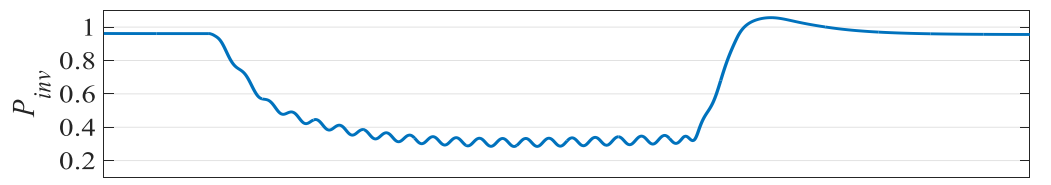

(a)

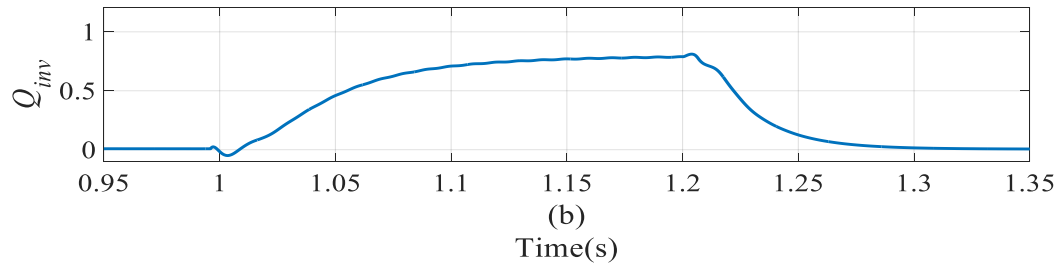

Figure 4.18: DLG fault (all results in pu) (a) The active power (b) The reactive power

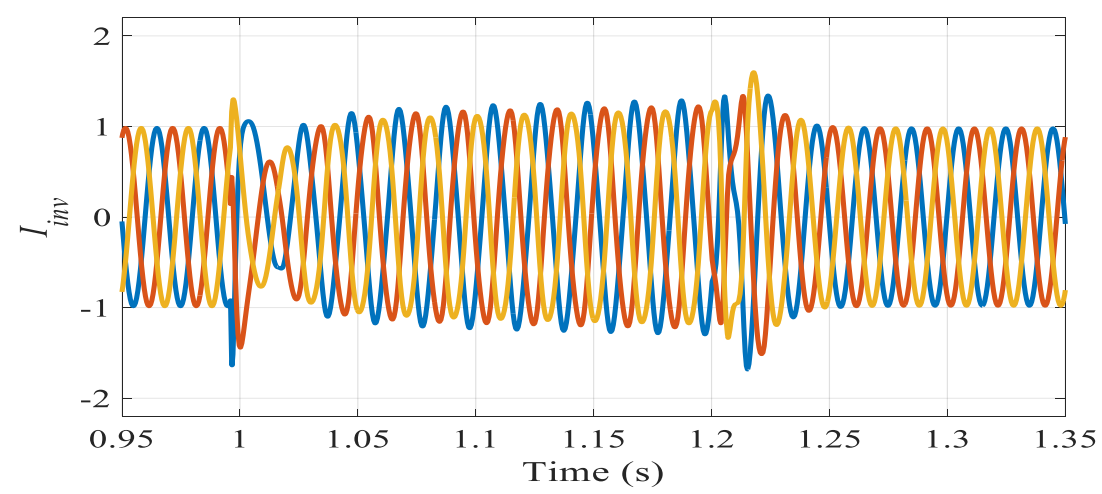

Figure 4.19: The 3-phase inverter currents under DLG fault (result in pu)

\section{(c) DL fault}

Figure 4.20 and Figure 4.21 show the results for a DL fault, which occurs at $\mathrm{t}=1 \mathrm{~s}$ and lasts for $0.2 \mathrm{~s}$. As it can be seen from Figure 4.20 (a), the voltage of phase A and B drop to $0.5 \mathrm{pu}$. The inverter currents are limited to less than $1.5 \mathrm{pu}$ for the whole period of fault and after the fault clearance as shown in Figure 4.20 (b). During the fault, $0.7 \mathrm{pu}$ active power is produced (see Figure 4.21 (a)). Figure 4.21 (b) shows that $0.3 \mathrm{pu}$ reactive power is injected during the fault. The results in [81] show that after the DL fault is cleared, the inverter currents recover in 0.175 s. However, Figure 4.22 shows that the inverter currents recover in less than $0.05 \mathrm{~s}$, which is much faster than the 
results shown in [81] (note that the average value of the 3-phase voltage sag is about 0.3 pu during the fault in [81], which is even not as severe as this scenario).

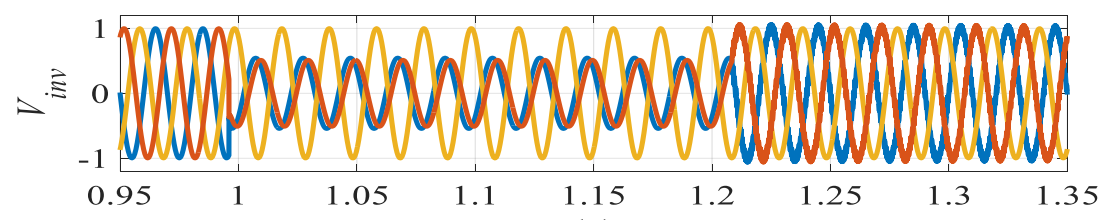

(a)

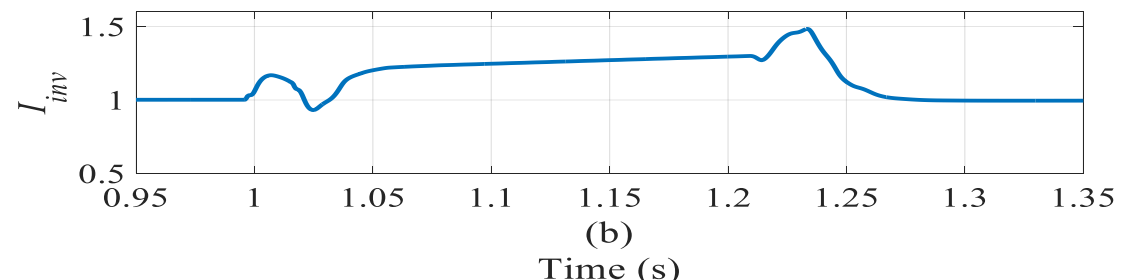

Figure 4.20: DL fault (all results in pu) (a) The 3-phase voltage. (b) The average of the RMS inverter phase currents

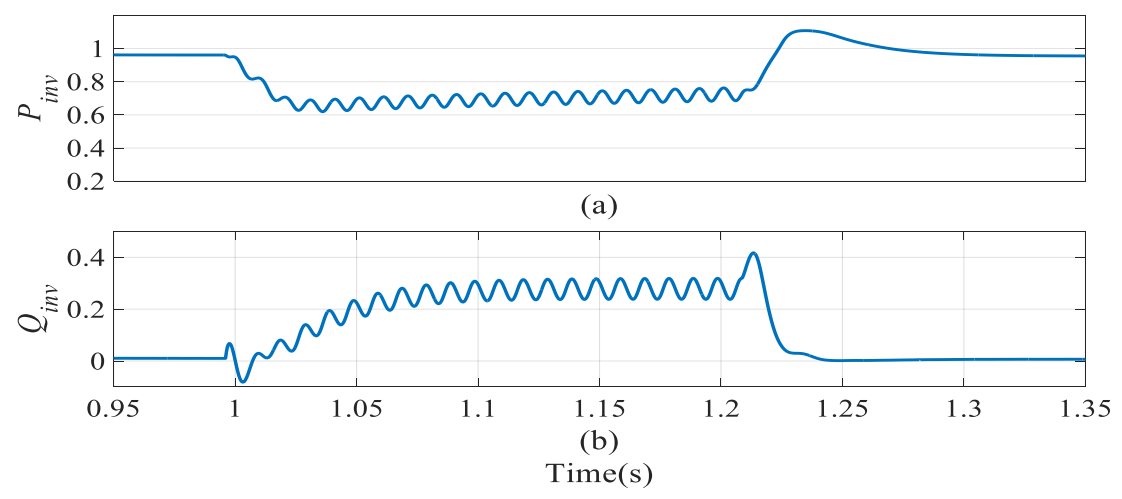

Figure 4.21: DL fault (all results in pu) (a) The active power. (b) The reactive power

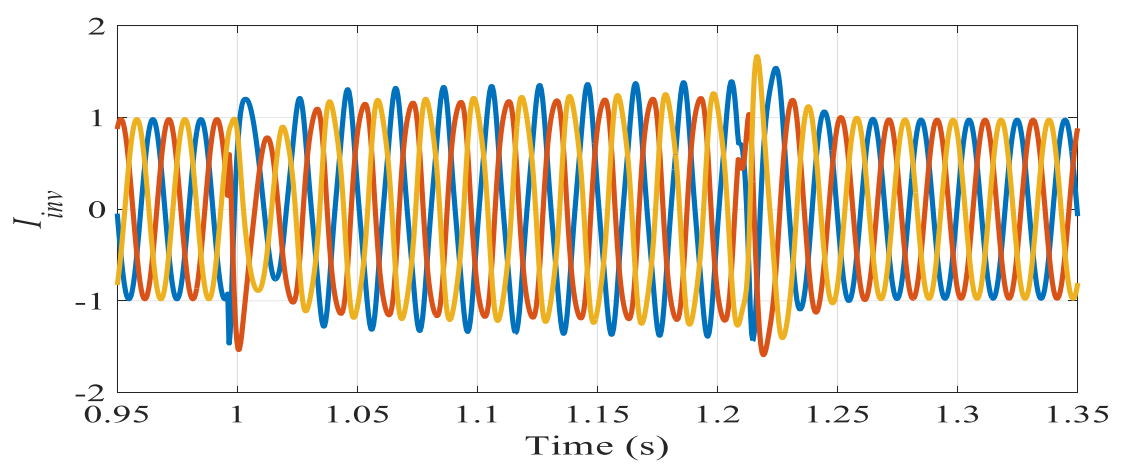

Figure 4.22: The 3-phase inverter currents under DL fault (result in pu) 


\section{(d) SLG fault}

Figure 4.23 and Figure 4.24 show the results for the SLG fault. As shown in Figure 4.23 (a) phase A voltage drops to $0.2 \mathrm{pu}$ at $\mathrm{t}=1 \mathrm{~s}$ and lasts for $0.2 \mathrm{~s}$. Figure 4.23 (b) shows the inverter current is limited to 1.2 pu during the fault and limited under $1.4 \mathrm{pu}$ after the fault clearance. Figure 4.24 (a) shows the active power is reduced to $0.8 \mathrm{pu}$ during the fault and about 0.2 pu reactive power is injected to the grid during the fault according to the Chinese grid code (see Figure 4.24 (b)). Figure 4.25 shows that the proposed method provides sinusoidal currents during the fault and a smooth recovery.

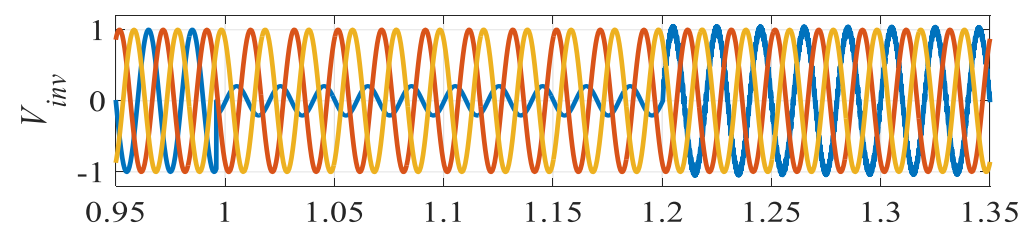

(a)

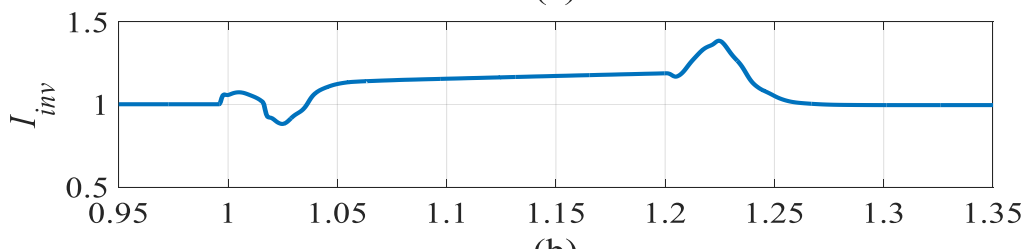

(b)

Time (s)

Figure 4.23: SLG fault (all results in pu) (a) The 3-phase voltage. (b) The average of the RMS inverter phase currents.
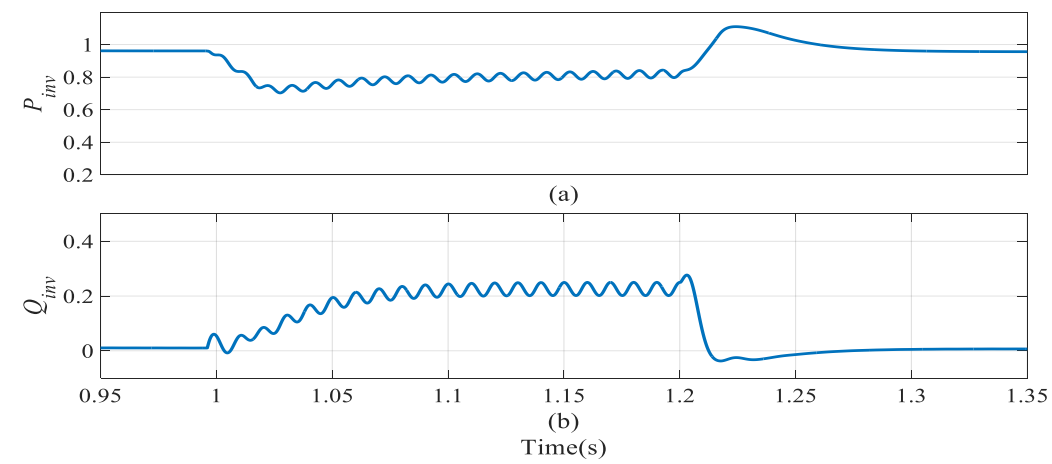

Figure 4.24: SLG fault (all results in pu) (a) The active power. (b) The reactive power 


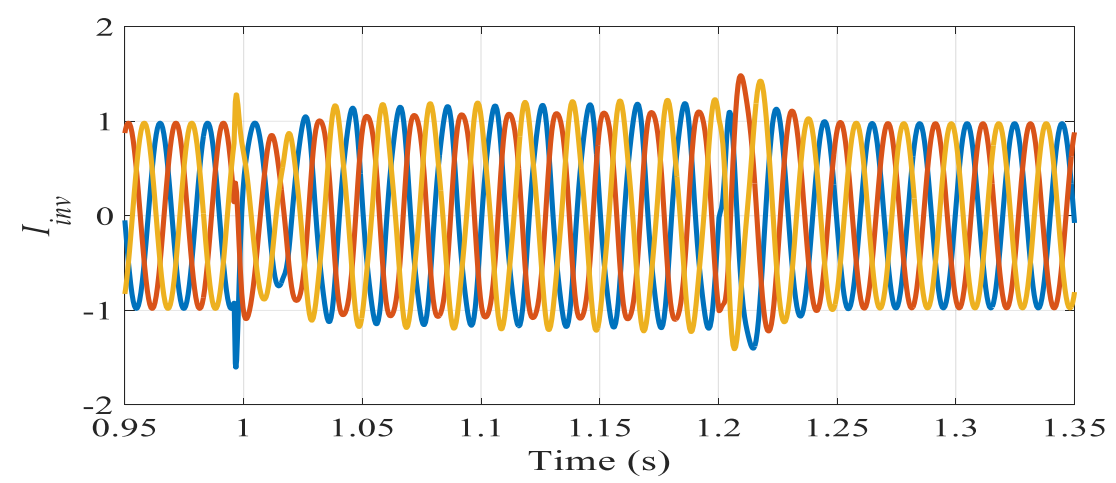

Figure 4.25: The 3-phase inverter currents under SLG fault (result in pu)

The method is also simulated under two-stage PV system, which is the same as [79] to investigates the post-fault recovery performance under an SLG fault. The inverter currents recovery is $0.05 \mathrm{~s}$ faster than the results shown in [79] with the proposed method applied to the reference model (i.e. Figure 4.26 (b)). Also, it can be observed that in [79], the reactive power increases from $25 \mathrm{kVA}$ to $60 \mathrm{kVA}$ after fault clearance. However, Figure 4.24 (b) shows there is no sudden increase of reactive power after fault clearance with the proposed method.
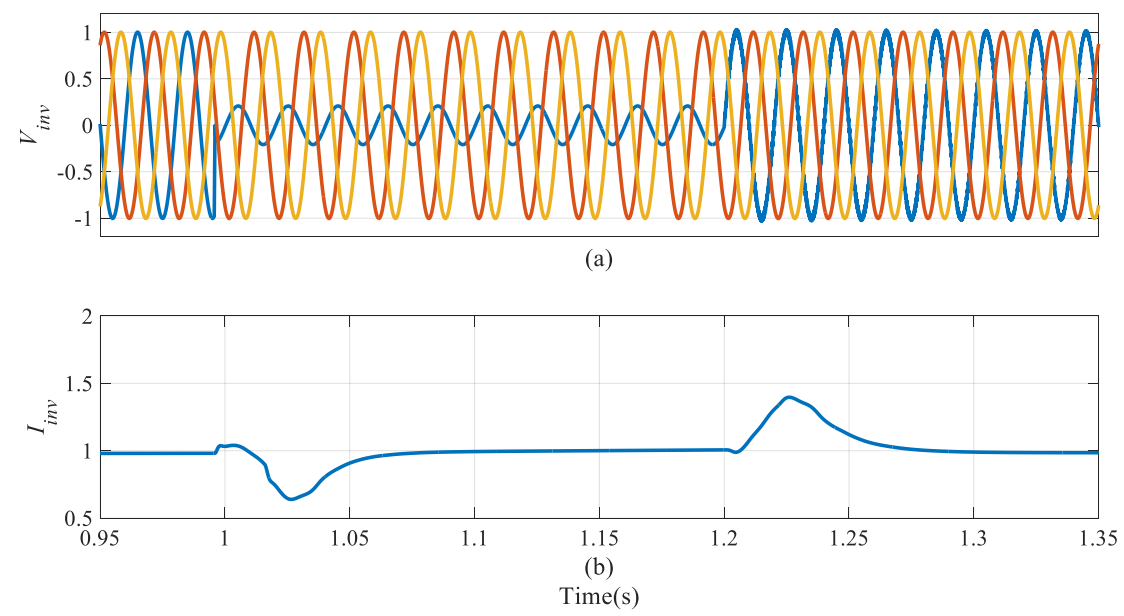

Figure 4.26: SLG fault with LVRT applied to the reference model (all results in pu) (a) The 3-phase voltage. (b) The average of the RMS inverter phase currents 

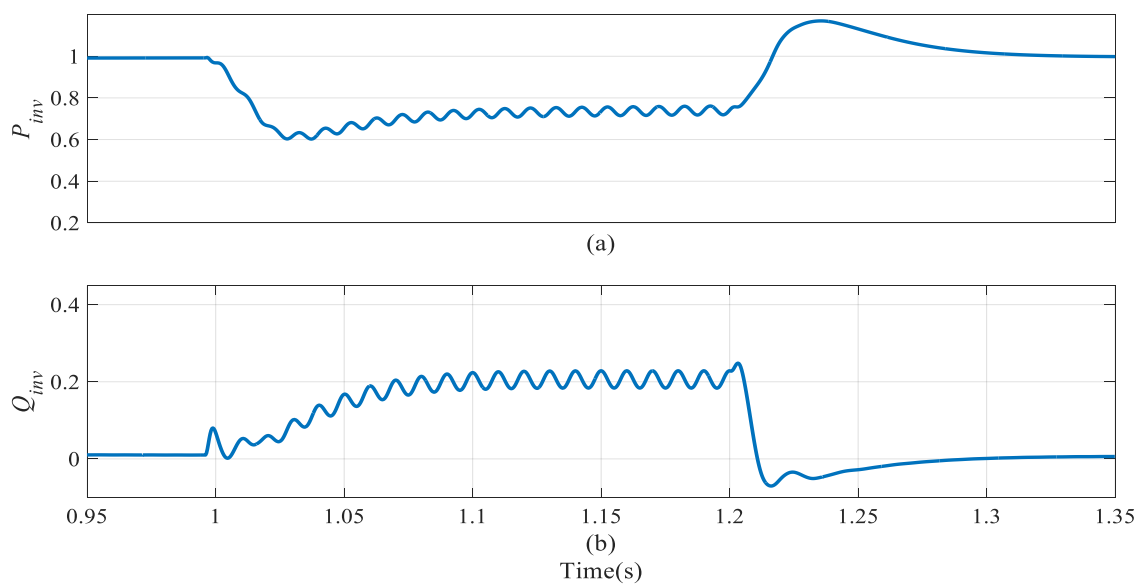

Figure 4.27: SLG fault with LVRT applied to the reference model (all results in pu) (a) The active power. (b) The reactive power

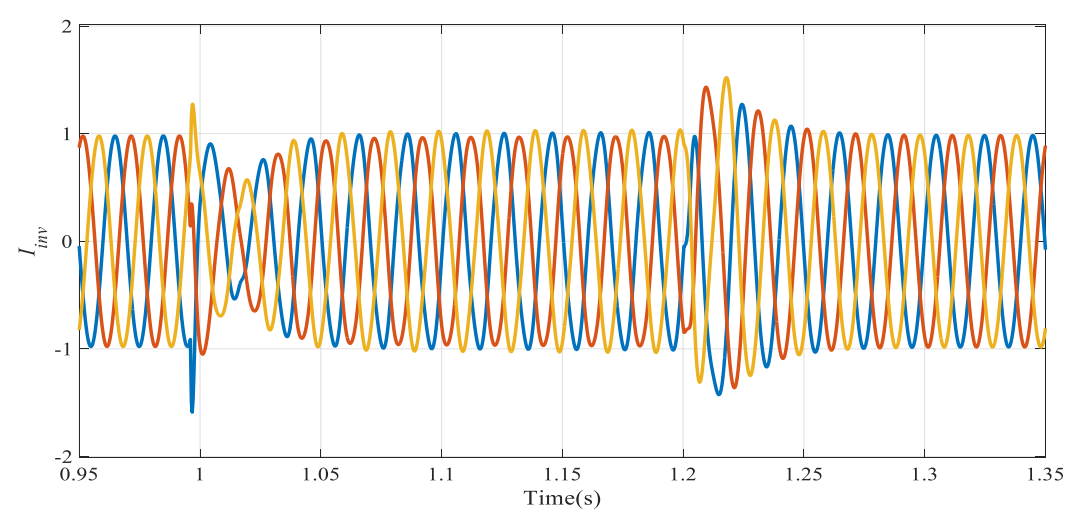

Figure 4.28: The 3-phase inverter currents under SLG fault with LVRT applied to the reference model (result in pu)

\subsection{Summary of chapter 4}

The LVRT strategy for a grid-connected PV system based on the STRF is introduced in this chapter. The proposed method is developed based on the LVRT strategy in the SYRF, which includes the MPF-VCU. However, the proposed LVRT method in this chapter introduces a novel approach for reference current calculation in the STRF and a reactive power injection block, which includes a transient reactive power suppression unit. The proposed inverter reference current calculation block is designed to control the active and reactive power independently during normal operation. The proposed 
method can produce sinusoidal currents during asymmetrical faults and provide fast and smooth recovery after the fault is cleared. With the transient reactive power suppression unit, the proposed method can reduce the inverter current after the fault clearance for a server 3-phase fault. By doing frequency analysis, the PR controller for the LVRT control scheme is designed.

The proposed method is verified in MATLAB/Simulink for normal operation and different types of faults. The simulation results illustrate that the proposed LVRT strategy guarantees excellent system performance for normal operation. For a severe 3-phase fault, the proposed transient reactive power suppression unit can reduce the inverter current and reactive power after the fault is being cleared. Simulation results show that the proposed LVRT strategy in the STRF provides fast and smooth recovery after the fault clearance. Results by applying the proposed method for other different types of asymmetrical faults are compared with state-of-the-art to highlight and demonstrate the improvements caused by the proposed method. In summary, the proposed LVRT strategy in this chapter has the following advantages:

1) The presented simple and effective inverter reference current calculation block works for both normal operation and all types of faults in the STRF.

2) The proposed approach for the inverter reference current calculation can achieve independent control of active and reactive power in the STRF.

3) The proposed transient reactive power suppression unit can reduce the inverter current after the fault clearance for a severe grid fault. 
4) The proposed LVRT method provides fast post-fault recovery. Meanwhile, it ensures the inverter current remains within acceptable limits and produces sinusoidal currents during asymmetrical faults.

5) The proposed method eliminates the needs for a symmetrical components' separation strategy and the STRF to the SYRF transformation. 


\section{Chapter 5 Conclusion and future work}

\subsection{Conclusion}

The main research work of this Ph.D. thesis is the development of the LVRT control strategy for the 3-phase grid-connected PV system in two different reference frames. The exhaustive background study of the 3-phase grid-connected PV system is introduced in Chapter 1 and 2. Chapter 2 also presents the LVRT requirements for the grid-connected PV system and discusses the state-of-the-art on LVRT strategies. In Chapter 3 and 4, two LVRT strategies based on SYRF and STRF are introduced.

Instead of disconnecting the MPPT while the fault is detected, this research work uses the MPF-VCU for the 3-phase grid-connected PV system to achieve LVRT. This is one of the most important contributions of this thesis since other state-of-the-art requires a non-MPPT mode during the fault. With the MPPT operating during the fault, results in an increase in. Physically, the increasing of the DC-link voltage means the capacitor will continue charging during the fault. Thus, a suitable capacitor needs to be chosen, which means the cost of the implementation may be higher; however, considering the fault only lasts for a fraction of a second, the capacity of the capacitor should not be very large. Moreover, because of the operation of the proposed VCU, both PV current and power will reduce, which protects the capacitor from overcharging.

Since the method proposed in Chapter 3 is developed based on SYRF, the PLL plays an important role in this work. It is used to synchronise the grid and the inverter side frequency and contributes to the NRF to SYRF computation. The proposed method highly depends on the PLL; when the PLL is faulty, the control scheme will not be 
working. The similar consequence will appear for the method presented in Chapter 4. Although the method is proposed in STRF to avoid using reference frame translation, the inverter reference current is calculated by the frequency provided by the PLL. This implies that the PLL still plays a very important role in the control scheme of the power system. Although the dependency on the PLL can be considered as a drawback, it is noted that all the commercial PV inverters use PLLs to synchronise with the grid even during the normal operation. Therefore, if the PLL is faulty, it must be detected and fixed in the normal operation.

Simulation results show the proposed LVRT control strategy based on both SYRF and STRF can be used for both symmetrical and asymmetrical faults. The simulation results also demonstrate that the proposed MPF-VCU reduces the double grid frequency oscillation. The results shown in Chapter 4 shows that the post-fault recovery is faster than other state-of-the-art, which means a suitable designed with larger cut-off frequency PR controller can be considered in the current controller when considering faults.

\subsection{Potential Future Work}

The following imminent recommendations at this stage are proposed:

1) The test of the proposed control schemes for the LVRT connected to a weak grid (low inertia and $\mathrm{X} / \mathrm{R}$ ratio grid) can be undertaken. With the penetration of the low inertia power sources connected to the grid, i.e. PV system, wind farms and other inverter-based power generation, the grid will become weaker. A weak grid is not as stable as a strong grid. It can be affected by the voltage and frequency fluctuations, such as faults. Thus, the performances of the LVRT 
strategies for the PV system connecting to the weak grid or synchronous generator are valuable. The results will help to study the LVRT strategies for the future trend.

2) The current work uses the average model for the inverter; future work could consider a switching model for the inverter. It is worth of using switching model for the inverter since the switching frequency of the PWM may affect the results of the LVRT.

3) Since the control of PMSG or DFIG is different from the PV system, it is worth trying to find if the proposed method is still working for a wind turbine system. In addition, proposing an LVRT strategy for a hybrid system may be a challenge. Thus, duplication of the proposed method to DFIG or PMSG system or even a hybrid system, i.e. one PV system and one wind turbine connected to the bus could be considered.

4) Since the condition of having an experimental work for LVRT strategy is very strict, the proposed LVRT methods could be tested on the IEEE 14-bus, which helps to practically implement the methods in the future. However, the experimental work is the best way to validate the proposed method if possible. 


\section{REFERENCES}

[1] $\mathrm{CO}_{2}$ emissions from fuel combustion Highlights", International Energy Agency, 2019.

[2] International Energy Agency, "World Energy Outlook", IEA, Beijing, 2017.

[3] Department for Business, Energy \& Industrial Strategy, "UK Energy Statistics, Q1 2019", 2019.

[4] International Energy Agency, "Next Generation Wind and Solar Power", IEA, Paris, 2016.

[5] V. Bosetti, M. Catenacci, G. Fiorese, and E. Verdolini, "The future prospect of PV and CSP solar technologies: An expert elicitation survey," Energy Policy, vol. 49, pp. 308-317, 2012, doi: 10.1016/j.enpol.2012.06.024.

[6] D. W. H. Cai, S. Adlakha, S. H. Low, P. De Martini, and K. Mani Chandy, “Impact of residential PV adoption on Retail Electricity Rates,” Energy Policy, vol. 62 , pp. 830-843, 2013, doi: 10.1016/j.enpol.2013.07.009.

[7] A. Luque, "Will we exceed 50\% efficiency in photovoltaics?," Journal of Applied Physics, vol. 110, no. 3. 2011, doi: 10.1063/1.3600702.

[8] "Solar PV - Tracking Power - Analysis - IEA", IEA, 2020. [Online]. Available: https://www.iea.org/reports/tracking-power-2019/solar-pv\#abstract. [Accessed: 04- Feb- 2020].

[9] M. Bollen and F. Hassan, Integration of Distributed Generation in the Power System. Wiley, 2011.

[10] D. Halliday, R. Resnick, and J. Walker, Fundamentals of Physics Extended 9th Edition, 9th ed. Wiley, 2010. 
[11] R. a. Serway and J. W. Jewett, Physics for Scientists and Engineers with Modern Physic, 7th ed. Cengage Learning, 2008.

[12] G. M. Masters, Renewable and Efficient Electric Power Systems, 2nd ed. Wiley, 2013.

[13] W. EL-BASIT, "Mathematical Model for Photovoltaic Cells," Leonardo Journal of Sciences, no. 23, pp. 13-28, 2013.

[14] C. S. SOLANKI, SOLAR PHOTOVOLTAIC TECHNOLOGY AND SYSTEMS: A Manual for Technicians, Trainers and Engineers. PHI Learning, 2013.

[15] N. Kumar, I. Hussain, B. Singh, and B. K. Panigrahi, "Framework of Maximum Power Extraction from Solar PV Panel Using Self Predictive Perturb and Observe Algorithm," IEEE Transactions on Sustainable Energy, vol. 9, no. 2, pp. 895-903, 2018, doi: 10.1109/TSTE.2017.2764266.

[16] K. L. Lian, J. H. Jhang, and I. S. Tian, “A maximum power point tracking method based on perturb-and-observe combined with particle swarm optimization," IEEE Journal of Photovoltaics, vol. 4, no. 2, pp. 626-633, 2014, doi: 10.1109/JPHOTOV.2013.2297513.

[17] D. M. K. Schofield, M. P. Foster, and D. A. Stone, "Low-cost solar emulator for evaluation of maximum power point tracking methods," Electronics Letters, vol. 47, no. 3, pp. 208-209, 2011, doi: 10.1049/el.2010.2930.

[18] T. Esram and P. L. Chapman, "Comparison of photovoltaic array maximum power point tracking techniques," IEEE Transactions on Energy Conversion, vol. 22, no. 2 , pp. 439-449, 2007, doi: 10.1109/TEC.2006.874230.

[19] T. P. Sahu and T. V. Dixit, "Modelling and analysis of perturb and observe and incremental conductance MPPT algorithm for PV array using Cuk converter," 
2014 IEEE Students' Conference on Electrical, Electronics and Computer Science, SCEECS 2014 2014, doi: 10.1109/SCEECS.2014.6804468.

[20] J. Ahmed and Z. Salam, “An improved perturb and observe (P\&O) maximum power point tracking (MPPT) algorithm for higher efficiency," Applied Energy, vol. 150, pp. 97-108, 2015, doi: 10.1016/j.apenergy.2015.04.006.

[21] D. B. Talbot, "A Review of PLL Fundamentals," in Frequency Acquisition Techniques for Phase Locked Loops, 2012, pp. 3-15, doi: 10.1002/9781118383285.ch2.

[22] S. Gao and M. Barnes, "Phase-locked loop for AC systems: Analyses and comparisons," in IET Conference Publications, 2012, vol. 2012, no. 592 CP, doi: 10.1049/cp.2012.0199.

[23] S. K. Chung, "Phase-locked loop for grid-connected three-phase power conversion systems," IEE Proceedings: Electric Power Applications, vol. 147, no. 3, pp. 213-219, 2000, doi: 10.1049/ip-epa:20000328.

[24] H. E. P. de Souza, F. Bradaschia, F. A. S. Neves, M. C. Cavalcanti, G. M. S. Azevedo, and J. P. de Arruda, "A method for extracting the fundamental-frequency positive-sequence voltage vector based on simple mathematical transformations," IEEE Transactions on Industrial Electronics, vol. 56, no. 5, pp. 1539-1547, 2009, doi: 10.1109/TIE.2008.2009525.

[25] Q. Huang and K. Rajashekara, “An Improved Delayed Signal Cancellation PLL for Fast Grid Synchronization under Distorted and Unbalanced Grid Condition," IEEE Transactions on Industry Applications, vol. 53, no. 5, pp. 49854997, 2017, doi: 10.1109/TIA.2017.2700282. 
[26] H. Awad, J. Svensson, and M. J. Bollen, "Tuning software phase-locked loop for series-connected converters," IEEE Transactions on Power Delivery, vol. 20, no. 1, pp. 300-308, 2005, doi: 10.1109/TPWRD.2004.837823.

[27] R. Cardenas, M. Diaz, F. Rojas, and J. Clare, "Fast Convergence Delayed Signal Cancellation Method for Sequence Component Separation," IEEE Transactions on Power Delivery, vol. 30, no. 4, pp. 2055-2057, 2015, doi: 10.1109/TPWRD.2014.2373038.

[28] J. Svensson, M. Bongiorno, and A. Sannino, "Practical implementation of delayed signal cancellation method for phase-sequence separation," IEEE Transactions on Power Delivery, vol. 22, no. 1, pp. 18-26, 2007, doi: 10.1109/TPWRD.2006.881469.

[29] "Grid Code | National Grid ESO", Nationalgrideso.com, 2020. [Online]. Available: https://www.nationalgrideso.com/codes/grid-code. [Accessed: 11- Feb2020].

[30] "The Grid Code: Rules for the power network", Next Kraftwerke .com, 2020. [Online]. Available: https://www.next-kraftwerke.com/knowledge/what-isthe-grid-code. [Accessed: 11- Feb- 2020].

[31] National Grid Electricity Transmission plc, "The Grid Code", 2019.

[32] "IEC Glossary", Std.iec.ch, 2020. [Online]. Available: http://std.iec.ch/terms/terms.nsf/0/DB2CF1567097E866C1257E29002C35B3 ?OpenDocument. [Accessed: 11- Feb- 2020].

[33] National Grid, "GC0062-Fault Ride Through."

[34] F. Franco, "Low Voltage Ride-through for Photovoltaic System Using Finite Control-Set Model Predictive Control", Ph.D., Florida State University, 2017. 
[35] National Grid ESO, "Stability Pathfinder Technical Performance and Assessment Criteria (Attachment 1))."

[36] Y. Jia et al., "Powering China's sustainable development with renewable energies: Current status and future trend," Electric Power Components and Systems, vol. 43, no. 8-10, pp. 1193-1204, 2015, doi: 10.1080/15325008.2015.1009585.

[37] Y. Yang, H. Wang, and F. Blaabjerg, "Reactive power injection strategies for single-phase photovoltaic systems considering grid requirements," in IEEE Transactions on Industry Applications, 2014, vol. 50, no. 6, pp. 4065-4076, doi: 10.1109/TIA.2014.2346692.

[38] D. Maxwell, "Parts of Northern Ireland's electricity grid overloaded," BBC News, Nov. 13, 2013. [Online]. Available: http://www.bbc.co.uk/

[39] E. J. Coster, J. M. A. Myrzik, B. Kruimer, and W. L. Kling, "Integration issues of distributed generation in distribution grids," Proceedings of the IEEE, vol. 99, no. 1, pp. 28-39, 2011, doi: 10.1109/JPROC.2010.2052776.

[40] H. Gaztanaga, J. Landaluze, I. Etxeberria-Otadui, A. Padros, I. Berazaluce, and D. Cuesta, "Enhanced experimental PV plant grid-integration with a MW Lithium-Ion energy storage system," in 2013 IEEE Energy Conversion Congress and Exposition, ECCE 2013, 2013, pp. 1324-1329, doi: 10.1109/ECCE.2013.6646858.

[41] Forum Netztechnik Netzbetrieb, Power generation systems connected to the low-voltage distribution network: Technical minimum requirements for the connection to and parallel operation with low-voltage distribution networks. VDE Verlag, 2011. 
[42] Comitato Elettrotecnico Italiano, Reference Technical Rules for Connecting Users to the Active and Passive LV Distribution Companies of Electricity, CEI 0-21, Dec. 2011.

[43] Y. Chen, A. Luo, Z. Shuai, and S. Xie, "Robust predictive dual-loop control strategy with reactive power compensation for single-phase grid-connected distributed generation system," IET Power Electronics, vol. 6, no. 7, pp. 13201328, 2013, doi: 10.1049/iet-pel.2013.0011.

[44] A. Cagnano, E. De Tuglie, M. Liserre, and R. A. Mastromauro, "Online optimal reactive power control strategy of PV inverters," IEEE Transactions on Industrial Electronics, vol. 58, no. 10, pp. 4549-4558, 2011, doi: 10.1109/TIE.2011.2116757.

[45] C. T. Lee, C. W. Hsu, and P. T. Cheng, "A low-voltage ride-through technique for grid-connected converters of distributed energy resources," IEEE Transactions on Industry Applications, vol. 47, no. 4, pp. 1821-1832, 2011, doi: 10.1109/TIA.2011.2155016.

[46] R. Meyer, A. Zlotnik, and A. Mertens, "Fault ride through control of mediumvoltage converters with LCL filter in distributed generation systems," in 2013 IEEE Energy Conversion Congress and Exposition, ECCE 2013, 2013, pp. 1954-1961, doi: 10.1109/ECCE.2013.6646947.

[47] G. Arnold, Challenges of Integrating Multi-GW Solar Power Into the German Distribution Grids, Aug. 2011. [Online]. Available: http://www. iwes.fraunhofer.de/

[48] Z. Shao, X. Zhang, F. Wang, R. Cao, and H. Ni, "Analysis and Control of Neutral-Point Voltage for Transformerless Three-Level PV Inverter in LVRT 
Operation," IEEE Transactions on Power Electronics, vol. 32, no. 3, pp. 23472359, 2017, doi: 10.1109/TPEL.2016.2565640.

[49] R. M. Monteiro Pereira, A. J. C. Pereira, C. M. Ferreira, and F. P. Maciel Barbosa, "Influence of crowbar and chopper protection on DFIG during low voltage ride through," Energies, vol. 11, no. 4, 2018, doi: 10.3390/en11040885.

[50] E. Afshari et al., "Control Strategy for Three-Phase Grid-Connected PV Inverters Enabling Current Limitation under Unbalanced Faults," IEEE Transactions on Industrial Electronics, vol. 64, no. 11, pp. 8908-8918, 2017, doi: 10.1109/TIE.2017.2733481

[51] E. K. Mohammedsaeed and K. Jia, "Comparison of some low voltage ridethrough strategies," in Proceedings IECON 2017 - 43rd Annual Conference of the IEEE Industrial Electronics Society, 2017, vol. 2017-Janua, pp. 152-157, doi: 10.1109/IECON.2017.8216030.

[52] S. R. Mohamed, P. A. Jeyanthy, D. Devaraj, M. H. Shwehdi, and A. Aldalbahi, "DC-Link voltage control of a grid-connected solar photovoltaic system for fault ride-through capability enhancement," Applied Sciences (Switzerland), vol. 9, no. 5, 2019, doi: 10.3390/app9050952.

[53] Y. Bak, J. S. Lee, and K. B. Lee, "Low-voltage ride-through control strategy for a grid-connected energy storage system," Applied Sciences (Switzerland), vol. 8 , no. 1, 2018, doi: 10.3390/app8010057.

[54] L. Zhou, S. Yan, G. Wang, and M. Wu, "A rapid voltage detection method for low voltage ride through under distorted voltage conditions," in 2015 IEEE International Conference on Mechatronics and Automation, ICMA 2015, 2015, pp. 54-59, doi: 10.1109/ICMA.2015.7237456. 
[55] A. Q. Al-Shetwi, M. Z. Sujod, and F. Blaabjerg, "Low voltage ride-through capability control for single-stage inverter-based grid-connected photovoltaic power plant," Solar Energy, vol. 159, pp. 665-681, 2018, doi: 10.1016/j.solener.2017.11.027.

[56] Z. C. Zou, J. C. Liao, Y. Lei, Z. L. Mu, and X. Y. Xiao, "Postfault LVRT Performance Enhancement of DFIG Using a Stage-Controlled SSFCL-RSDR," IEEE Transactions on Applied Superconductivity, vol. 29, no. 2, 2019, doi: 10.1109/TASC.2019.2892821.

[57] R. Ntare, N. H. Abbasy, and K. H. M. Youssef, "Low Voltage Ride through Control Capability of a Large Grid Connected PV System Combining DC Chopper and Current Limiting Techniques," Journal of Power and Energy Engineering, vol. 07, no. 01, pp. 62-79, 2019, doi: 10.4236/jpee.2019.71004.

[58] X. Wang, Z. Yang, B. Fan, and W. Xu, "Control strategy of three-phase photovoltaic inverter under low-voltage ride-through condition," Mathematical Problems in Engineering, vol. 2015, 2015, doi: 10.1155/2015/790584.

[59] H. Khan, S. J. Chacko, B. G. Fernandes, and A. Kulkarni, “An integrated controller to perform LVRT operation in PV systems connected to a LV grid during balanced and unbalanced faults," in 2017 IEEE 3rd International Future Energy Electronics Conference and ECCE Asia, IFEEC - ECCE Asia 2017, 2017, pp. 2002-2007, doi: 10.1109/IFEEC.2017.7992358.

[60] I. Sadeghkhani, M. E. H. Golshan, J. M. Guerrero, and A. Mehrizi-Sani, “A Current Limiting Strategy to Improve Fault Ride-Through of Inverter Interfaced Autonomous Microgrids," IEEE Transactions on Smart Grid, vol. 8, no. 5, pp. 2138-2148, 2017, doi: 10.1109/TSG.2016.2517201. 
[61] Navitron.org.uk, "aurora power one installation manual," 2019. https://www.navitron.org.uk/backoffice/lanotattachments_download/file/id/114/store/1/aurora_power_one_installation_manual_pvi-50006000-outd-s.pdf [accessed Aug- 20- 2019].

[62] S. Alepuz et al., "Control strategies based on symmetrical components for gridconnected converters under voltage dips," IEEE Transactions on Industrial Electronics, vol. 56, no. 6, pp. 2162-2173, 2009, doi: 10.1109/TIE.2009.2017102.

[63] R. Teodorescu, M. Liserre, and P. Rodríguez, Grid Converters for Photovoltaic and Wind Power Systems, Wiley, 2010, doi: 10.1002/9780470667057

[64] A. Camacho, M. Castilla, J. Miret, A. Borrell, and L. G. De Vicuña, “Active and reactive power strategies with peak current limitation for distributed generation inverters during unbalanced grid faults," IEEE Transactions on Industrial Electronics, vol. 62, no. 3, pp. 1515-1525, 2015, doi: 10.1109/TIE.2014.2347266.

[65] R. Majumder, "Reactive power compensation in single-phase operation of microgrid," IEEE Transactions on Industrial Electronics, vol. 60, no. 4, pp. 1403-1416, 2013, doi: 10.1109/TIE.2012.2193860.

[66] K. Ma and F. Blaabjerg, "Modulation methods for neutral-point-clamped wind power converter achieving loss and thermal redistribution under low-voltage ride-through," IEEE Transactions on Industrial Electronics, vol. 61, no. 2, pp. 835-845, 2014, doi: 10.1109/TIE.2013.2254099. 
[67] S. S. Bhangale and N. Patel, "Design of LVRT capability for grid connected PV system," in 2017 International Conference on Intelligent Computing, Instrumentation and Control Technologies, ICICICT 2017, 2018, vol. 2018Janua, pp. 1625-1630, doi: 10.1109/ICICICT1.2017.8342814.

[68] E. M. Khawla, C. Dhia, and S. Lassaad, "LVRT control strategy for threephase grid connected PV systems," in International Conference on Green Energy and Conversion Systems, GECS 2017, 2017, pp. 1-7, doi: 10.1109/GECS.2017.8066237.

[69] M. Mohseni and S. M. Islam, "Review of international grid codes for wind power integration: Diversity, technology and a case for global standard," $R e$ newable and Sustainable Energy Reviews, vol. 16, no. 6. pp. 3876-3890, 2012, doi: 10.1016/j.rser.2012.03.039.

[70] A. Yazdani and R. Iravani, Voltage-Sourced Converters in Power Systems, Wiley, 2010.

[71] A. Uphues, K. Notzold, R. Wegener, and S. Soter, "Frequency adaptive PRcontroller for compensation of current harmonics," in IECON Proceedings (Industrial Electronics Conference), 2014, pp. 2103-2108, doi: 10.1109/IECON.2014.7048792.

[72] M. E. Meral and D. Çelik, "Comparison of SRF/PI- and STRF/PR-based power controllers for grid-tied distributed generation systems," Electrical Engineering, vol. 100, no. 2, pp. 633-643, 2018, doi: 10.1007/s00202-017-0530-6. 
[73] R. Teodorescu, F. Blaabjerg, M. Liserre, and P. C. Loh, "Proportional-resonant controllers and filters for grid-connected voltage-source converters," IEE Proceedings: Electric Power Applications, vol. 153, no. 5, pp. 750-762, 2006, doi: 10.1049/ip-epa:20060008.

[74] H. M. Hasanien, “An Adaptive Control Strategy for Low Voltage Ride Through Capability Enhancement of Grid-Connected Photovoltaic Power Plants," IEEE Transactions on Power Systems, vol. 31, no. 4, pp. 3230-3237, 2016, doi: 10.1109/TPWRS.2015.2466618.

[75] Y. Geng, K. Yang, Z. Lai, P. Zheng, H. Liu, and R. Deng, “A novel low voltage ride through control method for current source grid-connected photovoltaic inverters," IEEE Access, vol. 7, pp. 51735-51748, 2019, doi: 10.1109/ACCESS.2019.2911477.

[76] Z. Shao, X. Zhang, F. Wang, R. Cao, and H. Ni, "Analysis and Control of Neutral-Point Voltage for Transformerless Three-Level PV Inverter in LVRT Operation," IEEE Transactions on Power Electronics, vol. 32, no. 3, pp. 23472359, 2017, doi: 10.1109/TPEL.2016.2565640.

[77] C. Y. Tang, Y. T. Chen, and Y. M. Chen, "PV Power System With Multi-Mode Operation and Low-Voltage Ride-Through Capability," IEEE Transactions on Industrial Electronics, vol. 62, no. 12, pp. 7524-7533, 2015, doi: 10.1109/TIE.2015.2449777.

[78] Y. Yang, F. Blaabjerg, and H. Wang, "Low-voltage ride-through of singlephase transformerless photovoltaic inverters," IEEE Transactions on Industry Applications, vol. 50, no. 3, pp. 1942-1952, 2014, doi: 10.1109/TIA.2013.2282966. 
[79] A. Mojallal and S. Lotfifard, "Enhancement of Grid Connected PV Arrays Fault Ride Through and Post Fault Recovery Performance," IEEE Transactions on Smart Grid, vol. 10, no. 1, pp. 546-555, 2019, doi: 10.1109/TSG.2017.2748023.

[80] J. Wang, J. Liang, C. Wang, and X. Dong, "Circulating Current Suppression for MMC-HVDC under Unbalanced Grid Conditions," IEEE Transactions on Industry Applications, vol. 53, no. 4, pp. 3250-3259, 2017, doi: 10.1109/TIA.2017.2675992.

[81] K. Shi, W. Song, P. Xu, R. Liu, Z. Fang, and Y. Ji, "Low-Voltage RideThrough Control Strategy for a Virtual Synchronous Generator Based on Smooth Switching," IEEE Access, vol. 6, pp. 2703-2711, 2017, doi: 10.1109/ACCESS.2017.2784846.

[82] P. Nandi and R. Adda, "Three-Phase Grid-Connected Photovoltaic Switched Boost Inverter with Low-Voltage Ride-Through Capability," in Proceedings of 2018 IEEE International Conference on Power Electronics, Drives and Energy Systems, PEDES 2018, 2018, pp. 1-6, doi: 10.1109/PEDES.2018.8707858.

[83] S.S. Hu, Automatic Control Theory. 2017.

[84] P. Kundur, Power system stability and control, McGraw-Hill Education, 1993.

[85] R. K. Brayton and J. K. Moser, 'A Theory of Nonlinear Networks I', Quarterly of Applied Mathematics, vol. 22, no. 1, pp. 1-33, 1964, doi: 10.1090/qam/169746 
[86] R. K. Brayton and J. K. Moser, “A theory of nonlinear networks. II,” Quarterly of Applied Mathematics, vol. 22, no. 2, pp. 81-104, 1964, doi: 10.1090/qam/169747.

[87] L. Weiss, W. Mathis, and L. Trajkovic, “A generalization of brayton-moser's mixed potential function," IEEE Transactions on Circuits and Systems I: Fundamental Theory and Applications, vol. 45, no. 4, pp. 423-427, 1998, doi: 10.1109/81.669065.

[88] X. Liu, Y. Zhou, W. Zhang, and S. Ma, "Stability criteria for constant power loads with multistage LC filters," IEEE Transactions on Vehicular Technology, vol. 60, no. 5, pp. 2042-2049, 2011, doi: 10.1109/TVT.2011.2148133.

[89] M. Huang, Y. Peng, C. K. Tse, Y. Liu, J. Sun, and X. Zha, "Bifurcation and Large-Signal Stability Analysis of Three-Phase Voltage Source Converter under Grid Voltage Dips," in IEEE Transactions on Power Electronics, 2017, vol. 32, no. 11, pp. 8868-8879, doi: 10.1109/TPEL.2017.2648119.

[90] T. Yoshikawa, Foundations of Robotics: Analysis and Control, The MIT press, 2003

[91] Q. C. Zhong and T. Hornik, Control of Power Inverters in Renewable Energy and Smart Grid Integration, Wiley-IEEE press, 2012.

[92] National Grid ESO Stability Pathfinder Technical Request for Information, Available: https://www.nationalgrideso.com/insights/system-operabilityframework-sof. [Accessed: 05- Nov- 2019].

[93] National Grid ESO Stability Path finder RFI Technical Performance and Assessment Criteria, 2019 Available: https://www.nationalgrideso.com/insights/system-operability-framework-sof. [Accessed: 05- Nov- 2019]. 
References

[94] "10-kW, Three-Level, Three-Phase Grid Tie Inverter Reference Design for Solar String $\quad$ Inverters", $2018 . \quad$ Available: http://www.ti.com/lit/ug/tidue53a/tidue53a.pdf. [Accessed: 26- Mar- 2020].

[95] "Voltage Source Inverter Reference Design", 2015. Available: http://www.ti.com/lit/ug/tiduay6d/tiduay6d.pdf. [Accessed: 26- Mar- 2020]. 
Appendix-1

Table A-1 PV module parameters

\begin{tabular}{|c|c|c|}
\hline Parameter & Definition & Value \\
\hline$\overline{G_{r}}$ & Reference Irradiation & $1000 \mathrm{~W} / \mathrm{m}^{2}$ \\
\hline $\operatorname{Tr}$ & Reference Temperature & $25^{0} \mathrm{C}$ \\
\hline$V_{o c}$ & Open-circuit voltage at reference conditions & $23 \mathrm{~V}$ \\
\hline$\overline{I_{s c}}$ & Short-circuit current at reference conditions & $2 \mathrm{~A}$ \\
\hline$P_{\max }$ & Maximum power at reference conditions & $36 \mathrm{~W}$ \\
\hline$C_{T}$ & Temperature coefficient of photocurrent & $1.7 \times 10^{-3} \mathrm{~A} / \mathrm{K}$ \\
\hline$I_{0}$ & Saturation current at reference temperature & $1.2 \times 10^{-7} \mathrm{~A}$ \\
\hline$\eta$ & Ideality factor & 1.47 \\
\hline$k$ & Plank's constant & $1.38 \times 10^{-23} \mathrm{~J} / \mathrm{K}$ \\
\hline$q$ & Charge coulomb constant & $1.6 \times 10^{-19} \mathrm{C}$ \\
\hline$N_{s}$ & Number of cells in series per module & 36 \\
\hline$N_{p}$ & Number of cells in parallel per module & 1 \\
\hline
\end{tabular}

Table A-2 Parameters for the system under study in the SYRF

\begin{tabular}{|c|c|}
\hline Variable & Value \\
\hline Phase to Phase voltage $V_{L}$ & $650 \mathrm{~V}$ \\
\hline DC link capacitor $C_{d c}$ & $210 \mu \mathrm{F}$ \\
\hline LC filter parameters & $R_{d}=1.51 \Omega L_{f}=3 \mathrm{mH} C_{f}=1.4 \mu \mathrm{F}$ \\
\hline Line Impedance & $R_{l}=0.38 \Omega L_{l}=0.15 \mathrm{mH}$ \\
\hline Current Loop PI controller & $K_{p}=24 K_{i}=1598.7$ \\
\hline
\end{tabular}


Table A-3 Parameters for the system under study in the STRF

\begin{tabular}{|c|c|}
\hline Variable & Value \\
\hline Phase to Phase voltage $V_{L}$ & $650 \mathrm{~V}$ \\
\hline DC link capacitor $C_{d c}$ & $210 \mu \mathrm{F}$ \\
\hline LC filter parameters & $R_{d}=1.51 \Omega L_{f}=3 \mathrm{mH} C_{f}=1.4 \mu \mathrm{F}$ \\
\hline Line Impedance & $R_{l}=0.38 \Omega L_{l}=0.15 \mathrm{mH}$ \\
\hline PR controller & $\omega_{c}=0.5 K_{p}=20 K_{r}=2000$ \\
\hline Nominal Power & $S=11000 \mathrm{VA}$ \\
\hline
\end{tabular}




\section{Appendix-2}

\section{Inverter output Filter Design}

In this appendix, the design of the LC filter is introduced. The filter is designed using the guidelines provided by Texas Instruments $[94,95]$.

Considering system under study in this thesis, the system parameters are given:

DC-link voltage, $V_{d c}=1900 \mathrm{~V}$;

AC line voltage, $V_{L}=650 \mathrm{~V}$;

3-phase apparent power, $S=11 \mathrm{kVA}$;

Since the reactive power $Q=0$ during normal operation, it can be easily derived that the active power $P=S=11 \mathrm{~kW}$.

Thus, AC line peak current can be calculated as:

$$
I_{\text {peak }}=\frac{P}{1.5 \times \sqrt{2} \times V_{L}}=7.98 \mathrm{~A}
$$

Assuming the switching frequency, $f_{s w}=50 \mathrm{kHz}$, the filter inductor $L_{f}$ can be calculated as:

$$
L_{f}=\frac{V_{d c}}{8 \times f_{s w} \times I_{\text {ripple }}}
$$

Where $I_{\text {ripple }}$ is the ripple current of the AC line peak current, which is normal chosen to be $0.2 I_{\text {peak }}$. Thus, $L_{f}$ is calculated:

$$
L_{f}=\frac{V_{d c}}{8 \times f_{s w} \times I_{\text {ripple }}}=\frac{1900}{8 \times 50000 \times 0.2 \times 7.98}=3 \mathrm{mH}
$$

Normally, the capacitor is designed to absorb $5 \%$ of the reactive power. Thus, $C_{f}$ is calculated as: 


$$
C_{f}=\frac{0.05 \times P_{\text {phase }}}{2 \times \pi \times f_{\text {grid }} \times V_{L}^{2}}=\frac{0.05 \times \frac{11000}{3}}{2 \times \pi \times 50 \times 650^{2}}=1.4 \mu \mathrm{F}
$$

The LC filter is designed to damp out the switching frequency. To get a good frequency attenuation, the filter resonance frequency $\left(f_{\text {res }}\right)$ is kept at $f_{s w} / 2$ or lower. By choosing $f_{\text {res }}=25 \mathrm{kHz}$, the damping resistor $R_{d}$ is calculated as:

$$
R_{d}=\frac{1}{3 \times 2 \times \pi \times f_{\text {res }} \times C_{f}}=\frac{1}{6 \times \pi \times 25000 \times 1.4 \times 10^{-6}}=1.51 \Omega
$$

